\title{
Cochrane
}

Library

Cochrane Database of Systematic Reviews

\section{Interventions to facilitate shared decision making to address antibiotic use for acute respiratory infections in primary care} (Review)

Coxeter P, Del Mar CB, McGregor L, Beller EM, Hoffmann TC

Coxeter P, Del Mar CB, McGregor L, Beller EM, Hoffmann TC.

Interventions to facilitate shared decision making to address antibiotic use for acute respiratory infections in primary care.

Cochrane Database of Systematic Reviews 2015, Issue 11. Art. No.: CD010907.

DOI: 10.1002/14651858.CD010907.pub2.

www.cochranelibrary.com

Interventions to facilitate shared decision making to address antibiotic use for acute respiratory infections in 
TABLE OF CONTENTS

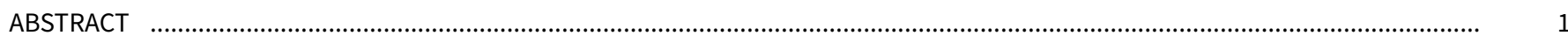

PLAIN LANGUAGE SUMMARY

SUMMARY OF FINDINGS

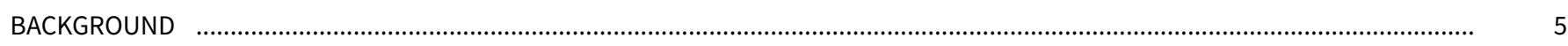

OBJECTIVES

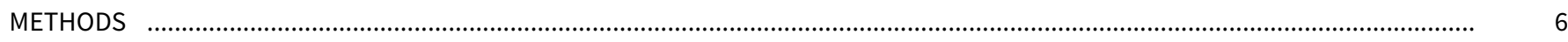

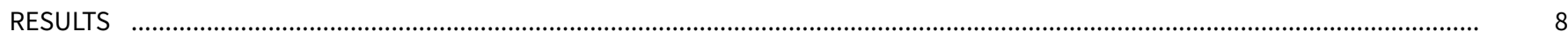

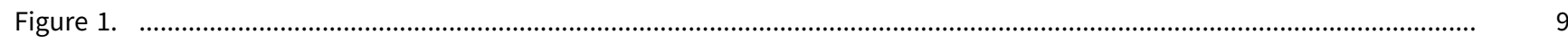

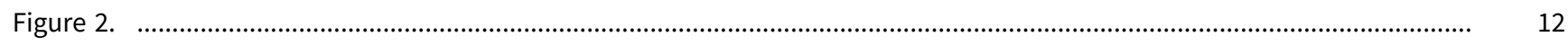

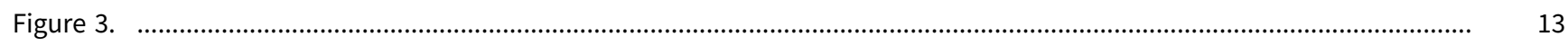

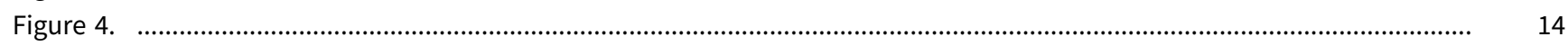

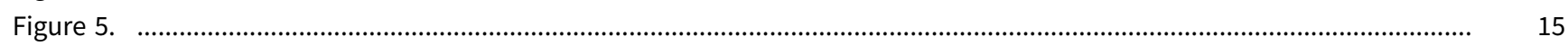

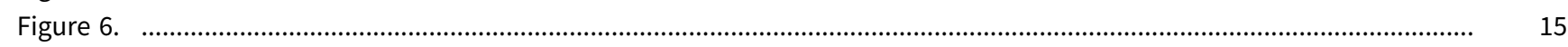

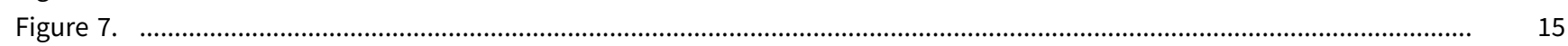

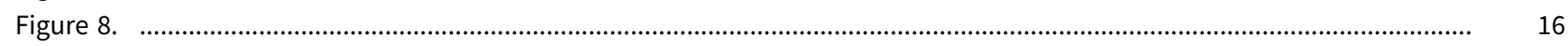

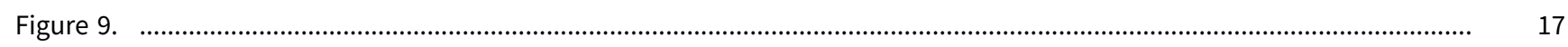

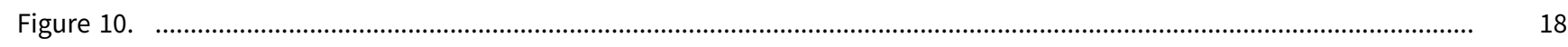

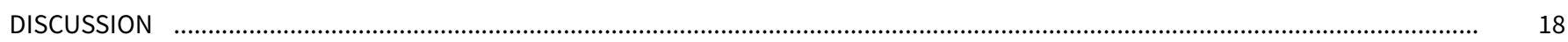

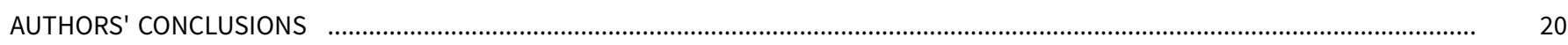

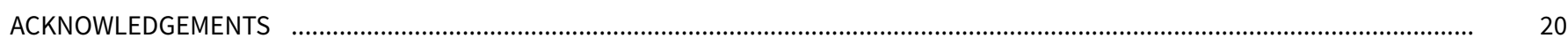

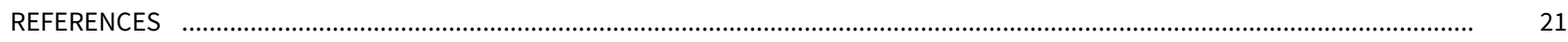

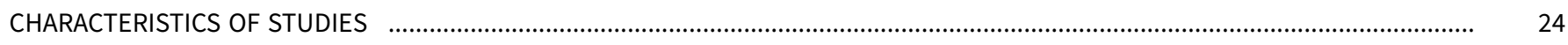

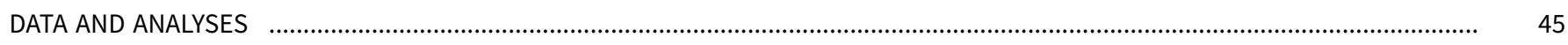

Analysis 1.1. Comparison 1 Shared decision making versus usual care (control), Outcome 1 Antibiotics prescribed, dispensed 46

or decision to use (short-term, index consultation to $\leq 6$ weeks).

Analysis 1.2. Comparison 1 Shared decision making versus usual care (control), Outcome 2 Antibiotics prescribed or dispensed (longer-term, $\geq 12$ months).

Analysis 1.3. Comparison 1 Shared decision making versus usual care (control), Outcome 3 Antibiotic prescriptions (index consultation) (adjusted odds ratio).

Analysis 1.4. Comparison 1 Shared decision making versus usual care (control), Outcome 4 Antibiotic prescriptions (index consultation) (adjusted risk ratio).

Analysis 1.5. Comparison 1 Shared decision making versus usual care (control), Outcome 5 Antibiotic prescriptions (index consultation or population rate per unit of time) (adjusted risk difference).

Analysis 1.6. Comparison 1 Shared decision making versus usual care (control), Outcome 6 Number or rate of re-consultations (risk ratio).

Analysis 1.7. Comparison 1 Shared decision making versus usual care (control), Outcome 7 Patient satisfaction with the consultation.

ADDITIONAL TABLES

APPENDICES

WHAT'S NEW

CONTRIBUTIONS OF AUTHORS

DECLARATIONS OF INTEREST

SOURCES OF SUPPORT

INDEX TERMS 
[Intervention Review]

\section{Interventions to facilitate shared decision making to address antibiotic use for acute respiratory infections in primary care}

Peter Coxeter ${ }^{1}$, Chris B Del Mar ${ }^{1}$, Leanne McGregor ${ }^{2}$, Elaine M Beller ${ }^{1}$, Tammy C Hoffmann ${ }^{1,3}$

${ }^{1}$ Centre for Research in Evidence-Based Practice (CREBP), Bond University, Gold Coast, Australia. ${ }^{2}$ Centre of National Research on Disability and Rehabilitation (CONROD), Menzies Health Institute Queensland | School of Allied Health, Griffith University, Southport, Australia. ${ }^{3}$ School of Health and Rehabilitation Sciences, The University of Queensland, Brisbane, Australia

Contact: Tammy C Hoffmann, Centre for Research in Evidence-Based Practice (CREBP), Bond University, Gold Coast, Queensland, 4229, Australia. thoffmann@bond.edu.au.

Editorial group: Cochrane Acute Respiratory Infections Group.

Publication status and date: Edited (no change to conclusions), published in Issue 2, 2017.

Citation: Coxeter P, Del Mar CB, McGregor L, Beller EM, Hoffmann TC. Interventions to facilitate shared decision making to address antibiotic use for acute respiratory infections in primary care. Cochrane Database of Systematic Reviews 2015, Issue 11. Art. No.: CD010907. DOI: 10.1002/14651858.CD010907.pub2.

Copyright ( 2017 The Cochrane Collaboration. Published by John Wiley \& Sons, Ltd.

\section{A B S T R A C T}

\section{Background}

Shared decision making is an important component of patient-centred care. It is a set of communication and evidence-based practice skills that elicits patients' expectations, clarifies any misperceptions and discusses the best available evidence for benefits and harms of treatment. Acute respiratory infections (ARIs) are one of the most common reasons for consulting in primary care and obtaining prescriptions for antibiotics. However, antibiotics offer few benefits for ARIs, and their excessive use contributes to antibiotic resistance - an evolving public health crisis. Greater explicit consideration of the benefit-harm trade-off within shared decision making may reduce antibiotic prescribing for ARIs in primary care.

\section{Objectives}

To assess whether interventions that aim to facilitate shared decision making increase or reduce antibiotic prescribing for ARIs in primary care.

\section{Search methods}

We searched CENTRAL (2014, Issue 11), MEDLINE (1946 to November week 3, 2014), EMBASE (2010 to December 2014) and Web of Science (1985 to December 2014). We searched for other published, unpublished or ongoing trials by searching bibliographies of published articles, personal communication with key trial authors and content experts, and by searching trial registries at the National Institutes of Health and the World Health Organization.

\section{Selection criteria}

Randomised controlled trials (RCTs) (individual level or cluster-randomised), which evaluated the effectiveness of interventions that promote shared decision making (as the focus or a component of the intervention) about antibiotic prescribing for ARIs in primary care.

\section{Data collection and analysis}

Two review authors independently extracted and collected data. Antibiotic prescribing was the primary outcome, and secondary outcomes included clinically important adverse endpoints (e.g. re-consultations, hospital admissions, mortality) and process measures (e.g. patient satisfaction). We assessed the risk of bias of all included trials and the quality of evidence. We contacted trial authors to obtain missing information where available. 


\section{Main results}

We identified 10 published reports of nine original RCTs (one report was a long-term follow-up of the original trial) in over 1100 primary care doctors and around 492,000 patients.

The main risk of bias came from participants in most studies knowing whether they had received the intervention or not, and we downgraded the rating of the quality of evidence because of this.

We meta-analysed data using a random-effects model on the primary and key secondary outcomes and formally assessed heterogeneity. Remaining outcomes are presented narratively.

There is moderate quality evidence that interventions that aim to facilitate shared decision making reduce antibiotic use for ARIs in primary care (immediately after or within six weeks of the consultation), compared with usual care, from $47 \%$ to $29 \%$ : risk ratio (RR) $0.61,95 \%$ confidence interval $(\mathrm{Cl}) 0.55$ to 0.68 . Reduction in antibiotic prescribing occurred without an increase in patient-initiated re-consultations (RR $0.87,95 \% \mathrm{Cl} 0.74$ to 1.03 , moderate quality evidence) or a decrease in patient satisfaction with the consultation $(\mathrm{OR} 0.86,95 \% \mathrm{Cl} 0.57$ to 1.30 , low quality evidence). There were insufficient data to assess the effects of the intervention on sustained reduction in antibiotic prescribing, adverse clinical outcomes (such as hospital admission, incidence of pneumonia and mortality), or measures of patient and caregiver involvement in shared decision making (such as satisfaction with the consultation; regret or conflict with the decision made; or treatment compliance following the decision). No studies assessed antibiotic resistance in colonising or infective organisms.

\section{Authors' conclusions}

Interventions that aim to facilitate shared decision making reduce antibiotic prescribing in primary care in the short term. Effects on longerterm rates of prescribing are uncertain and more evidence is needed to determine how any sustained reduction in antibiotic prescribing affects hospital admission, pneumonia and death.

\section{PLAIN LANGUAGE SUMMARY}

\section{Interventions that facilitate shared decisions between primary care clinicians and patients about antibiotic use for acute respiratory infections}

\section{Review question}

We wanted to see if shared decision making was better or worse than usual care in reducing antibiotic prescribing for an acute respiratory infection in primary care.

\section{Background}

Shared decision making enables health decisions to be made jointly by a clinician and patient. The decision making occurs after the options and their benefits and harms have been discussed together with the patient's values and preferences.

Acute respiratory infections (such as an acute cough, middle ear infection or sore throat) are one of the most common reasons to see a health professional, and antibiotics are commonly prescribed despite good evidence that they have little benefit for these conditions. Any decision to prescribe an antibiotic should be balanced by any benefits against the risk of common harms (such as rash and stomach upset) and the contribution to antibiotic resistance - now a major threat to human health.

Shared decision making provides an ideal opportunity within a primary care consultation for greater consideration about the trade-off between benefit and harm of antibiotics for acute respiratory illnesses. Antibiotic prescribing may decrease as a result.

\section{Study characteristics}

We identified 10 studies (nine trials and one follow-up study) up to December 2014. In total, the studies involved over 1100 primary care doctors and around 492,000 patients. The intervention was different in each study. Six of the studies involved training clinicians (mostly primary care doctors) in communication skills that are needed to facilitate shared decision making. In three studies, as well as training doctors in these skills, patients were also given written information about antibiotics for acute respiratory infections. All included trials received funding from government sources. No studies declared a conflict of interest.

\section{Key results}

Interventions that aim to facilitate shared decision making significantly reduce antibiotic prescribing for acute respiratory infections in primary care, without a decrease in patients' satisfaction with the consultation, or an increase in repeat consultations for the same illness. There was not enough information to decide whether shared decision making affects other clinically adverse secondary outcomes, measures of clinician and patient involvement in sharing decision making, or antibiotic resistance.

\section{Quality of the evidence}

We rated the quality of the evidence as moderate or low for all outcomes. 
SUMMARY OF FINDINGS

Summary of findings for the main comparison. Shared decision making compared to usual care for acute respiratory infections in primary care

Shared decision making compared to usual care for acute respiratory infections in primary care

Patient or population: antibiotic use in acute respiratory infections

Setting: primary care

Intervention: interventions to facilitate shared decision making

Comparison: usual care

\begin{tabular}{|c|c|c|c|c|c|c|}
\hline \multirow[t]{2}{*}{ Outcomes } & \multicolumn{2}{|c|}{ Anticipated absolute effects ${ }^{*}(95 \% \mathrm{Cl})$} & \multirow{2}{*}{$\begin{array}{l}\text { Relative effect } \\
(95 \% \mathrm{Cl})\end{array}$} & \multirow{2}{*}{$\begin{array}{l}\text { № of partici- } \\
\text { pants } \\
\text { (studies) }\end{array}$} & \multirow{2}{*}{$\begin{array}{l}\text { Quality of the } \\
\text { evidence } \\
\text { (GRADE) }\end{array}$} & \multirow[t]{2}{*}{ Comments } \\
\hline & $\begin{array}{l}\text { Risk with usual } \\
\text { care }\end{array}$ & $\begin{array}{l}\text { Risk with Interventions } \\
\text { to facilitate shared deci- } \\
\text { sion making }\end{array}$ & & & & \\
\hline \multirow{2}{*}{$\begin{array}{l}\text { Antibiotics prescribed or dispensed ( } 6 \\
\text { weeks or less) } \\
\text { assessed with: risk ratio }\end{array}$} & Moderate & & \multirow{2}{*}{$\begin{array}{l}\text { RR } 0.61 \\
\text { (0.55 to } 0.68)\end{array}$} & \multirow{2}{*}{$\begin{array}{l}10172 \\
\text { (8 RCTs) }\end{array}$} & \multirow{2}{*}{$\begin{array}{l}\oplus \oplus \oplus \odot \\
\text { MODERATE } 1\end{array}$} & \\
\hline & 47 per 100 & $\begin{array}{l}29 \text { per } 100 \\
\text { (26 to } 32)\end{array}$ & & & & \\
\hline \multirow{2}{*}{$\begin{array}{l}\text { Antibiotics prescribed or dispensed ( } 12 \\
\text { months or greater) } \\
\text { assessed with: risk ratio }\end{array}$} & Moderate & & \multirow{2}{*}{$\begin{array}{l}\text { RR } 0.74 \\
\text { (0.49 to } 1.11)\end{array}$} & \multirow{2}{*}{$\begin{array}{l}481588 \\
(3 \mathrm{RCTs})^{3}\end{array}$} & \multirow{2}{*}{$\begin{array}{l}\oplus \oplus \Theta \Theta \\
\text { LOW } 12\end{array}$} & \\
\hline & 47 per 100 & $\begin{array}{l}35 \text { per } 100 \\
\text { ( } 23 \text { to } 52)\end{array}$ & & & & \\
\hline \multirow{2}{*}{$\begin{array}{l}\text { Patient initiated re-consultations for the } \\
\text { same illness episode }\end{array}$} & Moderate & & \multirow{2}{*}{$\begin{array}{l}\text { RR } 0.87 \\
\text { (0.74 to } 1.03)\end{array}$} & \multirow{2}{*}{$\begin{array}{l}1861 \\
(4 \mathrm{RCTs})\end{array}$} & \multirow{2}{*}{$\begin{array}{l}\oplus \oplus \oplus \Theta \\
\text { MODERATE } 1\end{array}$} & \\
\hline & 40 per 100 & $\begin{array}{l}35 \text { per } 100 \\
\text { (30 to } 41)\end{array}$ & & & & \\
\hline \multirow[t]{2}{*}{ Patient satisfaction with the consultation } & Moderate & & \multirow{2}{*}{$\begin{array}{l}\text { OR } 0.86 \\
\text { (0.57 to } 1.30)\end{array}$} & \multirow{2}{*}{$\begin{array}{l}1052 \\
(2 \mathrm{RCTs})\end{array}$} & \multirow{2}{*}{$\begin{array}{l}\oplus \oplus \ominus \ominus \\
\text { LOW } 14\end{array}$} & \\
\hline & 71 per 100 & $\begin{array}{l}68 \text { per } 100 \\
(58 \text { to } 76)\end{array}$ & & & & \\
\hline
\end{tabular}

${ }^{*}$ The risk in the intervention group (and its $95 \%$ confidence interval) is based on the assumed risk in the comparison group and the relative effect of the intervention (and its $95 \% \mathrm{Cl})$.

Cl: confidence interval; OR: Odds ratio; RCT: randomised controlled trial; RR: Risk ratio

GRADE Working Group grades of evidence

High quality: We are very confident that the true effect lies close to that of the estimate of the effect 
Moderate quality: We are moderately confident in the effect estimate: The true effect is likely to be close to the estimate of the effect, but there is a possibility that it is substantially different

Low quality: Our confidence in the effect estimate is limited: The true effect may be substantially different from the estimate of the effect

Very low quality: We have very little confidence in the effect estimate: The true effect is likely to be substantially different from the estimate of effect

1 Downgraded one level because of risk of bias: participants in most studies were aware of whether they had received the intervention or not.

2 Downgraded one level because of imprecision: confidence interval includes reduction and possible increase in use of antibiotics. There was considerable heterogeneity in the rates of antibiotic prescribing during longer-term follow-up (12 months or greater).

3 Sample numbers in one trial, Butler 2012, were calculated from mean list size at baseline multiplied by the number of participating practices in each group (practice list sizes vary over time and no denominator data were available).

4 Downgraded one level due to imprecision: confidence interval includes both satisfaction and lack of satisfaction of patients with the consultation. 


\section{B A C K G R O U N D}

\section{Description of the condition}

Acute respiratory infections (ARIs) are one of the most common reasons for consulting in primary care. Antibiotics are often prescribed (Gill 2006; Gonzales 1997; Gonzales 2001), often unnecessarily as systematic reviews conclude that antibiotics have little benefit for reducing symptom duration or complications in acute otitis media (Venekamp 2015), sore throat (Spinks 2013), bronchitis (Smith 2014), and sinusitis (Ahovuo-Saloranta 2014), and no benefit for laryngitis (Gonzales 2001) or colds (Kenealy 2013). The limited benefits of antibiotics for ARIs may be outweighed by unnecessary exposure to common adverse reactions (such as diarrhoea, candidiasis, rash, abdominal pain and/or diarrhoea and nausea and/or vomiting (Gillies 2015)), increased healthcare costs and contribution to antibiotic resistance (Chung 2007; Costelloe 2010).

Several doctor- and patient-related factors influence clinicians' prescribing behaviour. They include: clinical uncertainty and fear of disease progression; inadequate physician knowledge (Altiner 2007); underestimates of the contribution of prescribing antibiotics to the development of resistance (Wood 2013); and perceived patient expectations for an antibiotic and the subsequent pressure felt to meet this expectation (Arroll 2002). Antibiotic prescribing for ARIs also creates a 'vicious cycle' through the medicalisation of otherwise uncomplicated and self limiting illnesses, encouraging patients to re-consult with similar expectations for an antibiotic for similar illness episodes in the future (Butler 1998).

Antibiotic use exerts a selection pressure on bacteria to develop resistance (WHO 2012). Patients prescribed an antibiotic for respiratory tract infections develop measurable bacterial resistance in their commensal bacteria to that antibiotic for up to 12 months (Costelloe 2010). Although the development of individual resistance is transient, and decays after about a year in the absence of antibiotic use, it is sufficient to sustain high levels of population resistance (Chung 2007). Persistent prescribing of antibiotics, and excessive use of broad spectrum antibiotics in place of narrower spectrum ones, are modifiable factors that contribute to resistance (WHO 2012). Antibiotic resistance is now an evolving global threat to public health (WHO 2012). The rational use of antibiotics is therefore one of the most important strategies for preserving the therapeutic benefit of antibiotic treatment (WHO 2001; WHO 2012).

\section{Description of the intervention}

Shared decision making is the process of enabling a health professional and patient to make a joint treatment or management decision based on the best available evidence and the patient's values and preferences (Charles 1997; Makoul 2006). It consists of eliciting patients' expectations and clarifying any misperceptions, discussing treatment options, and communicating the benefits and harms of each option and their likelihood. Shared decision making supports the principle of patient autonomy and the right to self determination (Elwyn 2012), and has been shown to improve patients' satisfaction with decisions and concordance of decisions with their values (Spatz 2012). Some of the skills required of clinicians to facilitate shared decision making include proficient communication and rapport building skills as well as access to the best available evidence. It is one of the most important ways of bringing evidence to the point of clinical decisions and a potential strategy for reducing the overuse of ineffective treatments (Elwyn 2012).

\section{How the intervention might work}

The diagnostic uncertainty associated with ARIs and the tradeoff between the benefits and harms of antibiotics mean that shared decision making may provide an ideal opportunity for clinicians and their patients to choose appropriate treatment or management options, including the decision to not use an antibiotic (Butler 2001). By engaging the patient and clinician to explicitly discuss the benefits and harms of antibiotics against a background of evidence demonstrating that it is less effective than most patients expect, there is high potential for it to be effective. Many patients elect for conservative treatment options after participating in shared decision making (Elwyn 2012).

\section{Why it is important to do this review}

Concern about antibiotic resistance is now an international public health crisis (WHO 2012), and finding ways to minimise unnecessary antibiotic prescribing in primary care is imperative. Shared decision making may be an important process to achieve this.

Several related Cochrane systematic reviews have been undertaken. Arnold 2005 reviewed the effectiveness of interventions to improve antibiotic stewardship in outpatient care (including the decision to prescribe an antibiotic, and the type, dose and duration of antibiotic therapy). However, broad inclusion criteria and subsequent heterogeneity of the identified interventions limited the generalisability of practice recommendations. Importantly, this review also did not focus on, or explicitly consider, shared decision making interventions for inclusion.

The review by Stacey assessed the effectiveness of decision aids for people facing any treatment or screening decision (Stacey 2014). Decision aids are only one tool used to facilitate shared decision making in clinical care, and it may be enabled through methods other than, or in addition to, decision aids. Similarly, the review by Kinnersley evaluated the effect of interventions to encourage patient health communication and information seeking prior to the primary care consultation that shared some but not all components necessary for shared decision making to occur (Kinnersley 2007). Légaré 2014 assessed the effectiveness of interventions to facilitate clinicians' uptake of shared decision making but not the use or effect of shared decision making in a particular condition. The growing interest in shared decision making for potential improvement in treatment decisions and patient outcomes is evident from Cochrane systematic reviews in other clinically important areas including mental health (Duncan 2010) and paediatric oncology (Coyne 2013). If shared decision making is shown to reduce prescribing among primary care doctors, then steps can be taken to incorporate it into primary care consultations for ARI across many countries.

\section{O B J E C T IVES}

To assess whether interventions that aim to facilitate shared decision making increase or reduce antibiotic prescribing for ARIs in primary care. 


\section{METHODS}

\section{Criteria for considering studies for this review}

\section{Types of studies}

Randomised controlled trials (RCTs) (individual level or clusterRCTs), which evaluated the effectiveness of shared decision making in reducing antibiotic prescribing in primary care. Quasi-RCTs, quasi-experimental studies (controlled clinical trials), controlled before and after studies and interrupted time series analyses were not eligible.

\section{Types of participants}

As interventions that aim to facilitate shared decision making may be directed at clinicians, patients, or both, participants eligible for this review could be:

1. clinicians who provide primary care (community practices, hospital-affiliated or government-run outpatient clinics); or

2. patients who present with any combination of symptoms of acute (less than four weeks' duration) respiratory infection (or the parents of similarly affected children).

\section{Types of interventions}

There is no one accepted definition of shared decision making (Makoul 2006); nor is there consensus on the core skills that shared decision making training should address (Légaré 2013). Therefore, we considered interventions eligible if the trial explicitly stated that the intervention was aimed at facilitating shared decision making or if the intervention explicitly addressed more than one of the essential elements of shared decision making that are described by Makoul 2006. These include: explaining the problem to be addressed; discussing options; communicating benefits and risks of each option; eliciting patient expectations, values, preferences or concerns; discussing patients' ability/self efficacy; and checking or clarifying understanding.

These elements may have been addressed by providing training in specific skills or providing decision support information or tools (such as decision aids (Stacey 2014), option grids (Elwyn 2013), or decision boxes (Giguere 2012)), which provide information about relevant issues (such as options, benefits, harms, questions to ask, etc). The skills training and information/tools could be provided to either clinicians, patients, or both. Interventions may have been delivered in any primary care environment and we imposed no restriction on the training and/or information mode, format or intensity of delivery.

We did not include interventions that consisted solely of the passive provision of patient information without the two-way sharing of information necessary for shared decision making, or which aimed to enhance clinicians' and/or patients' general communication skills.

\section{Types of outcome measures}

\section{Primary outcomes}

1. Prescription of antibiotics (for example, antibiotics prescribed per consultation, or a change in the population rate of antibiotic prescriptions per unit of time).

\section{Secondary outcomes}

1. Number or rate of patient-initiated re-consultations for unresolved ARI (i.e. same illness episode).

2. Incidence of colonisation with, or infection due to, antibioticresistant organisms.

3. Incidence of hospital admission.

4. Incidence of pneumonia (clinical with radiological confirmation).

5. Incidence of acute otitis media complications (for example, tympanic membrane perforation, contralateral otitis (in unilateral cases), mastoiditis, meningitis).

6. Mortality due to respiratory illness or similar.

7. All-cause mortality.

8. Measures of patient and caregiver satisfaction.

9. Measures of patient and caregiver satisfaction with the decision reached, decisional conflict and decisional regret.

10. Measures of extent of patient involvement in the decision making process (for example, consultations analysed using tools such as the OPTION instrument; Elwyn 2003).

11. Measures of treatment compliance or adherence to decision reached.

\section{Search methods for identification of studies}

\section{Electronic searches}

We searched the Cochrane Central Register of Controlled Trials (CENTRAL 2014, Issue 11), which includes the Cochrane Acute Respiratory Infections Group's Specialised Register, MEDLINE (1946 to November week 3, 2014), EMBASE (2010 to December 2014) and Web of Science (1985 to December 2014).

We searched MEDLINE using the search terms described in Appendix 1. We combined the MEDLINE search with the Cochrane Highly Sensitive Search Strategy for identifying randomised trials in MEDLINE: sensitivity- and precision-maximising version (2008 revision); Ovid format. We used the MEDLINE search strategy to search CENTRAL and adapted it to search EMBASE (Appendix 2) and Web of Science (Appendix 3). We imposed no language, publication date or publication status restrictions on the electronic database searches.

We searched the National Institutes of Health registry of clinical trials (www.clinicaltrials.gov) and the World Health Organization's (WHO) clinical trials registry (www.who.int/ictrp/en/) for completed and ongoing studies eligible for inclusion. We searched Web of Science and EMBASE to identify potentially relevant conference abstracts and proceedings.

\section{Searching other resources}

We searched the bibliographies of retrieved articles and published reviews for additional studies. We personally communicated with trial authors of significant publications and content experts (Professor Paul Little, Professor Christopher Butler and Professor France Légaré) to identify further published, unpublished or ongoing trials. 


\section{Data collection and analysis}

\section{Selection of studies}

We merged search results into reference management software (Endnote X6) and removed duplicate references. Two review authors (PC, LM) independently screened the titles and abstracts of retrieved records. We attempted to identify multiple reports of single studies following the criteria recommended in the Cochrane Handbook for Systematic Reviews of Interventions (Higgins 2011). We retrieved full-text copies of all potentially relevant articles for full-text evaluation. The final list of eligible trials was confirmed following discussion and consensus among review authors $(\mathrm{PC}, \mathrm{TH}$, LM, CDM).

\section{Data extraction and management}

Two review authors (PC, LM) independently extracted data from each included trial using a specifically designed electronic data extraction form. We resolved disagreements by discussion and consensus, with one review author (CDM) acting as arbitrator where required. Data extraction was blind to names of authors, institutions and publication title. We extracted the following key study features where available:

1. Trial characteristics and methodological quality - risk of bias (see below); trial design, including unit of randomisation and number of comparator arms; blinding; generation of allocation sequence; allocation concealment; number of participants; theoretical or conceptual basis of the intervention; number of intervention components; description of intervention and comparator arms; length of follow-up; sample size estimate (power calculation); number of patients randomised to each intervention arm; number of patients completing the trial; protocol analysis.

2. Patient (and/or caregiver) characteristics - age, gender and sociodemographic variables; types of ARI; duration of ARI prior to study recruitment; co-morbidities.

3. Healthcare professional characteristics - age; gender; experience; primary care setting type.

4. Outcome measures - all primary and secondary outcomes.

\section{Assessment of risk of bias in included studies}

Two authors (PC, LM) independently assessed the risk of bias of included studies and two acted as arbitrators (TH, CDM). We assessed risk of bias using the 'Risk of bias' tool available in RevMan 2014 and the criteria explained in the Cochrane Handbook for Systematic Reviews of Interventions (Higgins 2011). We assessed the reliability of the sequence generation, allocation concealment, blinding (participants, personnel and outcome assessors), incomplete outcome data and selective outcome reporting bias, as well as other sources of bias. We ranked studies as high, low or unclear risk of bias as described in the Cochrane Handbook for Systematic Reviews of Interventions and present our assessments in a 'Risk of bias' summary figure (Higgins 2011). As all included studies were cluster-RCTs, we assessed additional sources of bias including recruitment bias, baseline imbalance between clusters, loss of clusters and incorrect analysis (Higgins 2011). reasons for withdrawal; and intention-to-treat (ITT) or per

\section{Measures of treatment effect}

Measures of treatment effect included dichotomous (binary), rate and continuous primary or secondary outcome data. Some studies calculated mean difference (MD) for continuous outcomes (median difference or median and interquartile range where data are not normally distributed) and for dichotomous outcomes, risk ratio (RR), odds ratio (OR) or rate ratio (RaR) were reported. In accordance with our protocol we have based the primary analysis on data reported as adjusted risk ratios. Additional analyses of the prescribing outcomes also present adjusted odds ratios and risk differences to incorporate additional information as analysed in the included studies.

\section{Unit of analysis issues}

Studies presented effect measures adjusted for clustering effects (at practice, provider and/or patient hierarchies) or potential confounders in multilevel analysis, and/or applied generalised linear mixed models or generalised estimating equations. Intraclass correlation coefficients were estimated in sample size calculations (Briel 2006; Cals 2009; Francis 2009; Légaré 2012; Little 2013; Welschen 2004), or reported (Briel 2006; Francis 2009), to account for clustering effects. Where intraclass correlation coefficients were not reported (Butler 2012; Cals 2013), we imputed them from another similar included study.

\section{Dealing with missing data}

The majority of studies performed ITT analyses (Briel 2006; Butler 2012; Cals 2009; Francis 2009; Légaré 2011; Little 2013; Welschen 2004). One study presented data only from practices with complete follow-up (Altiner 2007). The long-term follow-up study of Cals 2009 included data only where medical records could be accessed for the follow-up period ( $87.9 \%$ of original trial cohort) (Cals 2013). The principle of analysis was not stated in one study (Légaré 2012). Drop-out rates and contributing reasons were sufficiently disclosed in all studies, and one study reporting relatively high attrition performed a sensitivity analysis to explore effects from differential missing values (Altiner 2007).

\section{Assessment of heterogeneity}

We used a random-effects model for all meta-analyses due the observed methodological diversity and used the 12 statistic to measure heterogeneity as recommended in the Cochrane Handbook for Systematic Reviews of Interventions (Higgins 2011).

\section{Assessment of reporting biases}

We minimised reporting bias by conducting a comprehensive search for studies that met the eligibility criteria, including grey literature and unpublished trials; and by contacting trials authors for missing information. There were insufficient studies to test for publication bias using a funnel plot.

\section{Data synthesis}

Meta-analyses of studies were limited to studies reporting a comparable effect estimate. Therefore, the test for overall effect is limited to analysis in each subgroup. Studies reporting data that could not be combined for meta-analysis are reported narratively. Forest plots were also not generated for data reported by a single study, or where the synthesis of available pilot data to the substantive study (for example, Légaré 2011) would not meaningfully increase the power or precision of observed

Interventions to facilitate shared decision making to address antibiotic use for acute respiratory infections in primary care (Review)

Copyright (c 2017 The Cochrane Collaboration. Published by John Wiley \& Sons, Ltd. 
effects. Similarly, meta-analyses of secondary outcomes were limited to studies reporting comparable measures, those providing similar effect estimates, or where there were sufficient trials for comparison (such as patient satisfaction with the consultation). Caution is warranted for conclusions for each outcome due to the low numbers of trials for each comparison. We used RevMan 2014 to enter and analyse data to estimate a weighted treatment effect (with 95\% confidence intervals (Cls). We analysed data using the random-effects model due to the expected heterogeneity in combining diverse shared decision making interventions.

We created Summary of findings for the main comparison using the following outcomes: antibiotic prescribing in the short term (less than six weeks), longer-term antibiotic prescribing (12 months or longer), re-consultation for the same illness episode and patient satisfaction with the consultation. We used the five GRADE considerations (study limitations, consistency of effect, imprecision, indirectness and publication bias) to assess the quality of evidence of the studies contributing data for meta-analyses of prespecified outcomes (GRADE Working Group 2004). We used the methods and recommendations described in Section 8.5 and Chapter 12 of the Cochrane Handbook for Systematic Reviews of Interventions (Higgins 2011), using GRADEpro GDT software (GRADEproGDT 2015). We justified decisions to downgrade or upgrade the quality of studies using footnotes and comments to aid the reader's understanding of the review.

\section{Subgroup analysis and investigation of heterogeneity}

There were insufficient studies to conduct a subgroup analysis of trials that incorporate shared decision making as part of a multifaceted intervention compared with trials in which shared decision making was the standalone intervention. Subgroup analysis of interventions targeted at clinicians versus patients/ parents was also not conducted due to a lack of studies. We did not conduct planned subgroup analyses of children versus adult trial populations, trials with low risk of bias versus high risk, and cluster-
RCTs versus individually randomised studies due to insufficient studies.

\section{Sensitivity analysis}

Insufficient studies prevented a planned sensitivity analysis excluding trials found to have a higher versus low risk of bias to examine the effect of trial quality on the magnitude and direction of effect.

\section{RE S U L T S}

\section{Description of studies}

\section{Results of the search}

We retrieved a total of 3272 studies from the searches of the electronic databases after duplicates were removed. Two review authors (PC, LM) independently screened record titles and abstracts and, following consensus, 3256 records did not meet our inclusion criteria and were excluded. A recent published study protocol was identified and we contacted the lead author to confirm the study was ongoing and study results would not be available in time for this review (Altiner 2012). We retrieved full-text reports of the remaining 16 records and two review authors (PC, LM) screened these independently. We excluded six studies after they did not meet the a priori eligibility criteria for shared decision making interventions. All review authors (PC, $\mathrm{TH}, \mathrm{LM}, \mathrm{CDM}$ ) considered the provisional list of 10 studies for inclusion. We contacted trial authors of two of these studies for further elaboration on respective study interventions to determine that both were eligible for inclusion (Altiner 2007; Briel 2006). We included 10 published reports of nine original studies: one publication reports long-term follow-up outcome data of an earlier study (Cals 2013), and another published report, Légaré 2011, presents pilot data for relevant outcomes distinct from the subsequent substantive cluster-RCT (Légaré 2012). See Figure 1. 
Figure 1. PRISMA study flow diagram.

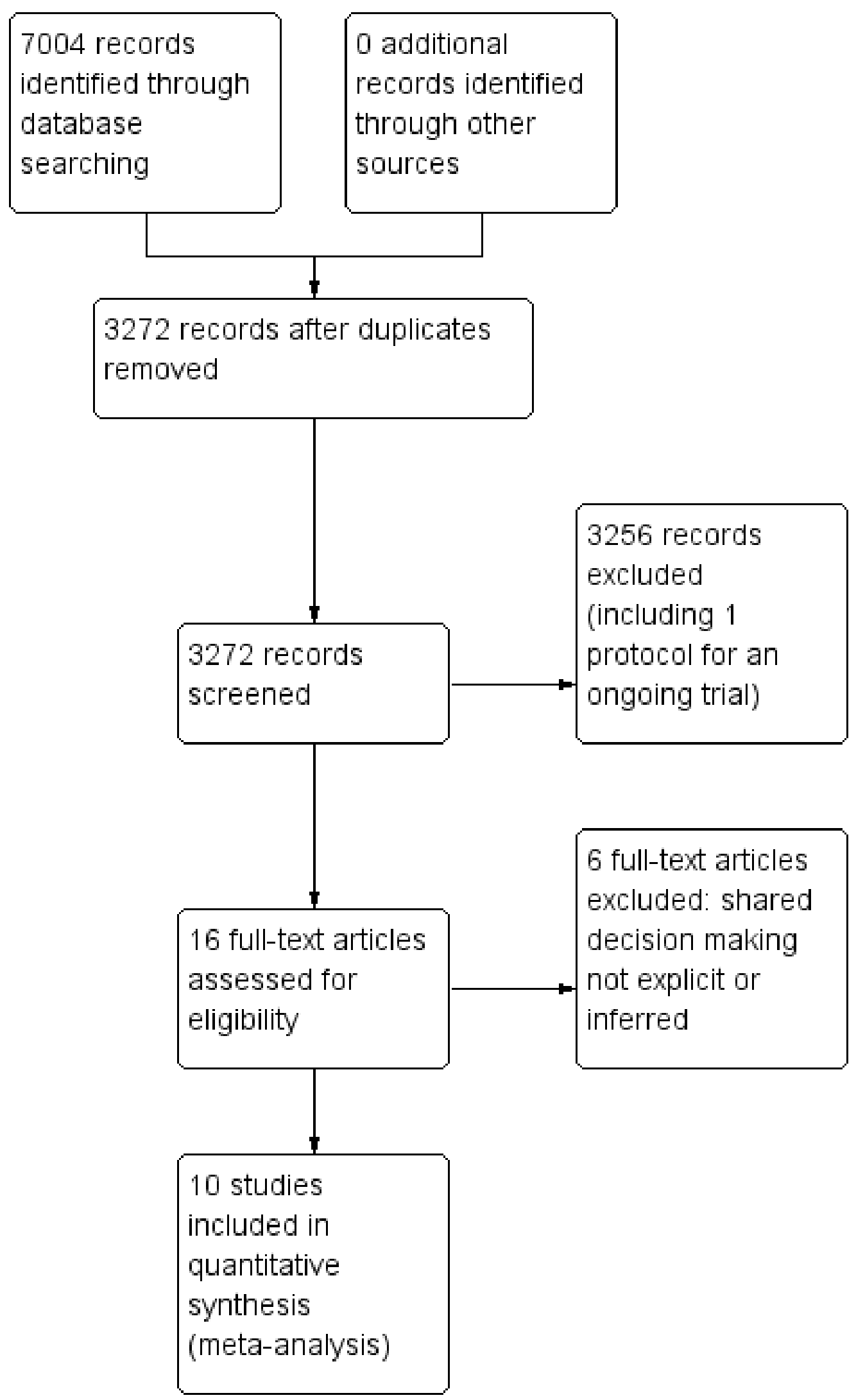




\section{Included studies}

\section{Study design}

Six studies used a two-arm randomised group design: experimental versus control (usual care) (Altiner 2007; Butler 2012; Francis 2009; Légaré 2011; Légaré 2012; Welschen 2004). In one study the control group received the intervention after the experimental group had been exposed to the programme (Légaré 2011). Briel 2006 compared three arms: full intervention versus limited intervention versus non-randomised controls that acted as distractors to the intention of the real comparison and were not analysed). Two studies compared four parallel study arms: intervention (a) versus intervention (b) versus intervention $(a+b)$ versus control (Cals 2009; Little 2013). These two cluster-RCTs incorporated a prespecified factorial analysis plan (Cals 2009; Little 2013). Trial data for interventions not relevant to the present review (such as Creactive protein point of care testing (Cals 2009; Little 2013), or costs (Butler 2012)) are not presented.

All nine original studies included were cluster-RCTs. The unit of randomisation in studies was the general practitioner (GP) (Altiner 2007; Briel 2006), general practice (Butler 2012; Cals 2009; Francis 2009; Little 2013), GP peer review group (Welschen 2004), family practice teaching unit (Légaré 2012), and family medicine group (Légaré 2011).

All trials received funding. None disclosed conflicts of interest except Cals 2013 (one study author received travel/lecture funds from a point of care test device manufacturer being evaluated in the study, for which data were not relevant to this review). Ethical approval was documented in all studies.

\section{Characteristics of settings and participants}

The studies were conducted in Germany (Altiner 2007), Switzerland (Briel 2006), the Netherlands (Cals 2009; Cals 2013; Welschen 2004); England (Francis 2009), Wales (Butler 2012; Francis 2009), and Canada (Légaré 2011; Légaré 2012). One multinational trial was conducted across six European countries (Netherlands, Belgium, Spain, Poland, England and Wales) (Little 2013).

\section{Recruitment of clinicians}

Participating general practitioners (GPs) were recruited directly (Altiner 2007; Briel 2006), or through participating general practices (Butler 2012; Cals 2009; Francis 2009; Little 2013), peer review groups (Welschen 2004), family practice teaching units (Légaré 2012), or family medicine groups (Légaré 2011). The existing nationwide structure of GP peer review groups in the Netherlands comprise GPs and collaborating pharmacists that aim to promote rational prescribing through audit and feedback (Welschen 2004). UK general practices comprise GPs and nurse prescribers (Little 2013). GPs within Family Medicine Groups in Canada (Quebec) also work closely with nurses for care of registered individuals (Légaré 2011). Family Practice Teaching Units in Quebec include both physician teachers and residents (Légaré 2012).

\section{Recruitment of patients}

Specific ARI diagnoses and participant eligibility varied a little across studies. In several studies GPs recruited all patients (adults and children accompanied by a legal guardian) (Légaré 2011; Légaré 2012; Welschen 2004), or only adult patients (Briel 2006), consulting with symptoms of ARI. One study included adult patients presenting predominately with acute lower respiratory tract infections (LRTIS) and upper respiratory tract infections (URTIs) (Little 2013). Cals 2009 included adult patients only with suspected LRTI. Altiner 2007 restricted patient eligibility to patients over 16 years of age consulting for acute cough. Conversely, Butler 2012 included patients with any condition registered with participating practices. Francis 2009 included only children (six months to 14 years) and their parents consulting for a respiratory tract infection.

Study exclusion criteria also differed a little among studies. Asthma was an explicit exclusion criterion in two studies (Altiner 2007; Francis 2009), and was not reason for exclusion in another (Welschen 2004). Patients with chronic obstructive pulmonary disease (COPD) were ineligible in one study (Altiner 2007), although were eligible for inclusion in two trials (Briel 2006; Welschen 2004). The proportion of patients diagnosed with asthma/COPD ranged from 2\% to 3.5\% (Briel 2006; Welschen 2004) up to 18.5\% (Little 2013). Patients with pneumonia were excluded from participation in one study (Briel 2006). However, they were eligible in two studies (Little 2013; Welschen 2004), and this was diagnosed in 3.5\% of participants in Welschen 2004.

\section{Characteristics of interventions and comparisons}

\section{Interventions}

Included trials assessed various multi-component interventions primarily aimed at facilitating clinicians shared management of decisions to reduce antibiotics for ARIs and their related symptoms in primary care.

The delivery of interventions occurred in usual clinical settings or central locations, and varied in intervention elements and scope and the frequency and duration (i.e. intensity) of sessions. All studies provided education and communication skills training that aimed to improve GPs' understanding of topics such as: the probability of bacterial or viral ARI; evidence for the benefit/risk of antibiotics and/or other treatment options; risk communication techniques; information exchange about symptoms and natural disease course; methods of eliciting patients' concerns and expectations; and agreement with the patient about a management plan and summing up. Communicative techniques used were derived from various theoretical models or frameworks.

Training in specific education and communication skills was delivered through peer- or facilitator-led interactive workshops and seminars or via web-based platforms, and supported with the use of videos, interactive exercises and decision aids or interactive booklets to facilitate patient participation in treatment decisions. Other programme components in some studies included consensus procedures, simulated patient consultations, personal reflection on clinical practice, reminders of expected behaviours and provision of antibiotic resistance trend data. Several interventions contained materials developed for patients, including education materials in waiting rooms (poster and leaflet), an interactive booklet for use within the consultation and as a take home resource, or decision support tool).

A summary of the main intervention components is described using the items from the Template for Intervention Description and Replication (TIDieR) checklist (Hoffmann 2014) (see Table 1). 


\section{Comparators}

In all trials the comparator was usual care, with the exception of Briel 2006 where GPs received training in a two-hour seminar on evidence-based US guidelines for ARIs.

\section{Excluded studies}

We excluded six studies as shared decision making was not explicit or inferred in the interventions evaluated (Characteristics of excluded studies).

\section{Risk of bias in included studies}

The methodological characteristics of the studies are reported in the Characteristics of included studies table. The 'Risk of bias' summary and 'Risk of bias' graph are presented in Figure 2 and Figure 3, respectively. 
Figure 2. 'Risk of bias' summary: review authors' judgements about each risk of bias item for each included study.

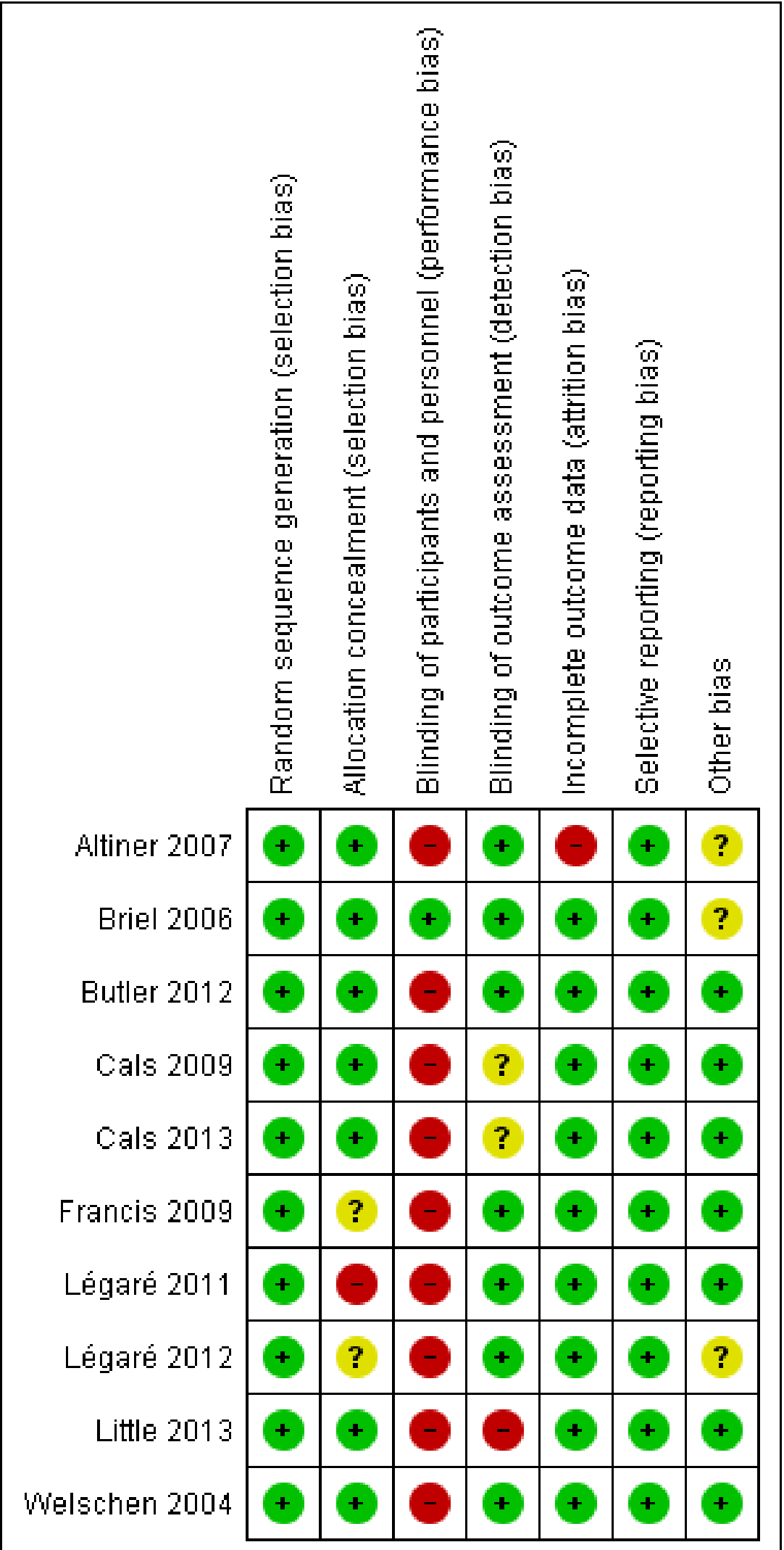


Figure 3. 'Risk of bias' graph: review authors' judgements about each risk of bias item presented as percentages across all included studies.

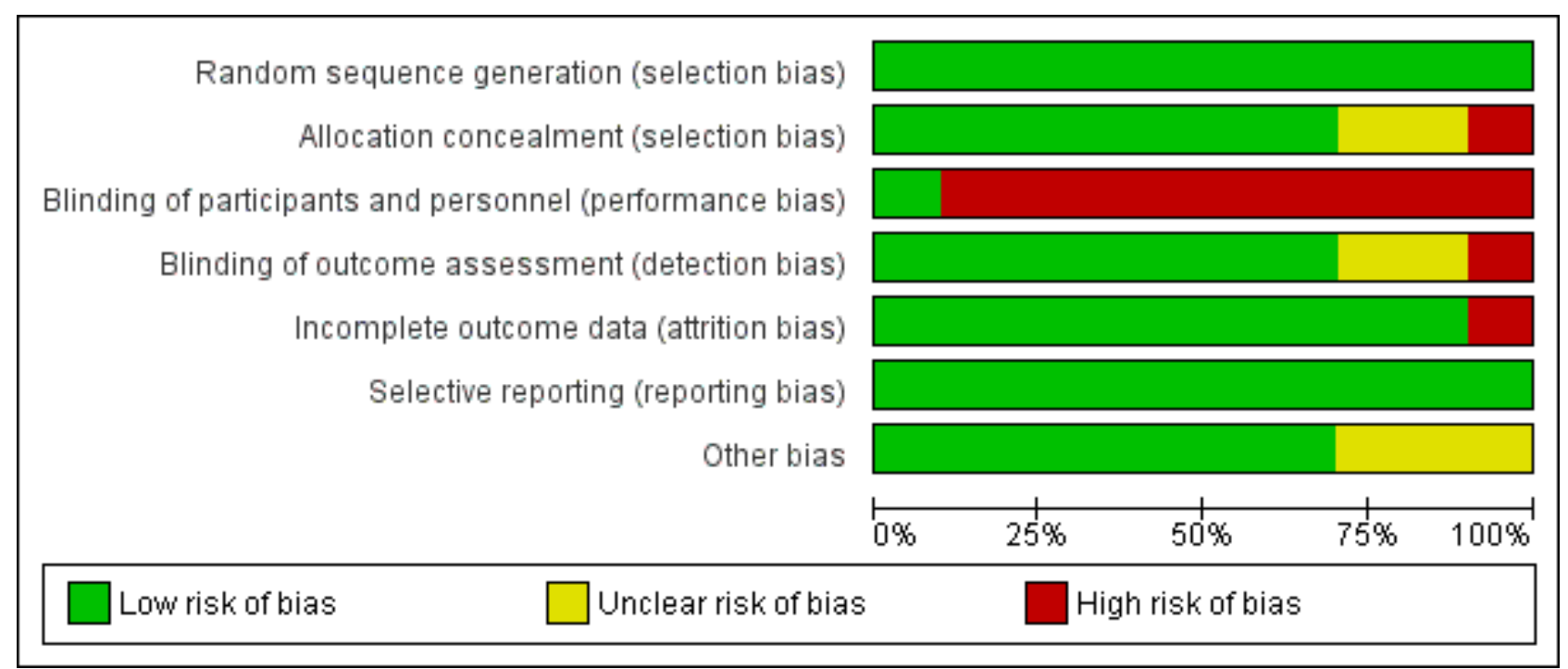

\section{Allocation}

Methods of sequence generation comprised computer and/or program-generated methods (Altiner 2007; Briel 2006; Francis 2009; Légaré 2011; Légaré 2012; Little 2013). Studies used stratification and minimisation techniques (Little 2013), or dynamic block allocation (Butler 2012; Francis 2009), to achieve balanced groups on selected variables.

Concealed allocation occurred in most trials, with GPs blinded to group allocation until after randomisation, although methods of doing so were not clearly described in several trials (Altiner 2007; Briel 2006; Cals 2009; Francis 2009; Little 2013; Welschen 2004). In Légaré 2012, the family practice units were recruited before randomisation, but it is not clear when physicians in the units were recruited/consented. In Légaré 2011, individual family physicians were recruited after randomisation of the family medicine groups.

\section{Blinding}

The nature of the interventions meant blinding of the clinicians delivering the intervention was not possible. Briel 2006 reported blinding of general practitioners although this is not credible. Blinding of outcome assessment was not reported in Little 2013, although it was adequately described in all other included studies.

\section{Incomplete outcome data}

One study had high risk of attrition bias. Altiner 2007 reported that $17 \%$ of GPs were lost to follow-up at six weeks post-intervention and $41 \%$ at 12 months. The study authors explored the effect of high attrition by conducting a cluster level sensitivity analysis by imputing new values for missing average antibiotic rates: firstly, by performing a regression analysis according to GPs with complete data sets to receive a prediction rule of six weeks and 12 months prescribing rates from baseline prescribing rates and, secondly, by using these rules to estimate follow-up prescription rates for those physicians that dropped out of the study. Alternative estimates using last observations (baseline or six weeks) were similar, and the results of both sensitivity analyses were in line with reported results. Légare 2012 reported that three of 12 randomised family practice teaching units were lost to follow-up. The loss of clusters was noted as a study limitation, but no further analysis was performed. Neither of these studies reported conducting statistical analysis on an intention-to-treat (ITT) basis.

The risk of attrition bias was low in the remaining studies.

\section{Selective reporting}

Several studies reported prospective trial registration (Butler 2012; Cals 2009; Cals 2013; Francis 2009; Légaré 2012; Little 2013), and/ or had published trial protocols (Butler 2012; Cals 2009; Francis 2009; Légaré 2011; Légaré 2012). We detected no reporting bias by comparing these to the final reports. Only Briel 2006 neither reported trial registration nor published a protocol.

\section{Other potential sources of bias}

We considered recruitment bias to be minimal in the included trials as the unit of allocation was recruited into the trial before clusters were randomised. Similarly, we considered baseline imbalances between study group characteristics minimal as all studies disclosed baseline comparability and adjusted for important baseline differences in the analysis. In two studies there was sufficient loss of clusters following randomisation that may have introduced bias (Altiner 2007; Légaré 2012). All studies sufficiently reported the use of robust statistical methods to account for clustering in the analysis.

All studies reported a sample size calculation with the exception of Légaré 2011, which was designed as a pilot trial. An ITT analysis was pre-specified in all but two trials (Altiner 2007; Légaré 2012). Altiner 2007 included only practices with complete follow-up in the analysis and the method of analysis was not described in Légaré 2012.

The methods, timing and duration of patient recruitment varied across studies. Recruitment in some trials was planned to capture winter and/or autumn months (Cals 2009; Francis 2009; Légaré 2012; Welschen 2004). In the long-term follow-up study, Cals 2013, of the original cluster-RCT (Cals 2009), the end date of 
the follow-up period was chosen to ensure a similar number of winter days in each period. Recruitment in the Little 2013 study occurred at the end of the season for respiratory tract infections in participating European countries (February and May). One trial included registered practice populations over an entire year (Butler 2012). The timing and duration of participant recruitment (e.g. during limited/winter months versus annual periods) may influence study outcomes and seasonal variation in the frequency and severity of ARIs may affect results.

The possibility of selection bias remains a possibility, although trial authors report that the risk of bias was minimal as baseline GP and patient characteristics were disclosed in all studies and no systematic differences between known group characteristics or case-mix were observed. Altiner 2007 could not rule out that GPs, who were not monitored during the trial, may not have reported patients with acute cough who received an antibiotic. Participating GPs in Briel 2006 were considered highly motivated and several authors considered the possibility that GPs may have behaved differently while being monitored (Hawthorn effect) (Briel 2006; Francis 2009).

Intervention adherence was measured in only a few trials. Treatment fidelity was not measured in any of the included studies and sub-optimal exposure or delivery of the intervention as planned may dilute the observed effect.

\section{Effects of interventions}

See: Summary of findings for the main comparison Shared decision making compared to usual care for acute respiratory infections in primary care

\section{Primary outcome}

\section{Prescription of antibiotics}

There were data from all 10 included studies on antibiotic prescribing decisions for acute respiratory infection. However, they could not all be combined into one meta-analysis because of differences in adjusted effect estimates reported and outcome measurement time.

We extracted event and denominator data, and reported (or imputed) intra-class correlation coefficients, to calculate the risk ratio (RR) adjusted for the effects of clustering (Analysis 1.1; Analysis 1.2) to allow presentation of outcome data within a common scale. This also allowed us to combine trials reporting short (index consultation to $\leq$ six weeks) and longer-term ( $\geq$ 12 months) intervention effects on antibiotic prescribing. Eight studies reporting short-term prescribing outcomes could be pooled in meta-analysis: the RR compared to usual care was $0.61,95 \%$ confidence interval $(\mathrm{Cl}) 0.55$ to $0.68 ; \mathrm{P}$ value $=<0.001$ (Figure 4). There was a trend towards a reduction in antibiotic prescribing being maintained in the longer term: RR compared with usual care $0.74,95 \% \mathrm{Cl} 0.49$ to 1.11 ; P value $=0.14$ (Figure 5). However, the non-significant results may be an artefact of the more conservative effect estimates using RR adjusted only for clustering.

Figure 4. Forest plot of comparison: 1 Shared decision making versus usual care (control), outcome: 1.1 Antibiotics prescribed, dispensed or decision to use (short-term, index consultation to $\leq 6$ weeks).

\begin{tabular}{|c|c|c|c|c|c|c|c|c|c|}
\hline Study or Subgroup & log[Risk Ratio] & \multicolumn{2}{|c|}{ Shared decision making } & \multicolumn{2}{|l|}{ Usual care } & $\begin{array}{c}\text { Risk Ratio } \\
\text { IV, Random, } 95 \% \mathrm{Cl}\end{array}$ & \multicolumn{3}{|c|}{$\begin{array}{c}\text { Risk Ratio } \\
\text { IV, Random, 95\% Cl }\end{array}$} \\
\hline Francis $2009(1)$ & -0.7867 & 0.4212 & 256 & 272 & $1.8 \%$ & $0.46[0.20,1.04]$ & . & & \\
\hline Briel $2006(2)$ & -0.1518 & 0.2619 & 259 & 293 & $4.8 \%$ & $0.86[0.51,1.44]$ & $\rightarrow$ & & \\
\hline Légaré 2012 (3) & -0.6931 & 0.2606 & 181 & 178 & $4.8 \%$ & $0.50[0.30,0.83]$ & $\rightarrow$ & & \\
\hline Légaré 2011 (4) & -0.3738 & 0.204 & 81 & 70 & $7.9 \%$ & $0.69[0.46,1.03]$ & $\rightarrow$ & & \\
\hline Cals $2009(5)$ & -0.6846 & 0.19 & 201 & 230 & $9.1 \%$ & $0.50[0.35,0.73]$ & $\rightarrow$ & & \\
\hline Altiner 2007 (6) & -0.6983 & 0.1666 & 1021 & 1143 & $11.8 \%$ & $0.50[0.36,0.69]$ & $\rightarrow$ & & \\
\hline Little $2013(7)$ & -0.3711 & 0.1251 & 2332 & 1932 & $20.9 \%$ & $0.69[0.54,0.88]$ & $=$ & & \\
\hline Welschen 2004 (8) & -0.4806 & 0.0917 & 905 & 818 & $38.9 \%$ & $0.62[0.52,0.74]$ & $=$ & & \\
\hline Total $(95 \% \mathrm{Cl})$ & & & 5236 & 4936 & $100.0 \%$ & $0.61[0.55,0.68]$ & 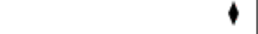 & & \\
\hline $\begin{array}{l}\text { Heterogeneity: } \mathrm{Tau}^{2} \\
\text { Test for overall effect }\end{array}$ & $\begin{array}{l}0.00 ; \mathrm{Chi}^{2}=6.62 \\
Z=8.63(\mathrm{P}<0.00\end{array}$ & $\begin{array}{l}d f=7(P=0.47) ;\left.\right|^{2}=0 \% \\
0001)\end{array}$ & & & & & \begin{tabular}{|lc}
0.005 & 0.1 \\
Shared decision making
\end{tabular} & $\begin{array}{l}10 \\
\text { Usual care }\end{array}$ & 200 \\
\hline
\end{tabular}

Footnotes

(1) Reported intra-class correlation co-efficient $(I C C)=0.24$. Design effect and effective sample size calculated.

(2) Reported intra-class correlation co-efficient $(\mathrm{ICC})=0.04$. Design effect and effective sample size calculated. Actual sample denomiator used to calculate risk ratio...

(3) Adjusted for cluster design, baseline values and patient age group (for analyses at teaching unit and physician levels).

(4) Reported intra-class correlation co-efficient $(I C C)=0.02$. Design effect and effective sample size calculated.

(5) Reported intra-class correlation co-efficient $(I C C)=0.12$. Design effect and effective sample size used to calculate risk ratio. Actual sample denominators reported in.

(6) Reported intra-class correlation co-efficient $(I C C)=0.20$. Design effect and effective sample size used to calculate risk ratio. Actual sample denominators reported in.

(7) Adjusted for baseline prescribing and clustering by physician and practice, age, smoking, sex, major cardiovascular or respiratory comorbidity, baseline symptoms,

(8) Reported intra-class correlation co-efficient $(I C C)=0.09$. Design effect and effective sample size used to calculate risk ratio. Actual sample denominators reported in. 
Figure 5. Forest plot of comparison: 1 Shared decision making versus usual care (control), outcome: 1.2 Antibiotics prescribed or dispensed (longer-term, $\geq 12$ months).

\begin{tabular}{lrrrrr} 
& \multicolumn{3}{c}{ Shared decision making } & Usual care & \multicolumn{2}{c}{ Risk Ratio } \\
Study or Subgroup & log[Risk Ratio] & SE & Total & Total & Weight \\
IV, Random, 95\% $\mathbf{C l}$
\end{tabular}

We also conducted a sensitivity analysis by pooling the results of trials reporting similar adjusted effect estimates (see Analysis 1.3; Analysis 1.4; Analysis 1.5). Three studies reported antibiotic prescription as an odds ratio (OR) adjusted for clustering and other covariates, and we were able to meta-analyse them: the pooled OR compared with usual care was $0.44,95 \% \mathrm{Cl} 0.26$ to $0.75 ; \mathrm{P}$ value $=0.003$ (Figure 6). Similarly a meta-analysis of two studies reporting a RR adjusted for clustering yielded a pooled RR compared with usual care of $0.64,95 \% \mathrm{Cl} 0.49$ to $0.84 ; \mathrm{P}$ value $=0.001$ (Figure 7). A meta-analysis of four studies reporting an adjusted risk difference (RD) yielded a pooled RD of $-18.44 \%$, $95 \% \mathrm{Cl}-27.24$ to $-9.65 \%$ compared with usual care (Figure 8). The results of the primary meta-analysis (RR adjusted for clustering) are generally concordant with trials reporting comparable adjusted effect estimates, although not adjusting for covariates that may have differed slightly between randomised groups (which were adjusted for in the reports) results in some loss of precision and wider $95 \%$ Cls.

Figure 6. Forest plot of comparison: 1 Shared decision making versus usual care (control), outcome: 1.3 Antibiotic prescriptions (index consultation) (adjusted odds ratio).

\begin{tabular}{|c|c|c|c|c|c|c|c|c|c|}
\hline Study or Subgroup & log[Odds Ratio] & \multicolumn{2}{|c|}{ Shared decision making } & Usual care & \multicolumn{2}{|r|}{ Odds Ratio } & \multicolumn{2}{|c|}{$\begin{array}{c}\text { Odds Ratio } \\
\text { IV, Random, } 95 \% \mathrm{Cl}\end{array}$} & \\
\hline Briel 2006 (1) & -0.1508 & 0.3906 & 259 & 293 & $26.7 \%$ & $0.86[0.40,1.85]$ & $\rightarrow$ & & \\
\hline Francis 2009 (2) & -1.2379 & 0.3716 & 256 & 272 & $28.1 \%$ & $0.29[0.14,0.60]$ & $\longrightarrow-$ & & \\
\hline Altiner 2007 (3) & -0.9676 & 0.1936 & 1021 & 1143 & $45.2 \%$ & $0.38[0.26,0.56]$ & $t$ & & \\
\hline Total $(95 \% \mathrm{Cl})$ & & & 1536 & 1708 & $100.0 \%$ & $0.44[0.26,0.75]$ & & & \\
\hline $\begin{array}{l}\text { Heterogeneity: } \operatorname{Tau}^{2}= \\
\text { Test for overall effect }\end{array}$ & $\begin{array}{l}0.13 ; \mathrm{Chi}^{2}=4.62,0 \\
Z=3.02(\mathrm{P}=0.003\end{array}$ & df $=2(P=$ & & & & & $\begin{array}{lc}0.002 & 0.1 \\
\text { Shared decision making }\end{array}$ & $\begin{array}{c}10 \\
\text { Usual care }\end{array}$ & $\overrightarrow{500}$ \\
\hline
\end{tabular}

Figure 7. Forest plot of comparison: 1 Shared decision making versus usual care (control), outcome: 1.4 Antibiotic prescriptions (index consultation) (adjusted risk ratio).

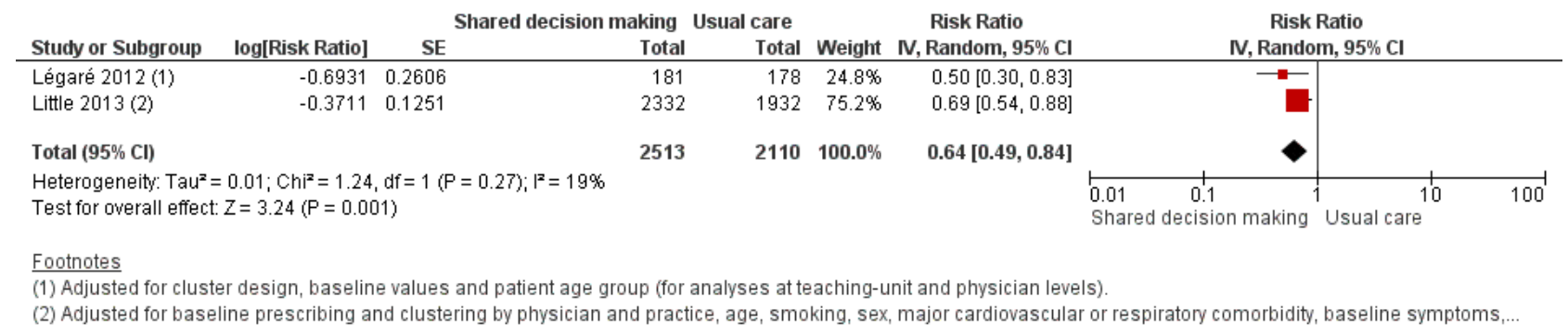


Figure 8. Forest plot of comparison: 1 Shared decision making versus usual care (control), outcome: 1.5 Antibiotic prescriptions (index consultation or population rate per unit of time) (adjusted risk difference).

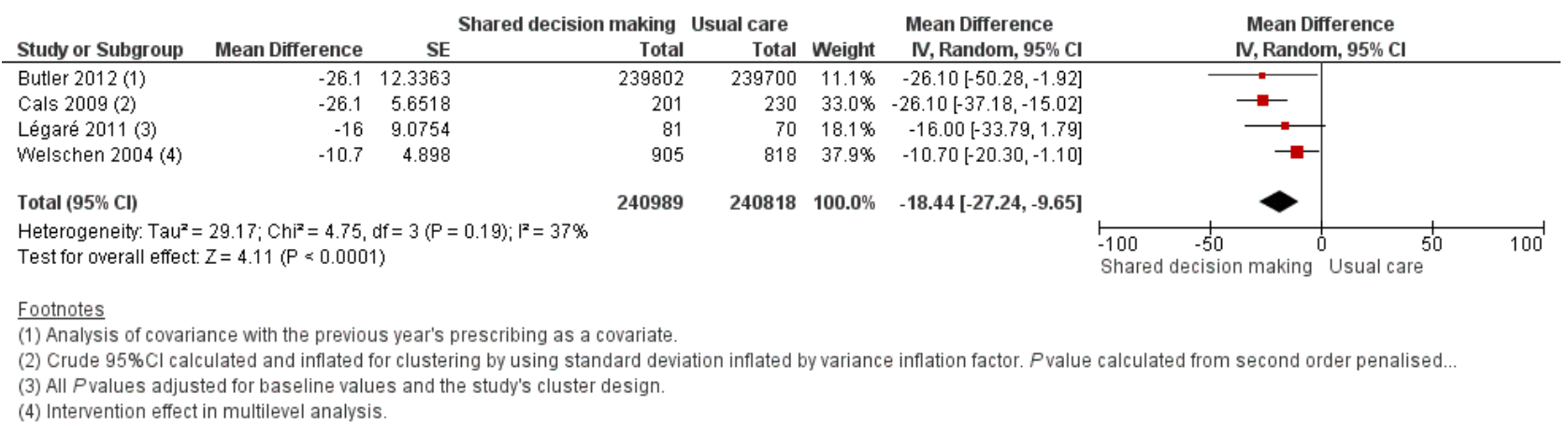

The absolute effect of the intervention for the outcome of antibiotics prescribed, dispensed, or decision to use, immediately after, or within six weeks, of the consultation was reduced from $47 \%$ to $29 \%$.

Francis 2009 showed important reductions in antibiotics prescribed for children consulting for an ARI at the index consultation (intervention versus control: $19.5 \%$ versus $40.8 \%$; adjusted OR 0.29 ; $95 \% \mathrm{Cl} 0.14$ to 0.60 . Francis 2009 was the only trial that also reported data on antibiotics taken (this was collected by telephone questionnaire). They reported the percentage of participants in each group that took antibiotics within the first two weeks (the data also include the antibiotics that were prescribed after the index consultation: $50(19.5 \%)$ in the intervention group and 111 $(40.8 \%)$ in the control group, with an adjusted OR of $0.35,95 \% \mathrm{Cl}$ 0.18 to 0.66 ). A significant decrease in antibiotic prescriptions for acute cough was observed in Altiner 2007 at six weeks (adjusted OR $0.38,95 \% \mathrm{Cl} 0.26$ to $0.5 ; \mathrm{P}$ value $<0.001$ ) and 12 months (adjusted OR $0.55,95 \% \mathrm{Cl} 0.38$ to $0.80 ; \mathrm{P}$ value $=0.002$ ) post-intervention. Conversely, Briel 2006 was the only trial that found no significant reduction in antibiotics dispensed within two weeks of the index consultation (full intervention versus limited intervention: $13.5 \%$ and $15.7 \%$; adjusted $\mathrm{OR} 0.86,95 \% \mathrm{Cl} 0.40$ to 1.93$)$. DECISION +2 led to fewer patients deciding to use antibiotics immediately after the consultation (immediate versus no or delayed antibiotic use) for ARIs compared with usual care $(27.2 \%$ versus $52.2 \%$; adjusted RR $0.5,95 \% \mathrm{Cl} 0.3$ to 0.7 ) (Légaré 2012). Little 2013 demonstrated that antibiotic prescribing for predominately acute lower respiratory tract infections (LRTIS) and upper respiratory tract infections (URTIS) was lower in the intervention group compared with controls (36.1\% versus $45.3 \%$; adjusted RR 0.69 , $95 \% \mathrm{Cl} 0.54$ to 0.87 ). Cals 2009 demonstrated a reduction in antibiotic prescribing for patients with suspected LRTI recruited during the winters of successive years (2005 to 2006 and 2006 to 2007) (intervention versus control: $27.4 \%, 95 \% \mathrm{Cl} 25.6 \%$ to $36.6 \%$ versus 53.5\%; $95 \% \mathrm{Cl} 43.8$ to $63.2 ; \mathrm{P}$ value $<0.01$ ). Butler 2012 measured a mean $4.2 \%(95 \% \mathrm{Cl} 0.6 \%$ to $7.7 \%$; $\mathrm{P}$ value $=0.02)$ reduction (as a percentage of the mean in controls) in the total number of dispensed oral antibiotic items per 1000 registered patients for the year after the intervention practices were exposed to the STAR programme. A non-significant reduction in the decision to immediately use antibiotics was also observed in the pilot trial by Légaré $2011(-16.0 \%$; P value $=0.08)$. Welschen 2004 reported significantly reduced antibiotic prescribing rates for symptoms of ARIs $(-10.7 \%, 95 \% \mathrm{Cl}-20.3 \%$ to $-1.0 \%)$. In a long-term followup of Cals 2009, enhanced communication skills training showed sustained reduction in antibiotic prescribing at 3.67 years mean follow-up (intervention versus control: $26.3 \%, 95 \% \mathrm{Cl} 20.6 \%$ to 32.0 versus $39.1 \%, 95 \% \mathrm{Cl} 33.1 \%$ to $45.1 \%$; corrected difference: $-10.4 \%$; P value $=0.02$ ). See Table 2 .

We graded the quality of evidence as moderate and low for antibiotic prescribing in the short term (less than six weeks) and long term (12 months or longer), respectively. See Summary of findings for the main comparison.

\section{Secondary outcomes}

\section{Number or rate of patient-initiated re-consultations for unresolved ARI}

Six studies reported adjusted effect estimates that we could not combine in a meta-analysis. We extracted data from four studies to calculate a RR adjusted for clustering, and pooled in meta-analysis. The RR compared to usual care was $0.87,95 \% \mathrm{Cl} 0.74$ to 1.03 ; $P$ value $=0.11$ (Analysis 1.6; Figure 9). 
Figure 9. Forest plot of comparison: 1 Shared decision making versus usual care (control), outcome: 1.6 Number or rate of re-consultations (risk ratio).

\begin{tabular}{|c|c|c|c|c|c|c|c|c|c|}
\hline Study or Subgroup & log[Risk Ratio] & $\begin{array}{l}\text { Shared decision } \\
\text { SE }\end{array}$ & $\begin{array}{l}\text { aking } \\
\text { Total }\end{array}$ & $\begin{array}{r}\text { Usual care } \\
\text { Total }\end{array}$ & Weight & $\begin{array}{c}\text { Risk Ratio } \\
\text { IV, Random, } 95 \% \mathrm{Cl}\end{array}$ & \multicolumn{3}{|c|}{$\begin{array}{c}\text { Risk Ratio } \\
\text { IV, Random, } 95 \% \mathrm{Cl}\end{array}$} \\
\hline Francis $2009(1)$ & -0.2252 & 0.3535 & 256 & 272 & $5.8 \%$ & $0.80[0.40,1.60]$ & $\longrightarrow$ & E & \\
\hline Légaré 2012 (2) & 0.2624 & 0.3158 & 181 & 178 & $7.3 \%$ & $1.30[0.70,2.41]$ & 千 & & \\
\hline Cals 2009 (3) & -0.288 & 0.1492 & 201 & 230 & $32.7 \%$ & $0.75[0.56,1.00]$ & $\rightarrow$ & & \\
\hline Briel 2006 (4) & -0.0901 & 0.116 & 253 & 290 & $54.1 \%$ & $0.91[0.73,1.15]$ & & & \\
\hline Total $(95 \% \mathrm{Cl})$ & & & 891 & 970 & $100.0 \%$ & $0.87[0.74,1.03]$ & $\bullet$ & & \\
\hline $\begin{array}{l}\text { Heterogeneity: Tau }{ }^{2} \\
\text { Test for overall effect: }\end{array}$ & $\begin{array}{l}0.00 ; \mathrm{Chi}^{2}=2.85 \\
Z=1.61(P=0.11\end{array}$ & $d f=3(P=0.42) ;\left.\right|^{2}=0 \%$ & & & & & \begin{tabular}{|lc|} 
& \multicolumn{1}{|c|}{} \\
0.01 & 0.1 \\
Shared decision making
\end{tabular} & Usual care $^{10}$ & 100 \\
\hline
\end{tabular}

Footnotes

(1) Reported intra-class correlation co-efficient $(I C C)=0.06$. Design effect and effective sample size calculated

(2) Adjusted for cluster design and baseline values.

(3) Reported intra-class correlation co-efficient $(I C C)=0.01$. Design effect and effective sample size calculated.

(4) Reported intra-class correlation co-efficient $(I C C)=0.04$. Design effect and effective sample size calculated.

The proportion of re-consultations for the same illness episode reported in Briel 2006 was 44.7\% versus 49.3\% (adjusted RR compared to controls $0.97,95 \% \mathrm{Cl} 0.78$ to 1.21 ). The betweengroup consultation rates in Cals 2009 were $27.9 \%(95 \% \mathrm{Cl} 21.4$ to 34.4$)$ and $37.0 \%(95 \% \mathrm{Cl} 30.4$ to 43.6$) ; \mathrm{P}$ value $=0.14$. Légaré 2012 reported no differences between groups $(22.7 \%$ versus $15.2 \%$; absolute difference 7.5\%; adjusted RR compared to controls 1.3 , $95 \% \mathrm{Cl} 0.7$ to 2.3). Francis 2009 also reported no difference in the odds of re-consulting in primary care during the two weeks after the index consultation ( $12.9 \%$ versus $16.2 \%$; adjusted OR $0.75(0.41$ to 1.38). Butler 2012 found no difference in median re-consultation rates after an index consultation for respiratory tract infections per 1000 registered patients at seven days $(-0.65,95 \% \mathrm{Cl}-1.69$ to 0.55 , $P$ value $=0.446) ; 14$ days $(-1.33,-2.12$ to $0.74 ; P$ value $=0.411)$; or 31 days $(-2.32,95 \% \mathrm{Cl}-4.76$ to $1.95 ; \mathrm{P}$ value $=0.503)$. Similarly, Little 2013 found the rates of new or worsening symptoms (including re-consultation in less than four weeks or hospital admission) did not differ significantly between groups (adjusted RR compared to controls 1.33, 95\% Cl 0.99 to 1.74; $\mathrm{P}$ value $=0.055)$. See Table 3 .

We graded the quality of evidence as moderate. See Summary of findings for the main comparison.

\section{Incidence of colonisation with, or infection due to, antibiotic- resistant organisms}

No studies reported this outcome.

\section{Incidence of hospital admission}

Six trials reported serious adverse events (SAEs) requiring hospitalisation, although no significant differences between groups were observed. Butler 2012 reported a non-significant difference in the proportion of hospital admissions for possible respiratory tract infections and complications relative to the control group $(-1.9 \%, 95 \% \mathrm{Cl}-13.2 \%$ to $8.2 \%$; $P$ value $=0.72)$. Briel 2006 reported that three patients were hospitalised (two patients in the full intervention group versus one in the limited intervention group). Six intervention and two usual care participants were hospitalised in Little 2013 (factorial analysis not reported). Francis 2009 reported seven hospitalisations (intervention $=$ three, control $=$ four). There were no occurrences of SAEs (death or admission to hospital) in Cals 2009. Cals 2013 reported five hospital admissions of 379 study participants: two patients receiving usual care (four exacerbations of chronic obstructive pulmonary disease (COPD) and one case of pneumonia), one randomised to C-reactive protein testing, and two episodes (pneumonia) in the combined intervention group (factorial analysis data not reported). See Table 4

\section{Incidence of pneumonia}

Two studies reported on the incidence of pneumonia. Briel 2006 reported one case of pneumonia in the control group, and Cals 2013 reported two cases of pneumonia in patients receiving a combined intervention (factorial analysis data not reported) and two cases of pneumonia in those receiving usual care. See Table 5.

\section{Incidence of acute otitis media complications}

No studies reported on this outcome.

\section{Mortality due to respiratory illness or similar}

One study, Briel 2006, reported a fatal myocardial infarction following pneumonia in an elderly patient receiving a limited (control) intervention.

\section{All-cause mortality}

No studies reported on this outcome.

\section{Measures of patient and caregiver satisfaction}

The results from two studies could be pooled, giving an OR compared to controls of $0.86,95 \% \mathrm{Cl} 0.57$ to 1.30 ; $\mathrm{P}$ value $=0.47$ (Analysis 1.7; Figure 10). 
Figure 10. Forest plot of comparison: 1 Shared decision making versus usual care (control), outcome: 1.7 Patient satisfaction with the consultation.

\begin{tabular}{|c|c|c|c|c|c|c|c|c|}
\hline Study or Subgroup & log[Odds Ratio] & \multicolumn{2}{|c|}{ Shared decision making } & \multicolumn{2}{|l|}{ Usual care } & $\begin{array}{c}\text { Odds Ratio } \\
\mathrm{I}, \text { Random, } 95 \% \mathrm{Cl}\end{array}$ & \multicolumn{2}{|l|}{$\begin{array}{c}\text { Odds Ratio } \\
\text { IV, Random, } 95 \% \mathrm{Cl}\end{array}$} \\
\hline Francis 2009 (1) & -0.4463 & 0.338 & 246 & 263 & $34.3 \%$ & $0.64[0.33,1.24]$ & $\rightarrow+$ & \\
\hline Briel 2006 (2) & 0 & 0.2277 & 253 & 290 & $65.7 \%$ & $1.00[0.64,1.56]$ & & \\
\hline Total $(95 \% \mathrm{Cl})$ & & & 499 & 553 & $100.0 \%$ & $0.86[0.57,1.30]$ & & \\
\hline $\begin{array}{l}\text { Heterogeneity: } \mathrm{Tau}^{2} \\
\text { Test for overall effect }\end{array}$ & $\begin{array}{l}0.02 ; \mathrm{Chi}^{2}=1.20 \\
Z=0.72(\mathrm{P}=0.47)\end{array}$ & $d f=1(P=$ & & & & & $\begin{array}{cccc}1 & 1 & 1 \\
0.005 & 0.1 & 1 & 10 \\
\text { Shared decision making } & \text { Usual care }\end{array}$ & 200 \\
\hline
\end{tabular}

There were no differences observed between intervention and control groups in studies that reported this outcome. Briel 2006 found no difference in scores for patient satisfaction (Patient Satisfaction Questionnaire; score 0 to 70 ) between intervention and control groups (median 68 out of 70 ; \% patients with 70 out of 70: $47.8 \%$ versus $49.0 \%$; adjusted OR $1.00 ; 95 \% \mathrm{Cl} 0.64$ to 1.31 ). Cals 2009 reported no differences in patient satisfaction with the index consultation (\% at least very satisfied: $78.7 \%, 95 \% \mathrm{Cl} 72.5$ to 84.9 versus $74.4 \%, 95 \% \mathrm{Cl} 68.2$ to 80.6 ; $\mathrm{P}$ value $=0.88$ ). In Francis 2009 , the proportion of parents that were reported to be satisfied or very satisfied with the consultation were similar between groups (90.2\% versus $93.5 \%$; adjusted OR $0.64,95 \% \mathrm{Cl} 0.33$ to 1.22 ). Patient satisfaction (one $=$ very dissatisfied, five $=$ very satisfied) was also high and no between-group differences were observed in Welschen 2004 (adjusted mean difference (MD) $-0.03,95 \% \mathrm{Cl}-0.2$ to 0.1 ). See Table 6.

We graded the quality of evidence as low. See Summary of findings for the main comparison.

\section{Measures of patient and caregiver satisfaction with the decision reached, decisional conflict and decisional regret}

Decisional conflict

One study measured GPs' decisional conflict using the Decisional Conflict Scale (DCS; 1 = low decisional conflict, $5=$ very high decisional conflict) and found no difference between the intervention group and controls (MD 3.4, adjusted RR 3.5, 95\% Cl 0.3 to 38.0) (Légaré 2012). For patients' decisional conflict scores, the MD was 1.7 and the adjusted RR $0.8,95 \% \mathrm{Cl} 0.2$ to 2.4. See Table 7 .

\section{Decision regret (patients)}

Légaré 2012 observed a clinically insignificant effect between the intervention and control groups on a decision regret measure $(0$ $=$ very low regret, $100=$ very high regret) with a mean of 12.4 in the intervention group and 7.6 in the control group; adjusted MD $4.8,95 \% \mathrm{Cl} 0.9$ to 8.7 . Légaré 2011 also reported no difference in the proportion of patients with decisional regret between the study groups ( $7 \%$ in the intervention group versus $9 \%$ in the control; adjusted MD -2, 95\% Cl-12 to 5). See Table 8.

\section{Measures of extent of patient involvement in the decision making process}

\section{Patient enablement}

Three studies reported on patient enablement. Cals 2009 found no difference between intervention and control group scores on the Patient Enablement Instrument (PEI; score 0 to 12) (mean (SD):
3.29 (2.52) versus 3.06 (2.54); $P$ value $=0.70)$. Francis 2009 found no between-group difference in a modified PEI measuring parent enablement (score 0 to 10 ; score greater or equal five: $40.2 \%$ versus $35.9 \%$; adjusted OR $1.20,95 \% \mathrm{Cl} 0.84$ to 1.73 ). Briel 2006 found weak evidence for higher patient enablement on the PEI (median 8 out of 12; mean (SD) 8.49 (1.98) versus 8.15 (2.03); adjusted MD 0.35, 95\% $\mathrm{Cl}-0.05$ to 0.75$)$. See Table 9.

\section{Measures of treatment compliance or adherence to decision reached}

\section{Decision quality}

Légaré 2012 found no difference between GPs on a measure of GPs' decision quality ( $1=$ very low quality, $10=$ very high quality) (MD $-0.2,95 \% \mathrm{Cl}-0.6$ to 0.2 ). The results were similar to the earlier pilot cluster-RCT, Légaré 2011 (MD $-0.2,95 \% \mathrm{Cl}-0.34$ to 0.89 ; $\mathrm{P}$ value $=0.29$ ). Similarly, there were no differences observed in patients' decision quality in Légaré 2012 (MD $0.0,95 \% \mathrm{Cl}-0.4$ to 0.4 ) and Légaré 2011 (MD 0.1, 95\% Cl -0.88 to 0.94; $\mathrm{P}$ value $=0.57$ ). See Table 10 and Table 11.

\section{Adherence to decision}

The only trial to measure adherence to the decision reached found no difference between intervention and control groups $(87.7 \%$ of patients versus $91.5 \%$; absolute difference of 3.8, adjusted RR 1.0, $95 \% \mathrm{Cl} 0.9$ to 1.0) (Légaré 2012).

\section{DISCUSSION}

\section{Summary of main results}

Interventions aiming to promote shared decision making in primary care, as the focus or a core component of multi-faceted interventions, significantly reduced antibiotic prescribing for acute respiratory infections by almost $40 \%$ compared with usual care in the short term. There was insufficient evidence for sustained reductions in antibiotic prescribing over the longer term. There were no significant differences between groups receiving the intervention or usual care in clinical complications such as reconsultation for the same illness, or patient satisfaction with the consultation. There was also insufficient evidence to assess intervention effects on other clinically adverse or patient and/or caregiver shared decision process outcomes.

\section{Overall completeness and applicability of evidence}

A growing number of trials have examined the effect of interventions that aim to facilitate shared decision making, with all studies being conducted in the last 10 years (seven of 10 studies in 
the last five years), highlighting that shared decision making is a relatively new intervention.

All studies included acute upper or lower respiratory tract infection in children and/or adults consulting primary care or academic general practice. Trials were conducted in several high-income European countries and Canada. Applicability of findings to lowand middle-income countries and different cultural and healthcare settings is unknown.

We identified considerable heterogeneity in longer-term prescribing outcomes meta-analysed as risk ratio (see Analysis 1.2), and moderate to substantial heterogeneity in pooled results grouped under each reported effect estimate for the primary outcome (see Analysis 1.3; Analysis 1.4; Analysis 1.5). There was considerable diversity across included studies within each comparison in terms of the population (adults, children, or both), scale and composition of multi-component interventions evaluated, timing of the intervention and follow-up, outcome measures used and statistical techniques. The considerable heterogeneity observed in antibiotic prescribing rates over the longer term may be due to measurement differences in one study (Butler 2012) (all oral dispensed antibiotic items per 1000 registered patients for the year following exposure of practices to the intervention), or the low number of studies reporting longerterm sustainability of intervention effects. Substantial (although non-significant) heterogeneity apparent in studies reporting an adjusted odds ratio (OR) (see Analysis $1.3 ; \mathrm{I}^{2}$ statistic $=57 \% ; \mathrm{P}$ value $=0.10$ ) may have resulted from the inclusion of one study reporting a statistically non-significant intervention effect (Briel 2006), where an unusually low antibiotic prescribing rate was noted $(13.5 \%$ and $15.7 \%$ in the study groups) compared with other studies. Detecting an intervention effect may be difficult in a low prescribing setting. Some heterogeneity in pooled studies reporting an adjusted relative risk (Analysis $1.4 ; \mathrm{I}^{2}$ statistic $=19 \%$; $P$ value $=0.27$ ) may result from true clinical and/or methodological diversity with the non-significant result being simply an artefact of only two studies being available for the comparison. Significant heterogeneity in four studies reporting adjusted risk differences (Analysis $1.5 ; 12$ statistic $=37 ; \mathrm{P}$ value $=0.19$ ) is likely due to inherent multiplicity of clinical and methodological factors.

The effect size of the included studies varied considerably, although there was general consistency in the direction of effects. The risk of bias overall in the included studies was low. Interventions varied markedly in the theoretical basis, and the components, scope, mode of delivery and duration. It is not possible, therefore, to identify which intervention components, combinations or modes of delivery most effectively promote shared decisions. Interventions and training were principally targeted at GPs. However, competence in the use of shared decision making was only reported in some trials, with no studies assessing intervention fidelity. Objective patient or clinician measures of adoption of shared decision making (e.g. OPTION (Elwyn 2003)) were not included in any studies. The usefulness of interventions aimed primarily at patients to help facilitate their role in initiating and making shared decisions remains unknown.

\section{Quality of the evidence}

We graded the quality of the evidence as moderate or low for all outcomes. All cluster-level randomised controlled trials (RCTs) used a method of sequence generation aimed at minimising chance between-group imbalance. All study participants (clusters) were randomised after they were enrolled and prior to group allocation to minimise selection bias. Blinding was not possible because of the nature of the interventions. We considered only two studies to have substantial loss to follow-up (Altiner 2007; Légaré 2012). Altiner 2007 did not conduct an intention-to-treat (ITT) analysis although they explored the effects of differential missing values in clusterlevel sensitivity analysis. An ITT analysis was not reported by Légaré 2012.

Pooled studies for the primary outcome, antibiotic prescribing, were limited by the diversity in adjusted effect estimates reported and resulted in a low number of studies in each presented comparison (see Analysis 1.3; Analysis 1.4; Analysis 1.5). This was surmounted by calculating a risk ratio (RR) (using the design effect to adjust for clustering) for meta-analysis (see Analysis 1.1; Analysis 1.2; Analysis 1.6), which results in some loss of precision, although it is still robust (and more conservative at least). Similarly, metaanalysis could not be performed for several clinically important secondary outcomes due to variance in effect estimates reported or measurement differences, which resulted in only a small number of trials being included for patient satisfaction (see Analysis 1.7). The low number of trials in addition to the presence of considerable heterogeneity in the longer-term reduction in antibiotic prescribing suggests that the overall pooled results and meaningful exploration of heterogeneity was limited and should be interpreted with caution. See Summary of findings for the main comparison.

\section{Potential biases in the review process}

Combining trials under a common effect estimate (RR) for antibiotic prescribing in the longer term ( $\geq 12$ months) required us to impute intra-class correlation coefficients for two studies (Butler 2012; Cals 2013), from similar studies, so that the design effect for adjustment of clustering effects could be calculated. The results for these outcomes should be interpreted with caution.

\section{Agreements and disagreements with other studies or reviews}

Other systematic reviews have assessed clinician- and/or patientoriented interventions to influence antibiotic prescribing for acute respiratory infections (ARIs) in primary care (Andrews 2012; Arnold 2005; Boonacker 2010; Ranji 2008; Thoolen 2013; van der Velden 2012; Vodicka 2013). Meaningful comparisons about the relative effectiveness of studies is limited by the diversity in study designs, interventions and outcome measures. Two reviews concluded that multiple component interventions that provided education to healthcare professionals and patients were most often effective in reducing antibiotic use for respiratory tract infections (Arnold 2005; van der Velden 2012). Multi-faceted interventions and computer strategies aimed at healthcare professionals most effectively reduced antibiotic prescribing in children with upper respiratory tract infections (Boonacker 2010). Provision of patient information alone (Thoolen 2013), or in addition to physician education (van der Velden 2012), appears to offer only moderate or little additional benefit, respectively. However, reviews exclude many recent high quality intervention trials incorporating patient information materials and training explicitly aiming to facilitate shared decision making. Two reviews found that educational interventions directed at parents and/or caregivers were effective in modifying consulting behaviour and antibiotic use for children with ARIs, and may be more successful when they engage children (Andrews 2012; 
Vodicka 2013). Interventions were also more successful when they were delivered prior to the consultation and focused on specific symptoms (Andrews 2012). Several reviews concluded that a reduction in antibiotics was not at the expense of adverse clinical outcomes (Ranji 2008), or patient satisfaction (Andrews 2012; Ranji 2008; Thoolen 2013). Previous reviews have raised the importance of a patient-centred approach to help patients adopt a more active role in decision making about antibiotics for ARIs (Thoolen 2013), and communication skills training for physicians has been highlighted as a promising intervention element (van der Velden 2012).

\section{AUTHORS' CONCLUSIONS}

\section{Implications for practice}

Interventions that aim to facilitate shared decision making reduce antibiotic prescribing for acute respiratory infections (ARIs) in primary care in the short term by a relative risk reduction of almost $40 \%$ compared with usual care, without an increase in patientinitiated re-consultations for the same illness or a decrease in patient satisfaction. There is insufficient evidence that the effect may be sustained in the medium to longer term ( $\sim$ one to three years). Whether the reduction in antibiotic prescribing achieved is sufficient, or sustained long enough, to reverse communitylevel resistance trends is not known as this was not measured in the included studies. We graded the quality of the evidence as moderate or low for all outcomes. The variety in the interventions and training components studied has important implications for knowing which intervention components should be used in clinical practice, or how best to adapt successful programmes to other primary care environments with different practice characteristics or access to financial and core support resources.

\section{Implications for research}

The addition of future trials into this systematic review may allow greater precision of the effects of shared decision making and an opportunity to explore reasons for the heterogeneity of the results. Evaluation of intervention adherence and fidelity (the degree to which the intervention was delivered as intended) should be incorporated into new studies. Further long-term follow-up of included studies would also provide greater certainty regarding the maintenance of intervention effects. Further research should also aim to determine which aspects of these interventions provide the greatest benefit to adapt programme implementation and uptake in diverse clinical settings. Research will also need to establish the link between a reduction in antibiotic prescribing for ARIs in primary care and the reversal in community-level antibioticresistance trends, to validate the usefulness and sustainability of programmes. Furthermore, while the interventions in studies are principally aimed at developing general practitioners' (GPs') communication skills to facilitate shared decision making, there appears to be scope to pursue ways of involving healthcare consumers in the design, planning and delivery of interventions to promote shared decision making for ARIs in primary care. Finally, although not relevant to the present review, the cost-effectiveness of establishing shared decision making training programmes in primary care to reduce antibiotic use for ARIs requires further research interest.

\section{ACKNOWLEDGEMENTS}

Thanks to the staff and editors of the Cochrane Acute Respiratory Infections Group. We thank the following people for commenting on the draft protocol: Adrian Edwards, Sreekumaran Nair and Sandra Arnold, and Inge Axelsson. We also thank those people commenting on the draft of this review: Jenny Negus, Noorin Bhimani, Sandra Arnold, Helena Liirra, Teresa Neeman, Inge Axelsson and Susan Smith. Finally, we are grateful to Toby Lasserson for comments during pre-publication screening (Cochrane Editorial Unit). 


\section{R E F E R E N C E S}

\section{References to studies included in this review}

\section{Altiner 2007 \{published data only\}}

Altiner A, Brockmann S, Sielk M, Wilm S, Wegscheider K, Abholz HH. Reducing antibiotic prescriptions for acute cough by motivating GPs to change their attitudes to communication and empowering patients: a cluster-randomized intervention study. Journal of Antimicrobial Chemotherapy 2007;60:638-44.

\section{Briel 2006 \{published data only\}}

Briel M, Langewitz W, Tschudi P, Young J, Hugenschmidt C, Bucher HC. Communication training and antibiotic use in acute respiratory tract infections. A cluster randomised controlled trial in general practice. Swiss Medical Weekly 2006;136:241-7.

\section{Butler 2012 \{published data only\}}

Butler CC, Simpson SA, Dunstan F, Rollnick S, Cohen D, Gillespie D, et al. Effectiveness of multifaceted educational programme to reduce antibiotic dispensing in primary care: practice based randomised controlled trial. $B M J$ 2012;344:d8173

\section{Cals 2009 \{published data only\}}

Cals JW, Butler CC, Hopstaken RM, Hood K, Dinant GJ. Effect of point of care testing for $\mathrm{C}$ reactive protein and training in communication skills on antibiotic use in lower respiratory tract infections: cluster randomised trial. BMJ 2009;338:b1374.

\section{Cals 2013 \{published data only\}}

Cals JW, de Bock L, Beckers PJ, Francis NA, Hopstaken RM, Hood K, et al. Enhanced communication skills and C-reactive protein point-of-care testing for respiratory tract infection: 3.5year follow-up of a cluster randomized trial. Annals of Family Medicine 2013;11:157-64.

\section{Francis 2009 \{published data only\}}

Francis NA, Butler CC, Hood K, Simpson S, Wood F, Nuttall J. Effect of using an interactive booklet about childhood respiratory tract infections in primary care consultations on reconsulting and antibiotic prescribing: a cluster randomised controlled trial. BMJ 2009;339:b2885.

\section{Légaré 2011 \{published data only\}}

Légaré F, Labrecque M, LeBlanc A, Njoya M, Laurier C, Cote L, et al. Training family physicians in shared decision making for the use of antibiotics for acute respiratory infections: a pilot clustered randomized controlled trial. Health Expectations 2011;14(Suppl 1):96-110.

\section{Légaré 2012 \{published data only\}}

Legare F, Labrecque M, Cauchon M, Castel J, Turcotte S, Grimshaw J. Training family physicians in shared decisionmaking to reduce the overuse of antibiotics in acute respiratory infections: a cluster randomized trial. Canadian Medical Association Journal 2012;184:E726-34.

\section{Little 2013 \{published data only\}}

Little P, Stuart B, Francis N, Douglas E, Tonkin-Crine S, Anthierens $S$, et al. Effects of internet-based training on antibiotic prescribing rates for acute respiratory-tract infections: a multinational, cluster, randomised, factorial, controlled trial. Lancet 2013;382:1175-82.

\section{Welschen 2004 \{published data only\}}

Welschen I, Kuyvenhoven MM, Hoes AW, Verheij TJ. Effectiveness of a multiple intervention to reduce antibiotic prescribing for respiratory tract symptoms in primary care: randomised controlled trial. BMJ 2004;329:431.

\section{References to studies excluded from this review}

Bourgeois 2010 \{published data only\}

Bourgeois F, Linder J, Johnson S, Co J, Fiskio J, Ferris T. Impact of a computerized template on antibiotic prescribing for acute respiratory infections in children and adolescents. Clinical Pediatrics 2010;49:976-83.

Gonzales 2013 \{published data only\}

Gonzales R, Anderer T, McCulloch C, Maselli J, Bloom Jr F, Graf T, et al. A cluster randomized trial of decision support strategies for reducing antibiotic use in acute bronchitis. JAMA Internal Medicine 2013;173:267-73.

Pshetizky 2003 \{published data only\}

Pshetizky Y, Naimer S, Shvartzman P. Acute otitis media--a brief explanation to parents and antibiotic use. Family Practice 2003;20:417-9.

Regev-Yochay 2011 \{published data only\}

Regev-Yochay G, Raz M, Dagan R, Roizin H, Morag B, Hetman S, et al. Reduction in antibiotic use following a cluster randomized controlled multifaceted intervention: the Israeli Judicious Antibiotic Prescription Study. Clinical Infectious Diseases 2011;53:33-41.

\section{Samore 2005 \{published data only\}}

Samore M, Bateman K, Alder S, Hannah E, Donnelly S, Stoddard G, et al. Clinical decision support and appropriateness of antimicrobial prescribing: a randomized trial. JAMA 2005;294:2305-14.

\section{Taylor 2005 \{published data only\}}

Taylor J, Kwan-Gett T, McMahon Jr E. Effectiveness of a parental educational intervention in reducing antibiotic use in children: a randomized controlled trial. Pediatric Infectious Disease Journal 2005;24:489-93.

\section{References to ongoing studies}

Altiner 2012 \{published data only\}

Altiner A, Berner R, Diener A, Feldmeier G, Kochling A, Loffler $C$, et al. Converting habits of antibiotic prescribing for respiratory tract infections in German primary care--the clusterrandomized controlled CHANGE-2 trial. BMC Family Practice 2012;13:124. 


\section{Additional references}

\section{Ahovuo-Saloranta 2014}

Ahovuo-Saloranta A, Rautakorpi UM, Borisenko OV, Liira H, Williams JW Jr, Makela M. Antibiotics for acute maxillary sinusitis in adults. Cochrane Database of Systematic Reviews 2014, Issue 2. [DOI: 10.1002/14651858.CD000243.pub3]

\section{Andrews 2012}

Andrews T, Thompson M, Buckley DI, Heneghan C, Deyo R, Redmond $\mathrm{N}$, et al. Interventions to influence consulting and antibiotic use for acute respiratory tract infections in children: a systematic review and meta-analysis. PloS One 2012;7(1):e30334. [PUBMED: 22299036]

\section{Arnold 2005}

Arnold SR, Straus SE. Interventions to improve antibiotic prescribing practices in ambulatory care. Cochrane Database of Systematic Reviews 2005, Issue 4. [DOI: 10.1002/14651858.CD003539.pub2]

\section{Arroll 2002}

Arroll B, Goodyear-Smith F, Thomas DR, Kerse N. Delayed antibiotic prescriptions: what are the experiences and attitudes of physicians and patients?. Journal of Family Practice 2002;51:954-9.

\section{Boonacker 2010}

Boonacker CW, Hoes AW, Dikhoff MJ, Schilder AG, Rovers MM. Interventions in health care professionals to improve treatment in children with upper respiratory tract infections. International Journal of Pediatric Otorhinolaryngology 2010;74(10):1113-21. [PUBMED: 20692051]

\section{Butler 1998}

Butler CC, Rollnick S, Kinnersley P, Jones A, Stott N. Reducing antibiotics for respiratory tract symptoms in primary care: consolidating 'why' and considering 'how'. British Journal of General Practice 1998;48:1865-70.

\section{Butler 2001}

Butler CC, Kinnersley P, Prout H, Rollnick S, Edwards A, Elwyn G. Antibiotics and shared decision-making in primary care. Journal of Antimicrobial Chemotherapy 2001;48:435-40.

\section{Charles 1997}

Charles C, Gafni A, Whelan T. Shared decision-making in the medical encounter: what does it mean? (or it takes at least two to tango). Social Science \& Medicine 1997;44:681-92.

\section{Chung 2007}

Chung A, Perera R, Brueggemann AB, Elamin AE, Harnden A, Mayon-White $R$, et al. Effect of antibiotic prescribing on antibiotic resistance in individual children in primary care: prospective cohort study. BMJ 2007;335:429.

\section{Costelloe 2010}

Costelloe C, Metcalfe C, Lovering A, Mant D, Hay AD. Effect of antibiotic prescribing in primary care on antimicrobial resistance in individual patients: systematic review and metaanalysis. BMJ 2010;340:c2096.

\section{Coyne 2013}

Coyne I, O'Mathuna DP, Gibson F, Shields L, Sheaf G. Interventions for promoting participation in shared decision-making for children with cancer. Cochrane Database of Systematic Reviews 2013, Issue 6. [DOI: 10.1002/14651858.CD008970.pub2]

\section{Duncan 2010}

Duncan E, Best C, Hagen S. Shared decision making interventions for people with mental health conditions. Cochrane Database of Systematic Reviews 2010, Issue 1. [DOI: 10.1002/14651858.CD007297.pub2]

\section{Elwyn 2003}

Elwyn G, Edwards A, Wensing M, Hood K, Atwell C, Grol R. Shared decision making: developing the OPTION scale for measuring patient involvement. Quality \& Safety in Health Care 2003;12(2):93-9. [PUBMED: 12679504]

\section{Elwyn 2012}

Elwyn G, Frosch D, Thomson R, Joseph-Williams N, Lloyd A, Kinnersley $\mathrm{P}$, et al. Shared decision making: a model for clinical practice. Journal of General Internal Medicine 2012;27:1361-7.

\section{Elwyn 2013}

Elwyn G, Lloyd A, Joseph-Williams N, Cording E, Thomson R, Durand MA, et al. Option Grids: shared decision making made easier. Patient Education and Counseling 2013;90:207-12.

\section{Giguere 2012}

Giguere A, Legare F, Grad R, Pluye P, Haynes RB, Cauchon M, et al. Decision boxes for clinicians to support evidence-based practice and shared decision making: the user experience. Implementation Science 2012;7:72.

\section{Gill 2006}

Gill JM, Fleischut P, Haas S, Pellini B, Crawford A, Nash DB. Use of antibiotics for adult upper respiratory infections in outpatient settings: a national ambulatory network study. Family Medicine 2006;38:349-54.

\section{Gillies 2015}

Gillies M, Ranakusuma A, Hoffmann T, Thorning S, McGuire T, Glasziou P, et al. Common harms from amoxicillin: a systematic review and meta-analysis of randomized placebo-controlled trials for any indication. Canadian Medical Association Journal 2015;187(1):E21-31. [PUBMED: 25404399]

\section{Gonzales 1997}

Gonzales R, Steiner JF, Sande MA. Antibiotic prescribing for adults with colds, upper respiratory tract infections, and bronchitis by ambulatory care physicians. JAMA 1997;278:901-4.

\section{Gonzales 2001}

Gonzales R, Malone DC, Maselli JH, Sande MA. Excessive antibiotic use for acute respiratory infections in the United States. Clinical Infectious Diseases 2001;33:757-62. 


\section{GRADE Working Group 2004}

GRADE Working Group. Grading quality of evidence and strength of recommendations. BMJ 2004;328:1490-4. [DOI: http://dx.doi.org/10.1136/bmj.328.7454.1490]

\section{GRADEproGDT 2015 [Computer program]}

McMaster University (developed by Evidence Prime, Inc.). GRADEpro Guideline Development Tool [www.guidelinedevelopment.org] [Computer program]. Version 12 August 2015. Hamilton: McMaster University (developed by Evidence Prime, Inc.), 2015.

\section{Higgins 2011}

Higgins JPT, Green S (editors). Cochrane Handbook for Systematic Reviews of Interventions Version 5.1.0 [updated March 2011]. The Cochrane Collaboration, 2011. Available from www.cochrane-handbook.org.

\section{Hoffmann 2014}

Hoffmann T, Glasziou P, Boutron I, Milne R, Perera R, Moher D, et al. Better reporting of interventions: template for intervention description and replication (TIDieR) checklist and guide. BMJ (Clinical research ed.) 2014;348:g1687. [PUBMED: 24609605]

\section{Kenealy 2013}

Kenealy T, Arroll B. Antibiotics for the common cold and acute purulent rhinitis. Cochrane Database of Systematic Reviews 2013, Issue 6. [DOI: 10.1002/14651858.CD000247.pub3]

\section{Kinnersley 2007}

Kinnersley P, Edwards A, Hood K, Cadbury N, Ryan R, Prout $\mathrm{H}$, et al. Interventions before consultations for helping patients address their information needs. Cochrane Database of Systematic Reviews 2007, Issue 3. [DOI: 10.1002/14651858.CD004565.pub2]

\section{Légaré 2013}

Légaré F, Moumjid-Ferdjaoui N, Drolet R, Stacey D, Härter M, et al. Core competencies for shared decision making training programs: insights from an international, interdisciplinary working group. Journal of Continuing Education in the Health Professions 2013;33(4):267-73. [DOI: 10.1002/chp.21197]

\section{Légaré 2014}

Légaré F, Stacey D, Turcotte S, Cossi MJ, Kryworuchko J, Graham ID, et al. Interventions for improving the adoption of shared decision making by healthcare professionals. Cochrane Database of Systematic Reviews 2014, Issue 9. [DOI: 10.1002/14651858.CD006732.pub3]

\section{Makoul 2006}

Makoul G, Clayman ML. An integrative model of shared decision making in medical encounters. Patient Education and Counseling 2006;60:301-12.

\section{Prochaska 1992}

Prochaska JO, DiClemente CC, Norcross JC. In search of how people change. Applications to addictive behaviors.. American Psychologist 1992;47:1102-14.

\section{Ranji 2008}

Ranji SR, Steinman MA, Shojania KG, Gonzales R. Interventions to reduce unnecessary antibiotic prescribing: a systematic review and quantitative analysis. Medical Care 2008;46(8):847-62. [PUBMED: 18665065]

\section{RevMan 2014 [Computer program]}

The Nordic Cochrane Centre, The Cochrane Collaboration. Review Manager (RevMan). Version 5.3. Copenhagen: The Nordic Cochrane Centre, The Cochrane Collaboration, 2014.

\section{Smith 2014}

Smith SM, Fahey T, Smucny J, Becker LA. Antibiotics for acute bronchitis. Cochrane Database of Systematic Reviews 2014, Issue 3. [DOI: 10.1002/14651858.CD000245.pub3]

\section{Spatz 2012}

Spatz ES, Spertus JA. Shared decision making: a path toward improved patient-centered outcomes. Circulation: Cardiovascular Quality and Outcomes 2012;5:e75-7.

\section{Spinks 2013}

Spinks A, Glasziou PP, Del Mar CB. Antibiotics for sore throat. Cochrane Database of Systematic Reviews 2013, Issue 11. [DOI: 10.1002/14651858.CD000023.pub4]

\section{Stacey 2014}

Stacey D, Legare F, Col NF, Bennett CL, Barry MJ, Eden KB, et al. Decision aids for people facing health treatment or screening decisions. Cochrane Database of Systematic Reviews 2014, Issue 1. [DOI: 10.1002/14651858.CD001431.pub4]

\section{Thoolen 2013}

Thoolen B, de Ridder D, van Lensvelt-Mulders G. Patientoriented interventions to improve antibiotic prescribing practices in respiratory tract infections: a meta-analysis. Health Psychology Review 2012;6 Special Issue(1):92-112.

\section{van der Velden 2012}

van der Velden AW, Pijpers EJ, Kuyvenhoven MM, TonkinCrine SK, Little P, Verheij TJ. Effectiveness of physiciantargeted interventions to improve antibiotic use for respiratory tract infections. British Journal of General Practice 2012;62(605):e801-7. [PUBMED: 23211259]

\section{Venekamp 2015}

Venekamp RP, Sanders S, Glasziou PP, Del Mar CB, Rovers MM. Antibiotics for acute otitis media in children. Cochrane Database of Systematic Reviews 2015, Issue 6. [DOI: 10.1002/14651858.CD000219.pub4]

\section{Vodicka 2013}

Vodicka TA, Thompson M, Lucas P, Heneghan C, Blair PS, Buckley DI, et al. Reducing antibiotic prescribing for children with respiratory tract infections in primary care: a systematic review. British Journal of General Practice 2013;63(612):e445-54. [PUBMED: 23834881]

\section{WHO 2001}

World Health Organization. WHO Global Strategy for Containment of Antimicrobial Resistance. http://www.who.int/ 
csr/resources/publications/drugresist/en/EGlobal_Strat.pdf. Geneva, 2001 (accessed 15 July 2013).

\section{WHO 2012}

World Health Organization. The evolving threat of antimicrobial resistance: options for action. http://whqlibdoc.who.int/ publications/2012/9789241503181_eng.pdf 2012 (accessed 15 July 2013).

\section{Wood 2013}

Wood F, Phillips C, Brookes-Howell L, Hood K, Verheij T, Coenen S, et al. Primary care clinicians' perceptions of

\section{CHARACTERISTICS OF STUDIES}

Characteristics of included studies [ordered by study ID] antibiotic resistance: a multi-country qualitative interview study. Journal of Antimicrobial Chemotherapy 2013;68:237-43.

\section{References to other published versions of this review Coxeter 2014}

Coxeter P, Hoffmann T, Del Mar Chris B. Shared decision making for acute respiratory infections in primary care. Cochrane Database of Systematic Reviews 2014, Issue 1. [DOI: 10.1002/14651858.CD010907]

\section{Altiner 2007}

\section{Methods}

Study design: cluster-randomised controlled trial

Unit of randomisation: general practitioner (GP)

Trial duration: November 2003 to March 2005

Recruitment: 2036 GPs from 9 regions in North-Rhine and Westphalia-Lippe, Germany, invited to participate (blinded to the primary outcome); of 239 GPs willing to participate and receiving baseline materials, 104 completed reliable baseline study documentation and were randomised (10 practice partners randomised as pairs) into intervention (GPs $=52$, patients $=1389)$ and control groups $(\mathrm{GPs}=52$, patients $=1398$ )

Methods of data collection: GPs recorded all consecutive and eligible patients during each documentation period on study specific paper documentation

Data collection time points: 3 documentation intervals of 6 weeks each: baseline (before randomisation), and 6 weeks and 12 months post-intervention

Length of follow-up: 12 months

Participants

GPs documented all consecutive and eligible patients: $\geq 16$ years of age with an initial episode of acute cough (without prior episode $<8$ weeks) and could comprehend German

Exclusion: patients with underlying chronic lung diseases (e.g. asthma, chronic obstructive pulmonary disease), immune deficiency or malignant diseases

Interventions

Recipients: GPs and patients (passive)

Providers: GP peers were trained to provide (in 3 sessions) the outreach visits in clinics during normal working hours (methods of training these GP peers were not specified)

Health professional components: focused on antibiotic 'misunderstanding' during a consultation, and aimed to motivate GPs to change attitudes to communication and empower patients. Peers addressed GP beliefs and attitudes by exploring and evaluating GPs 'opposite' motivational background using a standardised dialogue script and communication techniques derived from the elaboration likelihood model. Aspects of the intervention were also informed by previous qualitative work

Patients: waiting room poster and leaflet focusing on the patients' role within the antibiotic misunderstanding (e.g. GP perceptions that patients expect an antibiotic) and also brief evidence-based information about acute cough and antibiotics to enable patients to raise and clarify issues and make a joint decision about antibiotic use with their doctor

Materials: waiting room poster and leaflet (patient only); script used by GP peers 
Altiner 2007 (Continued)

Mode of delivery: face-to-face (GPs) and waiting room posters and leaflets (patients)

Duration and intensity: 1 peer outreach visit per GP (duration not specified)

Comparator: nil active comparator; GPs provided usual care

\begin{tabular}{ll}
\hline Outcomes & $\begin{array}{l}\text { Primary: rate of antibiotic prescriptions per acute cough and by GP (study specific paper documenta- } \\
\text { tion) } \\
\text { Secondary: nil }\end{array}$ \\
\hline Notes & Funding: yes \\
Conflict of interest: none disclosed \\
Published trial protocol: no \\
Trial registration: yes \\
Ethics approval: yes
\end{tabular}

\title{
Risk of bias
}

\begin{tabular}{lll}
\hline Bias & Authors' judgement & Support for judgement \\
\hline $\begin{array}{l}\text { Random sequence genera- } \\
\text { tion (selection bias) }\end{array}$ & Low risk & Program-generated complete randomisation list \\
\hline $\begin{array}{l}\text { Allocation concealment } \\
\text { (selection bias) }\end{array}$ & Low risk & Not described. However, GPs recruited prior to randomisation \\
\hline $\begin{array}{l}\text { Blinding of participants } \\
\text { and personnel (perfor- } \\
\text { mance bias) }\end{array}$ & High risk & Not possible (complex peer-led educational intervention) \\
$\begin{array}{l}\text { All outcomes } \\
\begin{array}{l}\text { Blinding of outcome as- } \\
\text { sessment (detection bias) } \\
\text { All outcomes }\end{array}\end{array}$ & Low risk & $\begin{array}{l}\text { Participating GPs sent data to researchers. Each patient was assigned a unique } \\
\text { identification number that could be connected with the patient only by the } \\
\text { participating GP }\end{array}$
\end{tabular}

Incomplete outcome data High risk (attrition bias)

All outcomes

\author{
Randomised: 104 GPs (intervention $=$ 52, 1389 patients; control = 52, $1398 \mathrm{pa}$ - \\ tients) \\ 6 weeks post-intervention: 86 GPs (intervention $=42(80 \%)$, patients $=1021$; \\ control $=44(84 \%)$, patients $=1143)$ \\ 12 months post-intervention: $61 \mathrm{GPs}$ (intervention = 28 (54\%); 787 patients; \\ control = 33 (63\%); 920 patients) \\ $17 \%(18 / 104)$ dropped out at 6 weeks and $41 \%(43 / 104)$ by 12 months (reasons \\ for GPs' exclusion from analysis: poor data quality or did not return data) \\ Cluster-level sensitivity analysis performed to explore effect of differential \\ missing values
}

\begin{tabular}{lll}
$\begin{array}{l}\text { Selective reporting (re- } \\
\text { porting bias) }\end{array}$ & Low risk & $\begin{array}{l}\text { All indicated results reported. Prospective trial registration: Projektdatenbank } \\
\text { Versorgungsforschung NRW, ID: 90/34/CHANGE }\end{array}$ \\
\hline Other bias & Unclear risk & $\begin{array}{l}\text { Sample size (power) calculation: yes. Sample size calculated on number of pa- } \\
\text { tients to detect a } 10 \% \text { difference in 6-month prescription rates (50\% control, } \\
40 \% \text { intervention). Allowing for 20\% drop-out rate, it was estimated 200 GPs }\end{array}$
\end{tabular}

Interventions to facilitate shared decision making to address antibiotic use for acute respiratory infections in primary care (Review) 
Altiner 2007 (Continued)

would be required to contribute 20 patients during each observation period (i.e. 4000 at each of the 3 documentation periods)

ITT or per protocol analysis: no, all analysis (with exception of sensitivity analyses) included only general practices with complete follow-up

Large baseline difference found in antibiotic prescription rates between intervention and control groups (36.4\% versus 54.7\%) (unadjusted and adjusted analysis performed)

GPs were not monitored during the trial period and may have under-reported patients who received an antibiotic

Government regulatory change during study to exclude OTC medicines from reimbursement by German statutory health insurance funds may have increased antibiotic prescribing decisions to minimise patient out-of-pocket cost

Generalised estimating equation (GEE) models applied

Intraclass correlation (coefficient): 0.20

Briel 2006

Study design: cluster-randomised controlled trial
Unit of randomisation: general practitioner (GP)
Trial duration: January to May 2004
Recruitment: 345 eligible GPs (criteria undefined) from 2 Swiss cantons (Basel-Stadt and Aargau),
where self dispensation of drugs is not allowed. 30 GPs (providing written consent by 1 December 2003)
were randomised to limited or full intervention groups (15 GPs each); the remaining 15 GPs (providing
written consent by 1 January 2004) formed the non-randomised control group
Methods of data collection: baseline data for eligible GPs obtained from the registry of the Swiss Med-
ical Association; GPs recorded patient baseline data; medical students conducted standardised patient
follow-up interviews at 7 and 14 days by telephone; pharmacists faxed all prescriptions with study la-
bels to the study centre
Length of follow-up: 14 days

Participants

GPs recruited all consecutive and eligible adult patients: $\geq 18$ years with symptoms of acute infections of the respiratory system (first experienced within the previous 28 days; including common cold, rhinosinusitis, pharyngitis, exudative tonsillitis, laryngitis, otitis media, bronchitis, exacerbated COPD or influenza)

Exclusion: patients with pneumonia, not fluent in German, with intravenous drug use or psychiatric disorders, and not available for phone interviews or unable to give written informed consent

Recipients: GPs

Providers: unclear

Health professional components: evidence-based guidelines (developed by 3 trial authors based on existing US guidelines, adapted to local conditions and reviewed by local experts) presented as a booklet and in a 2-hour interactive seminar, plus a 6-hour patient-centred communication seminar in small groups (number not defined) and 2 hours of personal feedback by phone prior to the start of the trial. Training aimed to teach GPs how to understand and modify patients' concepts and beliefs about the use of antibiotics for ARIs. Physicians were taught to practice elements of active listening, to respond 
Briel 2006 (Continued)

to emotional clues and tailor information given to patients. GPs identified patients' attitudes and readiness for behaviour change using a theoretical model (Prochaska and DiClemente 1992)

Patient components: nil

Materials: evidence-based guidelines for the treatment of ARIs distributed as a booklet (http:// www.bice.ch/publications/reports)

Mode of delivery: booklet and face-to-face small-group interactive patient-centred communication seminar

Duration and intensity: GPs attended $1 \times 2$-hour interactive evidence-based guidelines seminar and $1 \mathrm{x}$ 6 -hour small group interactive patient-centred communication seminar

Comparator 1 (Limited intervention): evidence-based guidelines presented as a booklet and in a 2-hour interactive seminar alone

Comparator 2 (Non-randomised control): usual care (data not extracted)

Outcomes Primary: antibiotic prescriptions dispensed by pharmacists $<2$ weeks following initial consultation
(prescriptions with study labels faxed by pharmacists to the study centre)

Secondary: rates of different diagnoses of respiratory infections (GP records)

Adherence to guidelines for antibiotic prescription (GP records)

Days with restrictions from respiratory infection (patient follow-up interview at 7 and 14 days)

Days off work (patient follow-up interview at 7 and 14 days)

Re-consultation rates (patient follow-up interview at 7 and 14 days)

Patient satisfaction (Patient Satisfaction Questionnaire; patient follow-up interview at 7 and 14 days)

Patient enablement (Patient Enablement Instrument; patient follow-up interview at 7 and 14 days)

Other: serious adverse events (independent monitoring board review of serious adverse events that occurred $<28$ days of study enrolment)

Funding: yes
Conflict of interest: none disclosed
Published trial protocol: no
Trial registration: not stated
Ethics approval: yes

\section{Risk of bias}

\begin{tabular}{lll}
\hline Bias & Authors' judgement & Support for judgement \\
\hline $\begin{array}{l}\text { Random sequence genera- } \\
\text { tion (selection bias) }\end{array}$ & Low risk & Computer-generated list created by an independent institution \\
\hline $\begin{array}{l}\text { Allocation concealment } \\
\text { (selection bias) }\end{array}$ & Low risk & $\begin{array}{l}\text { Allocation to either intervention was concealed. However, method not stated. } \\
\text { However, GPs recruited prior to randomisation }\end{array}$
\end{tabular}

Blinding of participants Low risk and personnel (performance bias)

All outcomes
Blinding of general practitioners and trial staff reported. As this trial had 3 arms ( 2 intervention arms where the intervention in each involved a seminar and distribution of evidence guidelines; 1 usual care arm), it is possible that 
Briel 2006 (Continued)

the GPs in the intervention arms would not have known which intervention group they were in

\begin{tabular}{|c|c|c|}
\hline $\begin{array}{l}\text { Blinding of outcome as- } \\
\text { sessment (detection bias) }\end{array}$ & Low risk & $\begin{array}{l}\text { Medical students, blinded to the goal of the trial, were trained to conduct stan- } \\
\text { dardised follow-up interviews at } 7 \text { and } 14 \text { days by phone }\end{array}$ \\
\hline
\end{tabular}

All outcomes

Prescriptions with study labels faxed by pharmacists to the study centre were checked and entered into the database by a person blinded to the intervention group

Trial authors assessed adherence of all prescriptions to guidelines independently and blinded to the intervention group

Incomplete outcome data Low risk (attrition bias)

All outcomes
GPs randomised into limited intervention (GPs = 15; patients $=293$ ) and full intervention groups (GPs $=15$; patients $=259) ; 15$ GPs (285 patients) participated as non-randomised controls (data not extracted). All GPs completed the trial. There were 290, 253 and a convenience sample of 93 patients (stratified by physician), respectively, interviewed at 7 days; and 287, 245 and 92 patients interviewed at 14 days. Reasons for loss to follow-up reported

\begin{tabular}{|c|c|c|}
\hline $\begin{array}{l}\text { Selective reporting (re- } \\
\text { porting bias) }\end{array}$ & Low risk & $\begin{array}{l}\text { All indicated results reported. Trial registration or published trial protocol not } \\
\text { stated }\end{array}$ \\
\hline \multirow[t]{5}{*}{ Other bias } & Unclear risk & Sample size (power) calculation: yes \\
\hline & & ITT or per protocol analysis: ITT \\
\hline & & Intraclass correlation (co-efficient) reported: $4.0 \%$ and a design effect of $1.6 \%$ \\
\hline & & $\begin{array}{l}\text { Low study baseline prescribing rates - full intervention (13.5\%), limited inter- } \\
\text { vention }(15.7 \%) \text { and non-randomised control }(21.4 \%)\end{array}$ \\
\hline & & $\begin{array}{l}\text { Highly motivated GPs: recruitment coincided with introduction of a new na- } \\
\text { tion-wide computer-based reimbursement system and due to increased work- } \\
\text { load participating GPs considered to be highly motivated }\end{array}$ \\
\hline
\end{tabular}

Butler 2012

Study design: cluster-randomised controlled trial
Unit of randomisation: general practices
Trial duration: conducted during 2007 and 2008
Recruitment: 212 general practices approached at random from 454 eligible practices in Wales, UK. 102
practices expressed interest to participate; 70 recruited; 68 practices ( 480,000 patients) randomised
to intervention or control groups (34 each)
Methods of data collection: routine administrative systems (see 'Outcomes')
Data collection time points: total numbers of dispensed oral antibiotic items (primary) and hospital ad-
missions for possible RTIs and their complications (secondary): rate per 1000 patients for the year after
the intervention practices were exposed to the intervention; re-consultation for RTIs: (secondary; 7,14
and 31 days after initial consultation). Cost data not extracted
Length of follow-up: 12 months

Participants

Clinicians (general practitioners (GPs) and nurse practitioners) and all patients registered with and consulting a participating general practice in Wales (practice list) 
Butler 2012 (Continued)

Interventions
Brief intervention name: Stemming the Tide of Antibiotic Resistance (STAR) educational programme: multifaceted flexible blended learning approach to continuing education for clinicians

Recipients: clinicians (GPs and nurse practitioners)

Providers: web-based modules and practice-based seminar led by a facilitator

Health professional components: the programme is a blended learning experience, and based on Social Learning Theory to develop GPs sense of importance about change (the 'why' of change) and confidence in their ability to achieve change (the 'how' of change). The intervention consist of 7 parts (5 online, 1 face-to-face and 1 facilitator-led practice-based seminar): case-scenarios and updated summaries of research evidence and guidelines; reflections on clinical judgement on antibiotic prescribing; a facilitator-led practice-based seminar presenting regional, local and practice-level antibiotic prescribing and resistance data; novel communicative consulting skills and information exchange based on motivational interviewing; personal reflections on clinical practice; web-based forum to share experiences and views; and a booster module completed 6 to 8 months after completion of the initial training to reinforce previously outlined communication skills. GPs had to complete each online learning component before the software would allow them access to the next. The intervention was flexible to allow GPs to access online components and try out new skills with patients at their convenience

Patient components: nil

Materials: web-based materials

Mode of delivery: interactive web-based modules (including online videos in addition to a facilitator-led practice-based seminar

Duration and intensity: not specified

Comparator: usual care
Primary: total number of dispensed oral antibiotic items per 1000 registered patients for the year after practices were exposed to the STAR programme (Prescribing Audit Reports and Prescribing Catalogues; www.nhsbsa.nhs.uk/prescriptions)

Secondary: hospital admission rates for possible RTIs and their complications per 1000 registered patients for the year after practices were exposed to the STAR programme.(Patient Episode Database for Wales); and practice re-consultation rates (for patients with RTIs, practice re-consultation rates were identified using diagnostic READ codes recorded by the general practitioner over 7, 14 and 31 days after an initial consultation)

Costs data not extracted

$\begin{array}{ll}\text { Notes } & \text { Funding: yes } \\ \text { Conflict of interest: none disclosed } \\ \text { Published trial protocol: yes } \\ \text { Trial registration: yes } \\ \text { Ethics approval: yes }\end{array}$

Risk of bias

Bias

Authors' judgement Support for judgement
Random sequence genera- Low risk tion (selection bias)

Randomisation was conducted once all practices were recruited and all participating physicians had provided written consent. Dynamic block allocation was used to achieve balance between groups of practices for the potential confounders of previous rate of antibiotic dispensing (averaged over the past year), practice size (number of whole time equivalent staff at recruitment), and proportion of clinicians in the practice registered for the study. The prac-

Interventions to facilitate shared decision making to address antibiotic use for acute respiratory infections in primary care (Review) 
Butler 2012 (Continued)

tices were divided into 3 sets of 24, 22 and 22 practices; within each set we generated all possible allocations into 2 groups and selected the 1000 allocations within each set with the best balance with respect to the specified confounders. The independent statistician on the trial steering committee selected 1 allocation at random for each set and randomly assigned intervention or control to the 2 groups in each set to construct the final allocation

\begin{tabular}{|c|c|c|}
\hline $\begin{array}{l}\text { Allocation concealment } \\
\text { (selection bias) }\end{array}$ & Low risk & $\begin{array}{l}\text { Clinicians and researchers were blinded to group allocation until after ran- } \\
\text { domisation }\end{array}$ \\
\hline
\end{tabular}

Blinding of participants High risk Not possible (multifaceted intervention programme)
and personnel (performance bias)

All outcomes

\begin{tabular}{lll}
\hline $\begin{array}{l}\text { Blinding of outcome as- } \\
\text { sessment (detection bias) }\end{array}$ & Low risk & $\begin{array}{l}\text { Data on antibiotic dispensing, hospital admissions and re-consultations were } \\
\text { collected through routine administrative systems that were not influenced by } \\
\text { the study research process }\end{array}$ \\
\hline
\end{tabular}

\begin{tabular}{|c|c|c|}
\hline $\begin{array}{l}\text { Incomplete outcome data } \\
\text { (attrition bias) } \\
\text { All outcomes }\end{array}$ & Low risk & $\begin{array}{l}68 \text { practices ( } ~ 480,000 \text { patients) randomised to intervention ( } 34 \text { practices; } 137 \\
\text { GPs, } 2 \text { nurse practitioners) or control ( } 34 \text { practices; } 122 \text { GPS, } 2 \text { nurse practi- } \\
\text { tioners) groups. } 2 \text { practices (one in each group; including } 12 \text { intervention GPs } \\
\text { and } 7 \text { control GPs) withdrew after randomisation but were included in the ITT } \\
\text { analyses }\end{array}$ \\
\hline
\end{tabular}

\begin{tabular}{lll}
\hline $\begin{array}{l}\text { Selective reporting (re- } \\
\text { porting bias) }\end{array}$ & Low risk & All indicated results reported. Published trial protocol available \\
\hline Other bias & Low risk & Sample size (power) calculation: yes \\
& ITT or per protocol analysis: ITT analysis for primary outcome \\
\hline
\end{tabular}

\author{
Study design: cluster-randomised controlled trial (factorial design). \\ Unit of randomisation: general practices (cluster of 2 general practitioners (GPs) per practice) \\ Trial duration: conducted during the winters of 2005 to 2006 and 2006 to 2007
}

Recruitment: 54 general practices within a large suburban region of the Netherlands were assessed for eligibility; 20 eligible general practices (with 2 participating GPs per practice) were randomised into groups of 10 practices per intervention (resulting in 4 trial arms of 5 general practices and $10 \mathrm{GPs}$ ):

- use of C-reactive protein (CRP) testing;

- training in enhanced communication skills;

- use of CRP and training in enhanced communication skills;

- control (usual care)

Methods of data collection: antibiotic prescribing and re-consultation data obtained from patient medical records. Patients rated symptoms (cough, phlegm, shortness of breath, disturbance of daily activities, sleeping problems and generally feeling unwell), satisfaction and enablement, on a 28-day daily diary validated for use in a RCT on management of LRTI in primary care

Data collection time points: index consultation and 28-day follow-up 
Cals 2009 (Continued)

Participants
General practitioners recruited sequential eligible adults within regular consultation hours during the winters of 2005 to 2006 and 2006 to 2007

Eligibility: suspected lower respiratory tract infection (LRTI) with a cough lasting $<4$ weeks together with 1 focal and 1 systemic symptom
Interventions
Brief intervention name: enhanced communication skills training

Recipients: GPs

Providers: seminars led by a moderator

Health professional components: enhanced communication skills training involved $1 \times 2$-hour training seminar at a central location, preceded and followed by consulting with simulated patients in routine surgeries and peer-review of transcripts. The moderator-led seminar on shared decision making (within 1 week of simulated patient consultation) comprised GPs' reflection on simulated patient transcript, current views and insights on LRTI (highlighting contrast between research and practice), outline of elicit-provide-elicit framework (elicit patient's main worries and expectations and conveying the balance of possible antibiotic benefits and harms, provide information relevant to the patients' individual understanding and interest, and elicit patients' interpretation about what has been said and done and discusses implications for help seeking behaviour), videos presenting practice-based examples and GPs identifying specific aspects during their consultations that need most attention

Patient components: nil

Materials: desk reminder for GPs

Mode of delivery: face-to-face seminar and simulated patient consultations with peer-review of transcripts

Duration and intensity: 1 x 2-hour moderator-led training seminar; pre- and post-seminar simulated patient consultations with peer-review of transcripts

Comparator 1: C-reactive protein point of care testing (date not extracted)

Comparator 2: enhanced communication skills training plus $\mathrm{C}$-reactive protein point of care testing (date not extracted)

Comparator 4: usual care (Dutch guidelines for managing acute cough, including diagnostic and therapeutic advice for lower respiratory tract infection are distributed to all GPs in the Netherlands)

Outcomes Primary: antibiotic prescribing in the index consultation (medical records)

Secondary: antibiotic prescribing during 28 days' follow-up (medical records)

Re-consultation (medical records)

Clinical recovery data not extracted

Patients' satisfaction (Likert scale; 28-day daily diary)

Patients' enablement (Patient Enablement Index; 28-day daily diary)
Funding: yes

Conflict of interest: none declared

Published trial protocol: yes

Trial registration: yes

Ethics approval: yes

Main comparator reported in this review: communication skills training $(n=201)$ versus no communication skills training $(n=230)$ 
Cals 2009 (Continued)

Risk of bias

\begin{tabular}{|c|c|c|}
\hline Bias & Authors' judgement & Support for judgement \\
\hline $\begin{array}{l}\text { Random sequence genera- } \\
\text { tion (selection bias) }\end{array}$ & Low risk & $\begin{array}{l}\text { General practices randomised into } 2 \text { groups of } 10 \text { practices per intervention, } \\
\text { balanced for recruitment potential, resulting in the } 4 \text { trial arms. The balanc- } \\
\text { ing factor used for randomisation was the amount of GP's consultation time } \\
\text { (expressed as full time equivalent (FTE)) that the practice was contributing } \\
\text { to the study (which equated to between } 1 \text { and } 2 \text { FTEs for clinical contact time. } \\
\text { The randomisation was balanced for those with } 1.5 \text { or less FTEs and those with } \\
\text { more than } 1.5 \text { FTEs }\end{array}$ \\
\hline $\begin{array}{l}\text { Allocation concealment } \\
\text { (selection bias) }\end{array}$ & Low risk & All practices and general practitioners were recruited before randomisation \\
\hline $\begin{array}{l}\text { Blinding of participants } \\
\text { and personnel (perfor- } \\
\text { mance bias) } \\
\text { All outcomes }\end{array}$ & High risk & Not possible (due to the nature of the intervention) \\
\hline
\end{tabular}

Blinding of outcome as- Unclear risk Not described

sessment (detection bias)

All outcomes

Incomplete outcome data Low risk (attrition bias)

All outcomes
20 practices ( $40 \mathrm{GPs}$ ) randomised to each of the 4 trial arms (5 practices, 10 GPs each) and recruited 431 patients. 37 GPs completed the trial ( 3 left on maternity leave in the enhanced communication skills group). All patients (100\%) had data for the primary outcome, $90 \%$ (mean) had 28-day diary data

For the communication skills training group ( $10 \mathrm{GPs}, 84$ patients), there was $100 \%$ prescribing data and $88 \%$ returned diaries.

Selective reporting (re- Low risk All indicative results reported. Published study protocol. Prospective trial regporting bias) istration

Other bias Low risk Sample size (power) calculation: yes

ITT or per protocol analysis: the primary analysis was ITT

Cals 2013

Methods Study design: 3.5 year follow-up of a cluster-randomised controlled trial (factorial design) (Cals 2009)

Trial duration: 3.5 years (mean 3.67 years)

Recruitment: patients recruited in the winter periods from September 2005 until March 2007 (Cals

2009), were observed until July 2010

Methods of data collection: medical records

Data collection time points: recorded consultations for RTI from original 28-day follow-up period until July 2010 (follow-up period); recorded consultation for RTI for the exact same period preceding the consultation in which the patient was recruited in the original trial (baseline period). Deceased patients and patients that moved practices and whose medical records could not be retrieved were excluded

Length of follow-up: mean 3.67 years 
Cals 2013 (Continued)

Patients: of the original 431 patients enrolled in the trial, 379 patients (87.9\%) had accessible medical records for the follow-up period. Only data for the enhanced communication training (178) versus no enhanced communication skills training (201) extracted

\begin{tabular}{ll}
\hline Interventions & See Cals 2009 \\
\hline Outcomes & $\begin{array}{l}\text { Primary outcome: average number of episodes of RTIs during the follow-up period for which patients } \\
\text { consulted their physician per patient per year (PPPY) and the proportion of these episodes that result- } \\
\text { ed in an antibiotic prescription } \\
\text { Secondary outcome: nil }\end{array}$ \\
\hline Notes & $\begin{array}{l}\text { Funding: yes } \\
\text { Conflict of interest: RH received travel/lecture funds from Axis-shield (Norway) and Orion Diagnostica }\end{array}$ \\
& Trial registration: yes \\
Ethics approval: yes
\end{tabular}

\section{Risk of bias}

\begin{tabular}{|c|c|c|}
\hline Bias & Authors' judgement & Support for judgement \\
\hline $\begin{array}{l}\text { Random sequence genera- } \\
\text { tion (selection bias) }\end{array}$ & Low risk & See Cals 2009 \\
\hline $\begin{array}{l}\text { Allocation concealment } \\
\text { (selection bias) }\end{array}$ & Low risk & See Cals 2009 \\
\hline $\begin{array}{l}\text { Blinding of participants } \\
\text { and personnel (perfor- } \\
\text { mance bias) } \\
\text { All outcomes }\end{array}$ & High risk & See Cals 2009 \\
\hline $\begin{array}{l}\text { Blinding of outcome as- } \\
\text { sessment (detection bias) } \\
\text { All outcomes }\end{array}$ & Unclear risk & $\begin{array}{l}\text { Data were extracted, by } 2 \text { researchers, from the patients' medical records sys- } \\
\text { tem. No mention if these researchers were blind to the practices' original allo- } \\
\text { cation }\end{array}$ \\
\hline $\begin{array}{l}\text { Incomplete outcome data } \\
\text { (attrition bias) } \\
\text { All outcomes }\end{array}$ & Low risk & $\begin{array}{l}379 \text { of } 431 \text { patients enrolled in the original trial ( } 87.9 \%) \text { had accessible medical } \\
\text { records for the follow-up period }\end{array}$ \\
\hline $\begin{array}{l}\text { Selective reporting (re- } \\
\text { porting bias) }\end{array}$ & Low risk & See Cals 2009 \\
\hline Other bias & Low risk & $\begin{array}{l}\text { Sample size (power) calculation: see Cals } 2009 \\
\text { ITT or per protocol analysis: see Cals } 2009\end{array}$ \\
\hline
\end{tabular}

\section{Francis 2009}

$\begin{array}{ll}\text { Methods } & \text { Study design: cluster-randomised controlled trial } \\ \text { Unit of randomisation: general practices } \\ \text { Trial duration: October } 2006 \text { to April } 2008\end{array}$


Recruitment: half of all general practices from 9 local health boards in Wales $(n=147)$ were randomly selected to be sent study information (the other half were provided information about a related RCT conducted in parallel); 49 returned a practice agreement and were randomised. 4 primary care research networks in England also recruited practices; 34 returned practice agreement and were randomised. All randomised practise (83) were allocated to intervention (41 practices; 30 recruited patients; patients $=274$ ) or control (42 practices; 31 recruited patients; patients $=284)$

Methods of data collection: baseline data (age, duration of illness, symptoms) collected by GPs. Follow-up via a telephone administered questionnaire (or self completion questionnaire contact unsuccessful by telephone) with child's parent or guardian

Data collection time points: index consultation and 14 days after recruitment

Length of follow-up: 14 days

Participants

Participating clinicians recruited sequential eligible children ( 6 months to 14 years) consulting with a respiratory tract infection (cough, cold, sore throat, earache for 7 days or less) and their parents

Exclusion: children with asthma and those with serious ongoing medical conditions such as malignancy or cystic fibrosis

Interventions

Brief intervention name: interactive booklet on respiratory tract infections in children for use within the consultation and provided as a take home resource

Recipients: parents and clinicians

Providers: not stated

Health professional components: the online training described the content and aims of the booklet, and encouraged its use within the consultation to facilitate the use of certain communication skills, mainly exploring the parent's main concerns, asking about their expectations, and discussing prognosis, treatment options and any reasons that should prompt re-consultation

Patient components: use of the booklet in the consultation and as a take home resource

Materials: 8-page interactive booklet (see www.whenshouldiworry.com)

Mode of delivery: 8-page interactive booklet and online training for clinicians in use of the booklet Duration and intensity: not stated

Comparator: usual care (clinicians were asked to conduct consultations in usual manner)

Outcomes Primary: re-consultation (primary or secondary care) during the 2 weeks after the index consultation (telephone administered questionnaire)

Secondary: antibiotic prescriptions (telephone administered questionnaire)

Antibiotic consumption (telephone administered questionnaire)

Future consulting intention (telephone administered questionnaire)

Parental satisfaction with the index consultation (5-point Likert; telephone administered questionnaire)

Parental enablement (modified Patient Enablement Instrument; telephone administered questionnaire)

Perception of the usefulness (value) of the information received during the index consultation (5-point Likert; telephone administered questionnaire)

Parental reassurance (3-point Likert; telephone administered questionnaire)

Notes Funding: yes


Francis 2009 (Continued)

Conflict of interest: none disclosed

Published trial protocol: yes

Trial registration: yes

Ethics approval: yes

\section{Risk of bias}

\begin{tabular}{lll}
\hline Bias & Authors' judgement & Support for judgement \\
\hline $\begin{array}{l}\text { Random sequence genera- } \\
\text { tion (selection bias) }\end{array}$ & Low risk & $\begin{array}{l}\text { Practices were randomised by a statistician using block randomisation with } \\
\text { random block sizes and stratification by practice list size, antibiotic prescrib- } \\
\text { ing rate for 2005, and country }\end{array}$
\end{tabular}

\begin{tabular}{|c|c|c|}
\hline $\begin{array}{l}\text { Allocation concealment } \\
\text { (selection bias) }\end{array}$ & Unclear risk & $\begin{array}{l}\text { It is reported that practices were randomised after agreeing to take part, but } \\
\text { no other details are provided }\end{array}$ \\
\hline
\end{tabular}

\begin{tabular}{|c|c|c|}
\hline $\begin{array}{l}\text { Blinding of participants } \\
\text { and personnel (perfor- }\end{array}$ & High risk & $\begin{array}{l}\text { Not possible (training and use of an interactive booklet for use within consul- } \\
\text { tations and as a take home resource) }\end{array}$ \\
\hline
\end{tabular}

and personnel (perfortations and as a take home resource)

mance bias)

All outcomes

\begin{tabular}{lll}
\hline $\begin{array}{l}\text { Blinding of outcome as- } \\
\text { sessment (detection bias) }\end{array}$ & Low risk & $\begin{array}{l}\text { Telephone interviewers were blinded to treatment group and asked to record } \\
\text { any subsequent unblinding of allocation (e.g. parent talking about receiving } \\
\text { All outcomes }\end{array}$ \\
& $\begin{array}{l}\text { a booklet). Interviewers reported becoming aware of participants treatment } \\
\text { group in 34/509 }(6.7 \%) \text { of interviews }\end{array}$
\end{tabular}

Incomplete outcome data Low risk (attrition bias)

83 practices were randomised to intervention (41) or control (42) groups; 61

All outcomes practices, 30 intervention and 31 control practices, recruited 274 and 284 patients, respectively. Primary outcome data were available for 256 patients $(93 \%)$ in the intervention group (246 completed telephone interviews, 10 postal questionnaire returned) and $272(96 \%)$ control group patients (262 completing telephone interviews, 9 postal questionnaires returned)

\begin{tabular}{lll}
\hline $\begin{array}{l}\text { Selective reporting (re- } \\
\text { porting bias) }\end{array}$ & Low risk & All indicted outcomes reported. Published trial protocol \\
\hline Other bias & Low risk & Sample size (power) calculation: yes \\
& ITT or per protocol analysis: primary analysis was ITT \\
\hline
\end{tabular}

Little 2013

Study design: cluster-randomised controlled trial (factorial design)
Unit of randomisation: general practices
Trial duration: October 2010 to May 2011
Recruitment: all general practices ( $\mathrm{n}=440$ ) in the localities of study centres were approached, and all
clinicians (and nurse prescribers in the UK) in eligible practices who prescribed antibiotics for respira-
tory tract infections were invited to participate Eligibility: practices that had not previously used inter-
ventions to reduce antibiotic prescribing and could include > 10 patients at baseline audit. Networks of
at least 2 practices were selected separately in Antwerp (Belgium), Barcelona (Spain), Cardiff (Wales),
tódź (Poland), Southampton (UK), Szczecin (Poland), Utrecht (Netherlands) and the Spanish Society of
Family Medicine (Spain) to ensure a range of cultures, languages and regions of Europe (north, south
and east) were represented). Of the 259 eligible practices enrolled; 246 were randomised to usual care


Little 2013 (Continued)

$(n=61)$, training in the use of a C-reactive protein (CRP) test at point of care $(n=62)$, training in enhanced communication skills $(n=61)$, or in both CRP and enhanced communication skills training $(n=$ 62)

Methods of data collection: case report forms (index consultation and follow-up)

Data collection time points: index consultation and follow-up (until resolution of symptoms)

Participants

General practitioners (GPs and nurse prescribers in the UK) who prescribed antibiotics for RTIs consecutively recruited up to the first 30 patients with LRTI and up to the first 5 with URTI presenting at each practice. Eligible patients were $\geq 18$ years of age, attending a first consultation for acute cough of up to 28 days' duration or what the clinician believed to be an acute LRTI as the main diagnosis, despite cough not being the most prominent symptom; and diagnosis judged by the physician to be an acute upper respiratory tract infection (e.g. sore throat, otitis media, sinusitis, influenza and coryzal illness)

Exclusion: patients with a working diagnosis of a non-infective disorder (e.g. pulmonary embolus, heart failure, oesophageal reflux, or allergy); use of antibiotics in the previous month; inability to provide informed consent (e.g. due to dementia, psychosis or severe depression); pregnancy; and immunological deficiencies. Pneumonia was not an exclusion criterion

Interventions

Brief intervention name: enhanced communication skills training

Recipients: GPs

Providers: $\mathrm{n} / \mathrm{a}$

Health professional components: training focused on the gathering of information on patients' concerns and expectations; exchange of information on symptoms, natural disease course and treatments; agreement of a management plan, summing up and providing guidance about when to re-consult. Physicians were provided with an interactive booklet to use during consultations that included information on symptoms, use of antibiotics and antibiotic resistance, self help measures, and when to reconsult. The training was supported by video demonstrations of consultation techniques. The Internet modules and materials were translated into the relevant national language and mainly addressed lower respiratory tract infections, although many of the issues were relevant to all respiratory tract infections

Patient components: interactive booklet used within consultations

Materials: interactive booklet for use within consultations

Mode of delivery: Internet training supported by video demonstrations of consultation techniques

Duration and intensity: not described

Comparator:

1. Usual care

2. Training in use of C-reactive protein (CRP) test at point of care (data not extracted for this review)

3. Both CRP and enhanced communication skills training (data not extracted for this review)

Outcomes Primary: antibiotic use (index consultation; case-report form)

Secondary: new or worsening symptoms defined as re-consultation for new or worsening symptoms < 4 weeks, new signs or hospital admission (review of medical notes)

Symptom severity and duration defined as the severity of symptoms in the 2 to 4 days after seeing the physician (case report form; $0=$ no problem to 4 = severe problem)

Notes

Funding: yes

Conflict of interest: none disclosed 
Little 2013 (Continued)

Published trial protocol: no

Trial registration: yes

Ethics approval: yes

ITT or per protocol analysis: ITT analysis

\section{Risk of bias}

Bias Authors' judgement Support for judgement

Random sequence genera- Low risk tion (selection bias)

Randomisation of practices was done by 2 study authors, and was achieved by computer generation of random numbers, stratified by network. Minimisation was applied, on the basis of the proportion of patients prescribed antibiotics from the baseline audit, the number of participating physicians per practice, and the number of patients recruited

\begin{tabular}{lll}
\hline Allocation concealment $\quad$ Low risk $\quad$ Physicians and patients were unaware of initial group allocation \\
(selection bias)
\end{tabular}
(selection bias)

High risk Not possible (due to the nature of the intervention)

Blinding of participants

High risk

Not possible (due to the nature of the intervention)

and personnel (perfor-

mance bias)

All outcomes

\begin{tabular}{lll}
\hline $\begin{array}{l}\text { Blinding of outcome as- } \\
\text { sessment (detection bias) } \\
\text { All outcomes }\end{array}$ & High risk & GPs recorded data on a case-report from, during the index consultation \\
\hline $\begin{array}{l}\text { Incomplete outcome data } \\
\text { (attrition bias) }\end{array}$ & Low risk \\
All outcomes & $\begin{array}{l}259 \text { practices enrolled and provided baseline data (6771 patients); } 13 \text { practices } \\
\text { recruited }<10 \text { patients each) were excluded }\end{array}$ \\
& $\begin{array}{l}\text { Remaining were } 246 \text { practices randomised to CRP (62), enhanced communica- } \\
\text { tion training (61), both interventions combined (62), or usual care (61) }\end{array}$ \\
& $\begin{array}{l}\text { Antibiotic prescription documentation was available for } 58 \text { CRP practices } \\
(1062 \text { patients), } 55 \text { ( } 90 \%) \text { enhanced communication skills practices (1170 pa- } \\
\text { tients), } 62 \text { combined intervention practices (1162 patients) and } 53(87 \%) \text { usual } \\
\text { care practices ( } 870 \text { patients). Reasons for exclusion were reported as recruiting } \\
\text { no patients }\end{array}$ \\
&
\end{tabular}

\begin{tabular}{lll}
\hline $\begin{array}{l}\text { Selective reporting (re- } \\
\text { porting bias) }\end{array}$ & Low risk & All indicated outcomes are reported \\
\hline Other bias & Low risk & Sample size (power) calculation: not stated \\
& ITT analysis: yes \\
\hline
\end{tabular}

Légaré 2011

Study design: cluster-randomised controlled trial (pilot)
Unit of randomisation: family medicine groups (FMGs)
Trial duration: during November 2007 and March 2008
Recruitment: 24 FMGs (group of family physicians who work closely with nurses to offer family medi-
cine services to registered individuals) from the greater urban area of Quebec City, Canada, were invit-


Légaré 2011 (Continued)

ed to participate; 4 participating FMGs were randomised either to a group immediately exposed to the DECISION+ program $(n=2)$ or to a control group which exposure to DECISION+ program was delayed for 6 months $(n=2)$

Methods of data collection: self administered questionnaire completed following the consultation at each time point

Data collection time points: baseline, following exposure of the intervention group to DECISION $+(\sim 6$ months), and following delayed exposure of DECISION+ to controls ( 12 months)

Length of follow-up: 12 months

Participants

Eligible general practitioners (no previous participation in an implementation trial of SDM and planned to remain in clinical practice for the trial duration) recruited eligibility patients consulting their GP for an ARI: no age restriction, patients or their guardians had to be able to read, understand and write French and had to give informed consent to participate in the trial

Exclusion: patients with a condition requiring emergency care. A research professional waited in the FMG's waiting room and recruited patients of enrolled FPs during walk-in clinic hours; 15 patients were recruited per GP: 5 at baseline, 5 after the GPs in the experimental group were exposed to DECISION +, and 5 after the FPs in the control group were exposed to DECISION+

Interventions Brief intervention name: DECISION+

Recipients: GPs

Providers: principal investigators (or co-trainers)

Health professional components: DECISION+ is made up of 3 main components

1. Interactive workshops addressed the probability of bacterial versus viral ARIs in primary care, evidence of the benefit/risk of the various treatment options, risk communication techniques and strategies for fostering patient participation in the decision making process. Workshops included videos of simulated patient-GP consultations for each ARI and distinguished 2 approaches (usual care or SDM), and exercises to facilitate group discussion about facilitators and barriers to SDM. GPs were trained to use decision support tools (though video examples and group exercises) developed for each of the 4 targeted ARIs (rhinosinusitis, pharyngitis, bronchitis and acute otitis media) and 1 integrating all 4 ARIs

2. Reminders of expected behaviours: a reminder printed on a letter-sized piece of paper emphasised the use of the decision support tools, reiterated the expected SDM-related behaviours, and highlighted new studies relevant to the pilot trial topics (e.g. new evidence on the risks and benefits of antibiotics). These reminders were mailed to GPs between each workshop. A second reminder was postcards that participants had written to themselves in the last workshop to remind themselves of what they needed to implement in their practice. The research team collected the postcards and mailed them 6 to 8 weeks later

3. Feedback to GPs on the agreement between their decisional conflict scores and that of their first 5 patients

Patient components: decision support tools

Materials: a booklet summarising the content of the workshop and decision support tools was developed for physician participants and training manuals for the co-trainers

Mode of delivery: interactive workshops led by 2 study principal investigators (or co-trainers) and conducted face-to-face in a group format, and using videos and group exercises

Duration and intensity: DECISION+: 3 × 3 3-hour interactive workshops, reminders and feedback conducted over a 4- to 6-month period

Comparator: Usual care (delayed exposure to the DECISION+ intervention) 
Légaré 2011 (Continued)

Secondary:

Perception of the quality of the decision (GP/patient; single item on a 10-point Likert scale; self administered questionnaire)

Decisional conflict (GP/patient; Decisional Conflict Scale)

Patients' intention to engage in SDM in future consultations concerning antibiotics for ARIs (3-item, 7point Likert scale; self administered questionnaire)

GPs' intentions to engage in SDM and comply with clinical practice guidelines regarding prescribing antibiotics for ARIs (3-item, 7-point Likert scale)

Decision Regret Scale (patients; telephone interview; 2 weeks following consultation)

Perception of health changes since the consultation (patients; telephone interview; 2 weeks following consultation)

Number of prescriptions filled by patients covered by Quebec's public drug insurance plan (Regie de l'Assurance-Maladie du Quebec medication claims database) (during the 3 months preceding baseline and during the 3 months after FPs in the experimental group were exposed to DECISION+)

Script concordance test (probes whether respondents' knowledge is efficiently organised to take appropriate clinical action by placing respondents in written, but authentic, clinical situations in which they must interpret data to make decisions. It measures the concordance between respondents' scripts and the scripts of a panel of experts (administered to GPs at each data collection point)

Fotes
Conflict of interest: none disclosed
Published trial protocol: yes
Trial registration: not reported
Ethics approval: yes

\section{Risk of bias}

\begin{tabular}{lll}
\hline Bias & Authors' judgement & Support for judgement \\
\hline $\begin{array}{l}\text { Random sequence genera- } \\
\text { tion (selection bias) }\end{array}$ & Low risk & $\begin{array}{l}\text { A biostatistician simultaneously randomised all FMGs using Internet-based } \\
\text { software }\end{array}$ \\
\hline
\end{tabular}

\begin{tabular}{|c|c|c|}
\hline $\begin{array}{l}\text { Allocation concealment } \\
\text { (selection bias) }\end{array}$ & High risk & $\begin{array}{l}\text { A biostatistician allocated FMGs to groups using Internet-based software. } \\
\text { There was concealed allocation of the Family Medicine Groups, but not the } \\
\text { family physicians }\end{array}$ \\
\hline
\end{tabular}

\begin{tabular}{|c|c|c|}
\hline $\begin{array}{l}\text { Blinding of participants } \\
\text { and personnel (perfor- } \\
\text { mance bias) } \\
\text { All outcomes }\end{array}$ & High risk & $\begin{array}{l}\text { Not possible (multiple-component, continuing professional development pro } \\
\text { gramme in shared decision making) }\end{array}$ \\
\hline $\begin{array}{l}\text { Blinding of outcome as- } \\
\text { sessment (detection bias) } \\
\text { All outcomes }\end{array}$ & Low risk & $\begin{array}{l}\text { Codes were attributed to the trial groups and the bio-statistician analysed the } \\
\text { data blindly. Team members accessed the codes only after having completed } \\
\text { the analyses and interpreting the results }\end{array}$ \\
\hline $\begin{array}{l}\text { Incomplete outcome data } \\
\text { (attrition bias) } \\
\text { All outcomes }\end{array}$ & Low risk & $\begin{array}{l}4 \text { FMGs randomised to intervention }(2 ; \text { GPs }=18 ; \text { patients }=245) \text { or control } \\
\text { groups }(2 ; \text { GPs }=15 ; \text { patients }=214) .3 / 33(9 \%) \text { GPs dropped out of the trial } \\
\text { 20/245 patients in the intervention group and } 14 / 214 \text { controls could not be } \\
\text { contacted over the } 2 \text {-week follow-up }\end{array}$ \\
\hline
\end{tabular}


Légaré 2011 (Continued)
Selective reporting (reporting bias)

Other bias

Low risk

Sample size (power) calculation: no

Primary analysis was ITT

Légaré 2012

\begin{tabular}{|c|c|}
\hline \multirow[t]{6}{*}{ Methods } & Study design: cluster-randomised controlled trial \\
\hline & Unit of randomisation: family practice teaching units \\
\hline & Trial duration: July 2010 to April 2011 \\
\hline & $\begin{array}{l}\text { Recruitment: the network of } 12 \text { family practice teaching units in } 6 \text { regions of Quebec, Canada, were ran- } \\
\text { domised to intervention (6) or control (6) groups }\end{array}$ \\
\hline & $\begin{array}{l}\text { Methods of data collection: following the consultation, patients and GPs independently completed self } \\
\text { administered questionnaires (primary and secondary outcomes). } 2 \text { weeks later, a telephone follow-up } \\
\text { interview was conducted by a research assistant (secondary outcomes) }\end{array}$ \\
\hline & Data collection time points: immediately following consultation and 14 days \\
\hline Participants & $\begin{array}{l}\text { GPs, including physician teachers and residents, who provide care in the walk-in clinics of the } 12 \text { family } \\
\text { practice teaching units. GPs participating in the pilot trial (Légaré 2011) or those not expecting to prac- } \\
\text { tice in the teaching unit during the trial period were excluded. Patients with symptoms suggestive of an } \\
\text { ARI were recruited by a research assistant in the waiting room prior to consultation with a physician. El- } \\
\text { igible patients were adults (and children who were accompanied by a parent/legal guardian) with a di- } \\
\text { agnosis of ARI (e.g. bronchitis, otitis media, pharyngitis or rhinosinusitis) and for which the use of an- } \\
\text { tibiotics was subsequently considered either by the patient or physician during the visit. The patient, } \\
\text { parent or legal guardian had to be able to read, understand and write French }\end{array}$ \\
\hline
\end{tabular}

Interventions

Brief intervention name: DECISION+2 shared decision making program

Recipients: GPs

Providers: trained facilitators

Health professional components: an online tutorial comprised of 5 modules addressing key components of the clinical decision making process about antibiotic treatment for ARI in primary care: introduction to shared decision making and ARIs, estimating diagnostic probabilities for ARIs, therapeutic options, effective strategies to communicate risk and benefits, identify patients' values and preferences; and use of decision support tools that promote shared decision making. Participants had 1 month to complete the online tutorial. The on-site facilitator-led interactive workshop aimed to help physicians review and integrate the concepts they acquired during the online training

Patient components: decision support tools

Materials: both the online tutorial and workshop included videos, exercises and decision aids to help physicians communicate to their patients the probability of a bacterial acute respiratory infection and the benefits and harms associated with the use of antibiotics

Mode of delivery: online tutorial and facilitator-led interactive workshop

Duration and intensity: 2-hour online tutorial followed by a 2-hour on-site interactive workshop

Comparator: usual care 
Légaré 2012 (Continued)

Outcomes
Primary: proportion of patients who decided to use antibiotics immediately after consultation (GP and patient self administered questionnaire)

Secondary: decisional conflict (GP/patient; Decisional Conflict Scale)

Perception that shared decision making occurred (GP/patient; modified Control Preference Scale)

Quality of decision made (GP/patient; single question Likert scale)

Adherence to the decision (patient; single-item asking if decision made was maintained)

Repeat consultation (for the same reason) (patient)

Decisional Regret (patient; Decisional regret Scale)

Quality of life (patient; SF-12)

Intention to engage in SDM in future consultations regarding the use of antibiotics for ARIs (patients; questions based on Theory of Planned Behaviour)

Intentions to engage in shared decision making (GP)

Intention to adhere to clinical practice guidelines (GP)

Preferred role in decision making (Control Preference Scale)

Funding: yes
Conflict of interest: none disclosed
Published trial protocol: yes
Trial registration: yes
Ethics approval: yes

\section{Risk of bias}

Bias Authors' judgement Support for judgement

\begin{tabular}{ll}
\hline $\begin{array}{l}\text { Random sequence genera- } \\
\text { tion (selection bias) }\end{array}$ & Low risk \\
& $\begin{array}{l}\text { A biostatistician used Internet-based software to simultaneously randomise all } \\
12 \text { family practice teaching units to either the intervention group (DECISION+2) } \\
\text { or control group. The teaching units were stratified according to rural or urban } \\
\text { location }\end{array}$ \\
\hline
\end{tabular}

\begin{tabular}{|c|c|c|}
\hline $\begin{array}{l}\text { Allocation concealment } \\
\text { (selection bias) }\end{array}$ & Unclear risk & $\begin{array}{l}\text { The family practice teaching unites were recruited prior to randomisation, but } \\
\text { it is not clear when the physicians in the units were recruited }\end{array}$ \\
\hline
\end{tabular}

\begin{tabular}{|c|c|c|}
\hline $\begin{array}{l}\text { Blinding of participants } \\
\text { and personnel (perfor- }\end{array}$ & High risk & $\begin{array}{l}\text { Not possible (due to the nature of the intervention and the self administered } \\
\text { outcomes) }\end{array}$ \\
\hline
\end{tabular}
mance bias)

All outcomes

\begin{tabular}{lll}
\hline $\begin{array}{l}\text { Blinding of outcome as- } \\
\text { sessment (detection bias) } \\
\text { All outcomes }\end{array}$ & Low risk & $\begin{array}{l}\text { Statistical analysis was performed by a statistician who was unaware of the } \\
\text { teaching unit allocations }\end{array}$ \\
\hline $\begin{array}{l}\text { Incomplete outcome data } \\
\text { (attrition bias) }\end{array}$ & Low risk & $\begin{array}{l}12 \text { family practice teaching units randomised; 9 participated in the study and } \\
\text { all clusters completed the trial }\end{array}$ \\
\hline
\end{tabular}


Légaré 2012 (Continued)

Selective reporting (re- Low risk All indicated outcome reported. Prospective trial registration. Published trial porting bias) protocol

Other bias

Unclear risk

Sample size calculation: yes

ITT or per protocol analysis: not stated

Welschen 2004

Study design: cluster-randomised controlled trial
Unit of randomisation: GP peer review group
Trial duration: 2000 to 2002
Recruitment: general practitioners' (GP) peer review groups, with collaborating pharmacists (which
aim to promote rational prescribing through audit and feedback), in the region of Utrecht, Netherlands,
if the group consisted of $\geq 4$ GPs and all agreed to participate
Methods of data collection: during a 3-week period during 2000 and 2001
Data collection time points: index consultation
Length of follow-up: nil

Participants

Primary care setting type: recruited from general practitioner (GP) peer review groups

General practitioners: 100 GPs

Patients: all registered patients presenting with acute symptoms of the respiratory tract

${ }^{\star}$ Relatively low prescription rates in the Netherlands

Recipients: GPs and patients

Providers: GP peer facilitators

Health professional components:

a) Group education meeting (jointly led a GP and pharmacist in each peer review group) included a review of previous years claims data, discussion of evidence-based medicine and communication of evidence for treatment benefit and risk to inform group consensus about the indication and first choice of antibiotics per indication (AOM, sinusitis, tonsillitis and acute cough); communication skills training (how to explore patients' worries and expectations and to inform patients about the natural course of the symptoms, self medication and alarm symptoms). GPs received a summary of their group's guidelines by mail 1 week after the meeting, and received the results of the baseline measurement (to reinforce the consensus reached) after 2 months

b) Monitoring and feedback on prescribing behaviour ( 6 months post-intervention) based on insurance claims data comparing the period after the intervention (March to May 2001) with the same period before the intervention (March to May 2000). Volumes of different kinds of antibiotics and the extent to which prescribed antibiotics were in line with the consensus about first choice antibiotics were presented at practice level

c) Group education for assistants of GPs and pharmacists attended a 2-hour group education session informing them about Dutch guidelines for GPs, followed by skills training in educating patients

Patient components: education material for patients consisted of a brochure and accompanying posters (also translated into Turkish and Arabic) available in waiting rooms of intervention group gen- 
eral practices, pharmacies and municipal health services, aiming to inform patients about the self limiting character of most respiratory tract symptoms, self medication and serious symptoms ("alarm signals") necessitating a consultation with the GP

Materials: consensus guidelines for GPs and education material for patients

Mode of delivery: GP and pharmacist-led group education meeting for GPs and assistants, and patient education brochure and posters

Duration and intensity: 1 x group education meetings for GPs (duration not stated) and $1 \times 2$-hour group education meetings for assistants

Comparator: usual care

$\begin{array}{ll}\text { Outcomes } & \text { Primary: proportion of practice encounters for acute symptoms of the respiratory tract for which an- } \\ \text { tibiotics were prescribed (patient records) } & \text { Patient satisfaction (self reported questionnaire; } 1=\text { very dissatisfied to } 5=\text { very satisfied) } \\ \text { Secondary: administrative claims data (from regional health insurance company, Agis, over the period } \\ 2000 \text { to 2002) (March to May, } 2000 \text { and March to May, 2001) } \\ \text { Funding: yes } \\ \text { Conflict of interest: none declared } \\ \text { Published trial protocol: not reported } \\ \text { Trial registration: not reported } \\ \text { Ethics approval: yes }\end{array}$

\section{Risk of bias}

Bias Authors' judgement Support for judgement

Random sequence genera- Low risk The 12 peer review groups were allocated to groups A or B. All possible comtion (selection bias) positions of groups $A$ and $B$ were considered and the option chosen of those groups resulting in comparability between group $A$ and $B$ in groups with a high or low volume of antibiotic prescribing (above or below the median), rural or urban working groups, and number of general practitioners per group (above or below the median). MMK, who was blinded to the composition of the groups, flipped a coin to determine whether group A became the intervention or control group

Allocation concealment Low risk Not stated. However, practices recruited prior to randomisation
(selection bias)

Blinding of participants High risk Not possible (multiple intervention)
and personnel (perfor-
mance bias)
All outcomes

\begin{tabular}{|c|c|c|}
\hline \multirow[t]{2}{*}{$\begin{array}{l}\text { Blinding of outcome as- } \\
\text { sessment (detection bias) } \\
\text { All outcomes }\end{array}$} & Low risk & $\begin{array}{l}\text { Research assistants blinded to the intervention status of the practices extract- } \\
\text { ed information from patient records (age, sex, diagnoses, antibiotic prescrip- } \\
\text { tions and referrals to hospital doctors) }\end{array}$ \\
\hline & & $\begin{array}{l}\text { Patient satisfaction questionnaires returned directly to the investigators with- } \\
\text { out being shown to the GP }\end{array}$ \\
\hline
\end{tabular}

\begin{tabular}{ll}
$\begin{array}{l}\text { Incomplete outcome data } \\
\text { (attrition bias) }\end{array}$ & $\begin{array}{l}\text { Of the } 42 \text { of } 48 \text { peer-review groups in the Utrecht region that were invited to } \\
\text { participate, } 30 \text { groups refused or were unable to participate. The } 12 \text { remaining }\end{array}$ \\
\hline
\end{tabular}


Welschen 2004 (Continued) All outcomes peer-review groups were randomised to intervention (6 groups, $46 \mathrm{GPs}$ ) or control ( 6 groups, 54 GPs). All clusters and $89 / 100$ GPs completed the study (intervention $=42$, control $=49)$, with loss to follow-up due to retirement $(n=1)$, removal outside the region $(n=3)$, illness $(n=3)$, motivational problems $(n=2)$ or technical problems $(n=2)$

\begin{tabular}{ll}
\hline $\begin{array}{l}\text { Selective reporting (re- } \\
\text { porting bias) }\end{array}$ Low risk All indicative results reported \\
\hline
\end{tabular}
porting bias)

Other bias Low risk

AOM: acute otitis media

ARI: acute respiratory infection

COPD: chronic obstructive pulmonary disease

CRP: C-reactive protein

FP: family physician

GP: general practitioner

ITT: intention-to-treat

LRTI: lower respiratory tract infection

n/a: not applicable

OTC: over-the-counter

$\mathrm{RCT}$ : randomised controlled trial

RTI: respiratory tract infection

SDM: shared decision making

URTI: upper respiratory tract infection

Characteristics of excluded studies [ordered by study ID]

\begin{tabular}{ll}
\hline Study & Reason for exclusion \\
\hline Bourgeois 2010 & Shared decision making not explicit or inferred \\
\hline Gonzales 2013 & Shared decision making not explicit or inferred \\
\hline Pshetizky 2003 & Shared decision making not explicit or inferred \\
\hline Regev-Yochay 2011 & Shared decision making not explicit or inferred \\
\hline Samore 2005 & Shared decision making not explicit or inferred \\
\hline Taylor 2005 & Shared decision making not explicit or inferred \\
\hline
\end{tabular}

Characteristics of ongoing studies [ordered by study ID]

Altiner 2012

Trial name or title
Converting habits of antibiotic prescribing for respiratory tract infections in German primary care the cluster-randomised controlled (CHANGE-2) trial

Methods 3-arm cluster-randomised controlled trial


Altiner 2012 (Continued)
Participants
GPs $(n=94)$ or practice-based paediatricians $(n=94)$ and their patients ( $~ 30,000$ children and adults) who consult in general practices located in 2 German regions (Baden-Württemberg and Mecklenburg-Western Pomerania) for an ARI

\begin{tabular}{|c|c|}
\hline Interventions & $\begin{array}{l}\text { Communication training versus communication training and point of care testing (C-reactive pro- } \\
\text { tein and rapid antigen detection testing) versus control }\end{array}$ \\
\hline \multirow[t]{5}{*}{ Outcomes } & $\begin{array}{l}\text { Primary: physician antibiotic prescription rate for ARI at 2-year follow-up (post-intervention) de- } \\
\text { rived from data of the statutory health insurance company }\end{array}$ \\
\hline & Secondary: \\
\hline & 1. Re-consultation rate \\
\hline & 2. Use of medical services \\
\hline & 3. Hospital admissions \\
\hline Starting date & $\begin{array}{l}\text { GP and paediatrician recruitment commenced October 2012; patient recruitment over } 3 \text { successive } \\
\text { winter periods }\end{array}$ \\
\hline \multirow[t]{4}{*}{ Contact information } & $\begin{array}{l}\text { Prof Attila Altiner; Institute for General Practice, Rostock University Medical Center; POB 100888; } \\
\text { Rostock } 18055 \text { Germany }\end{array}$ \\
\hline & Phone: +49 (0)381 4942481 \\
\hline & Fax: +49 (0)381494 2482 \\
\hline & Email: ifa.sekretariat@med.uni-rostock.de \\
\hline Notes & - \\
\hline
\end{tabular}

ARI: acute respiratory infection

\section{DATA AND ANALYSES}

\section{Comparison 1. Shared decision making versus usual care (control)}

\begin{tabular}{lllll}
\hline Outcome or subgroup title & No. of studies & $\begin{array}{l}\text { No. of partici- } \\
\text { pants }\end{array}$ & Statistical method & Effect size \\
\hline $\begin{array}{l}1 \text { Antibiotics prescribed, dispensed or decision } \\
\text { to use (short-term, index consultation to } \leq 6 \\
\text { weeks) }\end{array}$ & 8 & 10172 & $\begin{array}{l}\text { Risk Ratio (Random, } \\
95 \% \mathrm{Cl})\end{array}$ & $0.61[0.55,0.68]$ \\
\hline $\begin{array}{l}2 \text { Antibiotics prescribed or dispensed (longer- } \\
\text { term, } 12 \text { months) }\end{array}$ & 3 & 481588 & $\begin{array}{l}\text { Risk Ratio (Random, } \\
95 \% \text { Cl) }\end{array}$ & 0.74 [0.49, 1.11] \\
\hline $\begin{array}{l}3 \text { Antibiotic prescriptions (index consultation) } \\
\text { (adjusted odds ratio) }\end{array}$ & 3 & 3244 & $\begin{array}{l}\text { Odds Ratio (Random, } \\
95 \% \text { Cl) }\end{array}$ & $0.44[0.26,0.75]$ \\
\hline $\begin{array}{l}4 \text { Antibiotic prescriptions (index consultation) } \\
\text { (adjusted risk ratio) }\end{array}$ & 2 & 4623 & $\begin{array}{l}\text { Risk Ratio (Random, } \\
95 \% \text { Cl) }\end{array}$ & 0.64 [0.49, 0.84] \\
\hline
\end{tabular}




\begin{tabular}{lllll}
\hline Outcome or subgroup title & No. of studies & $\begin{array}{l}\text { No. of partici- } \\
\text { pants }\end{array}$ & Statistical method & Effect size \\
\hline $\begin{array}{l}5 \text { Antibiotic prescriptions (index consultation } \\
\text { or population rate per unit of time) (adjusted } \\
\text { risk difference) }\end{array}$ & 4 & 481807 & $\begin{array}{l}\text { Mean Difference } \\
\text { (Random, 95\% Cl) }\end{array}$ & $\begin{array}{l}-18.44[-27.24, \\
-9.65]\end{array}$ \\
\hline $\begin{array}{l}6 \text { Number or rate of re-consultations (risk ratio) } \\
7 \text { Patient satisfaction with the consultation }\end{array}$ & 2 & 1861 & $\begin{array}{l}\text { Risk Ratio (Random, } \\
95 \% \text { Cl) }\end{array}$ & $0.87[0.74,1.03]$ \\
\hline
\end{tabular}

Analysis 1.1. Comparison 1 Shared decision making versus usual care (control), Outcome 1 Antibiotics prescribed, dispensed or decision to use (short-term, index consultation to $\leq 6$ weeks).

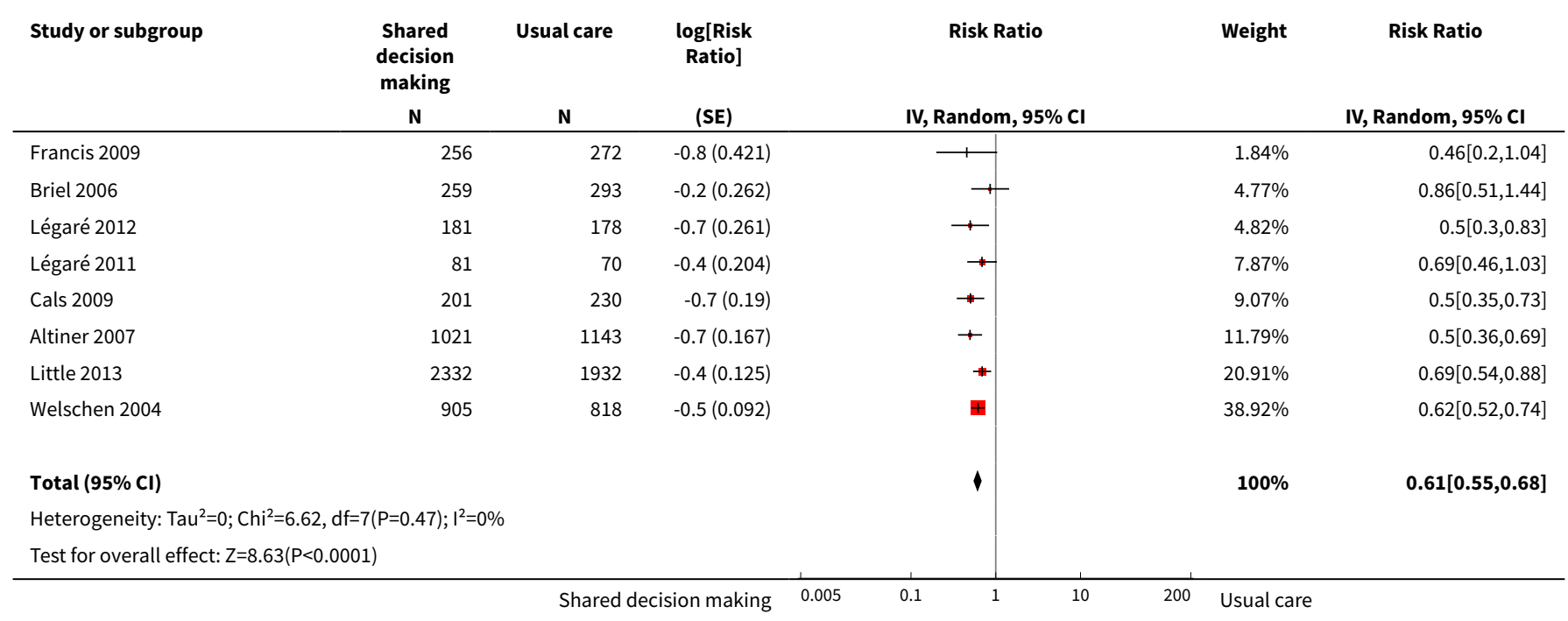

Analysis 1.2. Comparison 1 Shared decision making versus usual care (control), Outcome 2 Antibiotics prescribed or dispensed (longer-term, $\geq 12$ months).

\begin{tabular}{|c|c|c|c|c|c|c|}
\hline \multirow[t]{2}{*}{ Study or subgroup } & $\begin{array}{l}\text { Shared } \\
\text { decision } \\
\text { making }\end{array}$ & Usual care & \multirow[t]{2}{*}{$\begin{array}{c}\text { log[Risk } \\
\text { Ratio] } \\
\text { (SE) }\end{array}$} & Risk Ratio & \multirow[t]{2}{*}{ Weight } & \multirow[t]{2}{*}{$\begin{array}{l}\text { Risk Ratio } \\
\text { Indom, } 95 \% \mathrm{Cl}\end{array}$} \\
\hline & $\mathbf{N}$ & $\mathbf{N}$ & & IV, Random, 95\% CI & & \\
\hline Cals 2013 & 178 & 201 & $-0.4(0.219)$ & 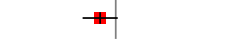 & $27.23 \%$ & $0.68[0.44,1.05]$ \\
\hline Altiner 2007 & 787 & 920 & $-0.6(0.138)$ & \# & $33.41 \%$ & $0.57[0.43,0.75]$ \\
\hline Butler 2012 & 239802 & 239700 & $-0(0.005)$ & $\Pi$ & $39.36 \%$ & $0.97[0.96,0.99]$ \\
\hline Total $(95 \% \mathrm{Cl})$ & & & & & $100 \%$ & $0.74[0.49,1.11]$ \\
\hline \multicolumn{7}{|c|}{ Heterogeneity: Tau $^{2}=0.11 ; \mathrm{Chi}^{2}=17.68, \mathrm{df}=2(\mathrm{P}=0) ; \mathrm{I}^{2}=88.69 \%$} \\
\hline Test for overall effect & & & & & & \\
\hline
\end{tabular}


Analysis 1.3. Comparison 1 Shared decision making versus usual care (control), Outcome 3 Antibiotic prescriptions (index consultation) (adjusted odds ratio).

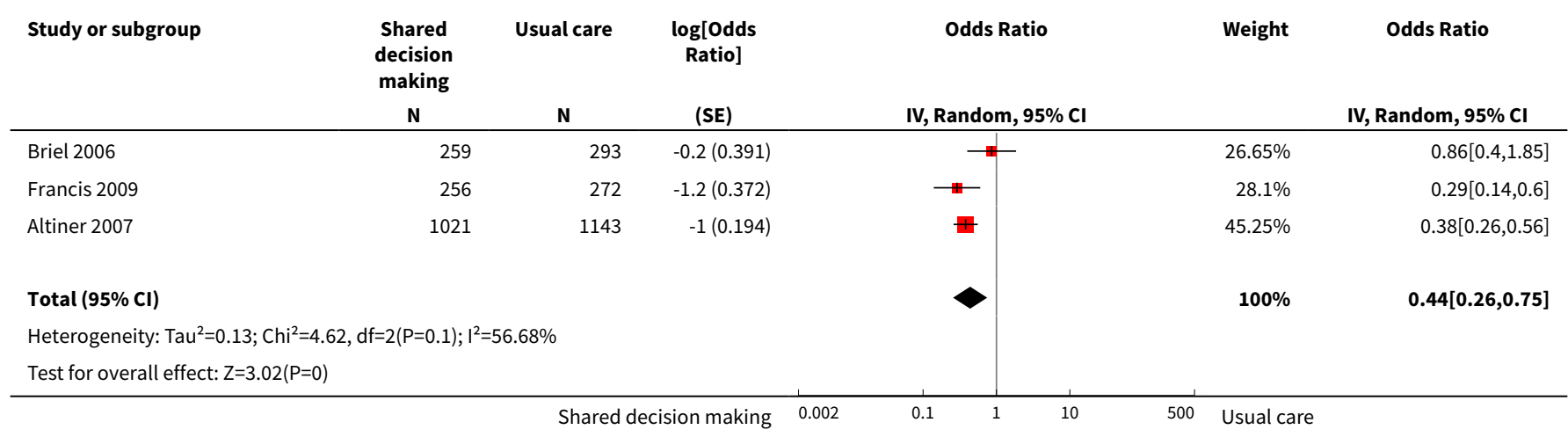

Analysis 1.4. Comparison 1 Shared decision making versus usual care (control), Outcome 4 Antibiotic prescriptions (index consultation) (adjusted risk ratio).

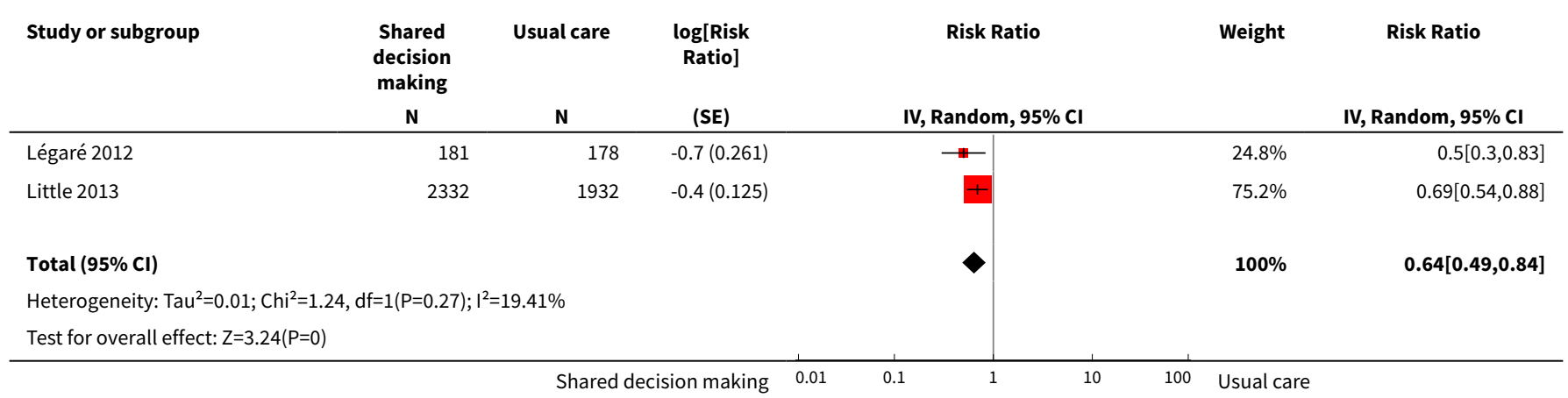

\section{Analysis 1.5. Comparison 1 Shared decision making versus usual care (control), Outcome 5 Antibiotic prescriptions (index consultation or population rate per unit of time) (adjusted risk difference).}

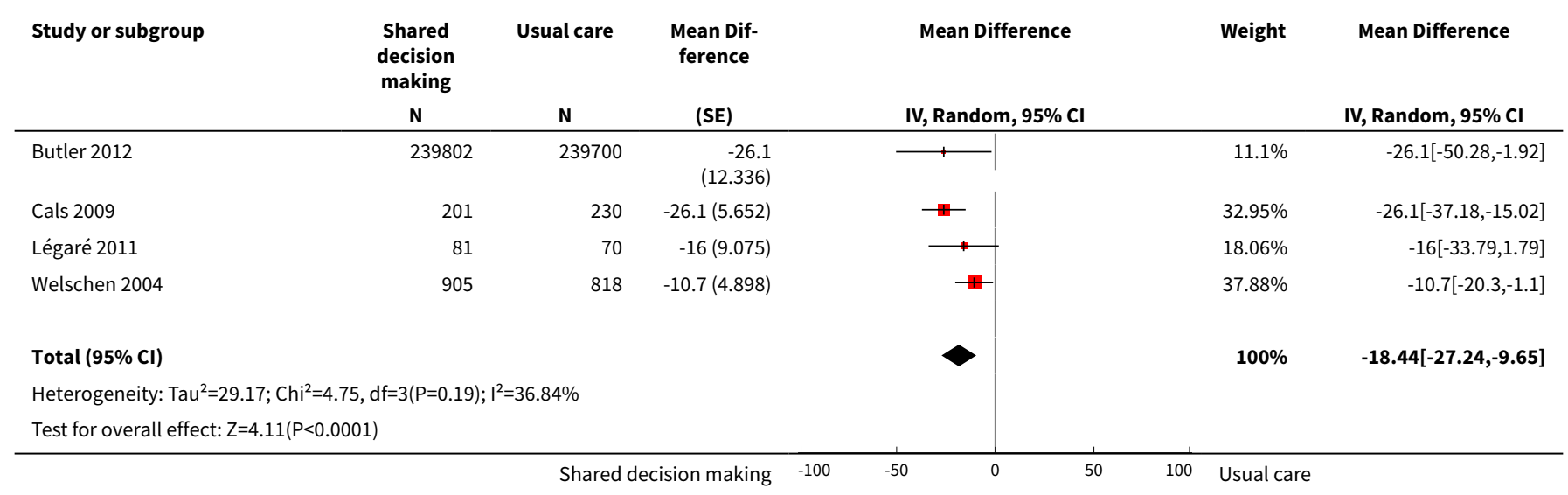


Analysis 1.6. Comparison 1 Shared decision making versus usual care (control), Outcome 6 Number or rate of re-consultations (risk ratio).

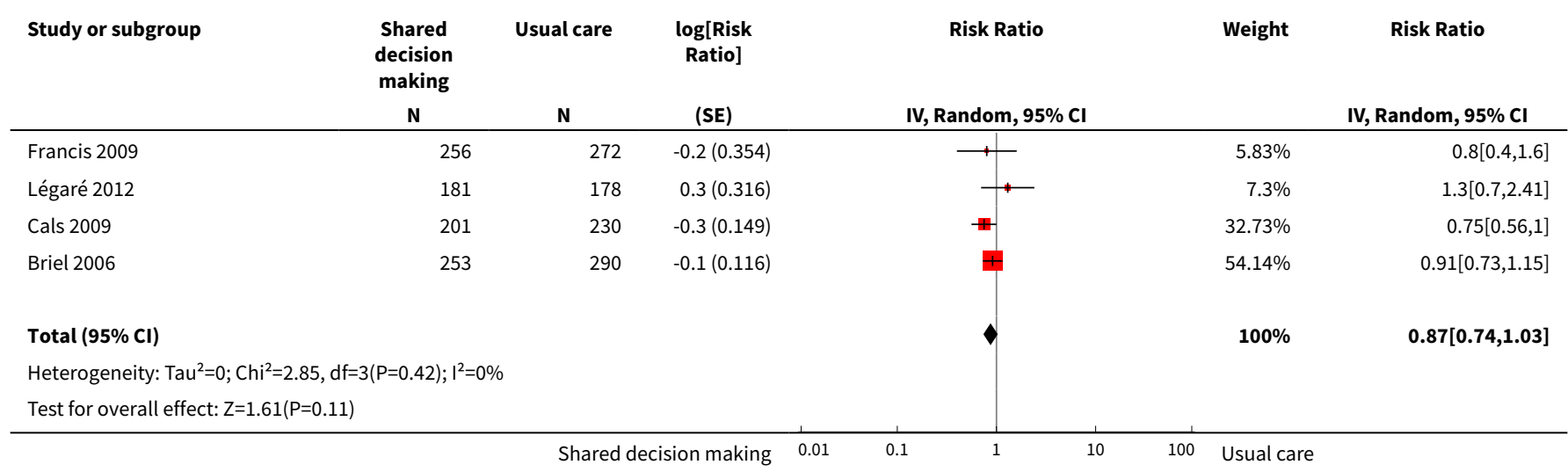

Analysis 1.7. Comparison 1 Shared decision making versus usual care (control), Outcome 7 Patient satisfaction with the consultation.

\begin{tabular}{|c|c|c|c|c|c|c|}
\hline \multirow[t]{2}{*}{ Study or subgroup } & $\begin{array}{l}\text { Shared } \\
\text { decision } \\
\text { making }\end{array}$ & Usual care & \multirow{2}{*}{$\begin{array}{c}\text { log[Odds } \\
\text { Ratio] } \\
\text { (SE) }\end{array}$} & \multirow{2}{*}{$\begin{array}{c}\text { Odds Ratio } \\
\text { IV, Random, } 95 \% \mathrm{CI}\end{array}$} & \multirow[t]{2}{*}{ Weight } & \multirow{2}{*}{$\begin{array}{c}\text { Odds Ratio } \\
\text { IV, Random, } 95 \% \mathrm{CI}\end{array}$} \\
\hline & $\mathbf{N}$ & $\mathbf{N}$ & & & & \\
\hline Briel 2006 & 253 & 290 & $0(0.228)$ & & $65.66 \%$ & $1[0.64,1.56]$ \\
\hline Total $(95 \% \mathrm{Cl})$ & & & & & $100 \%$ & $0.86[0.57,1.3]$ \\
\hline \multicolumn{7}{|c|}{ Heterogeneity: $\operatorname{Tau}^{2}=0.02 ; \mathrm{Chi}^{2}=1.2, \mathrm{df}=1(\mathrm{P}=0.27) ; \mathrm{I}^{2}=16.61 \%$} \\
\hline Test for overall effect & & & & & & \\
\hline
\end{tabular}




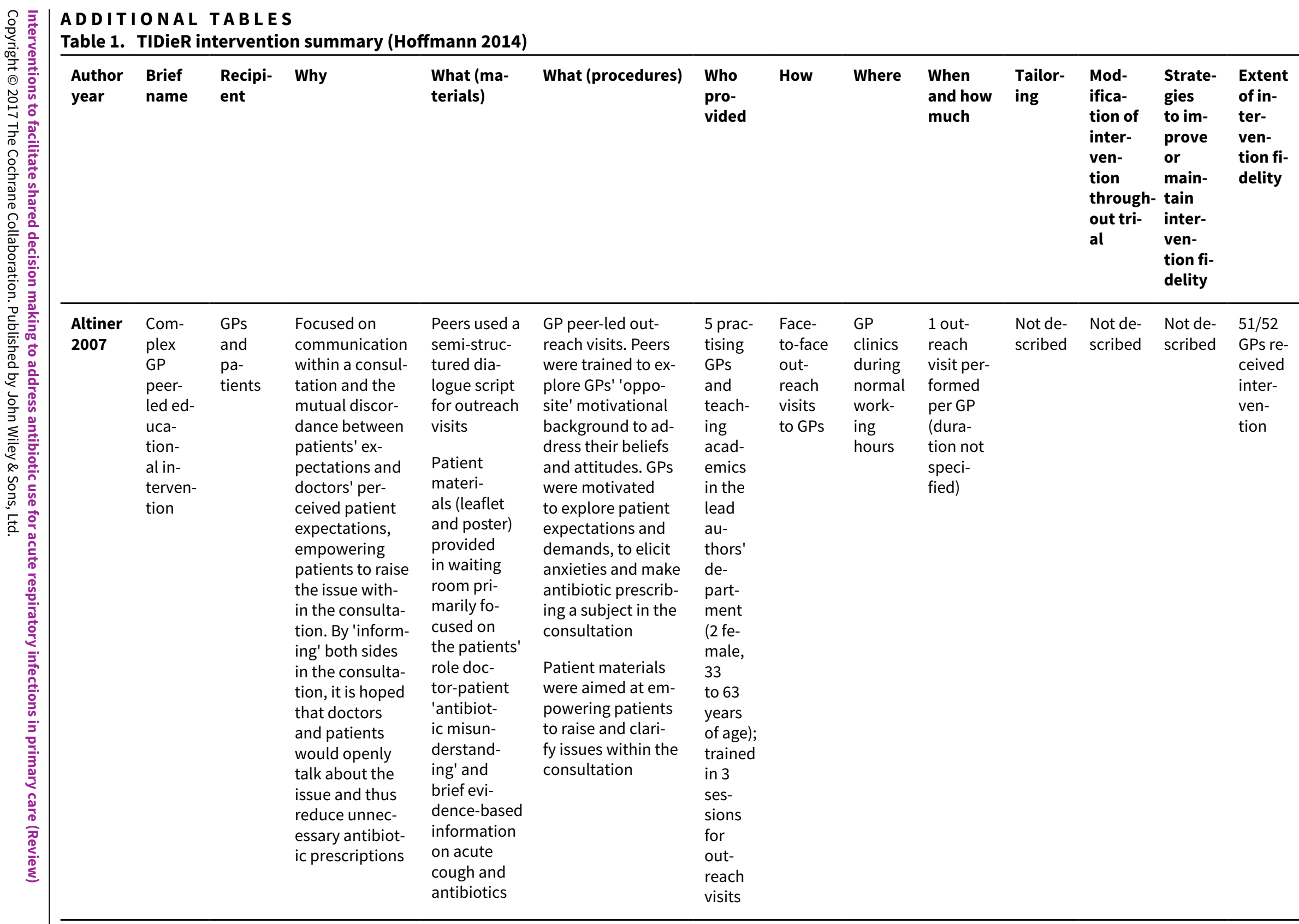




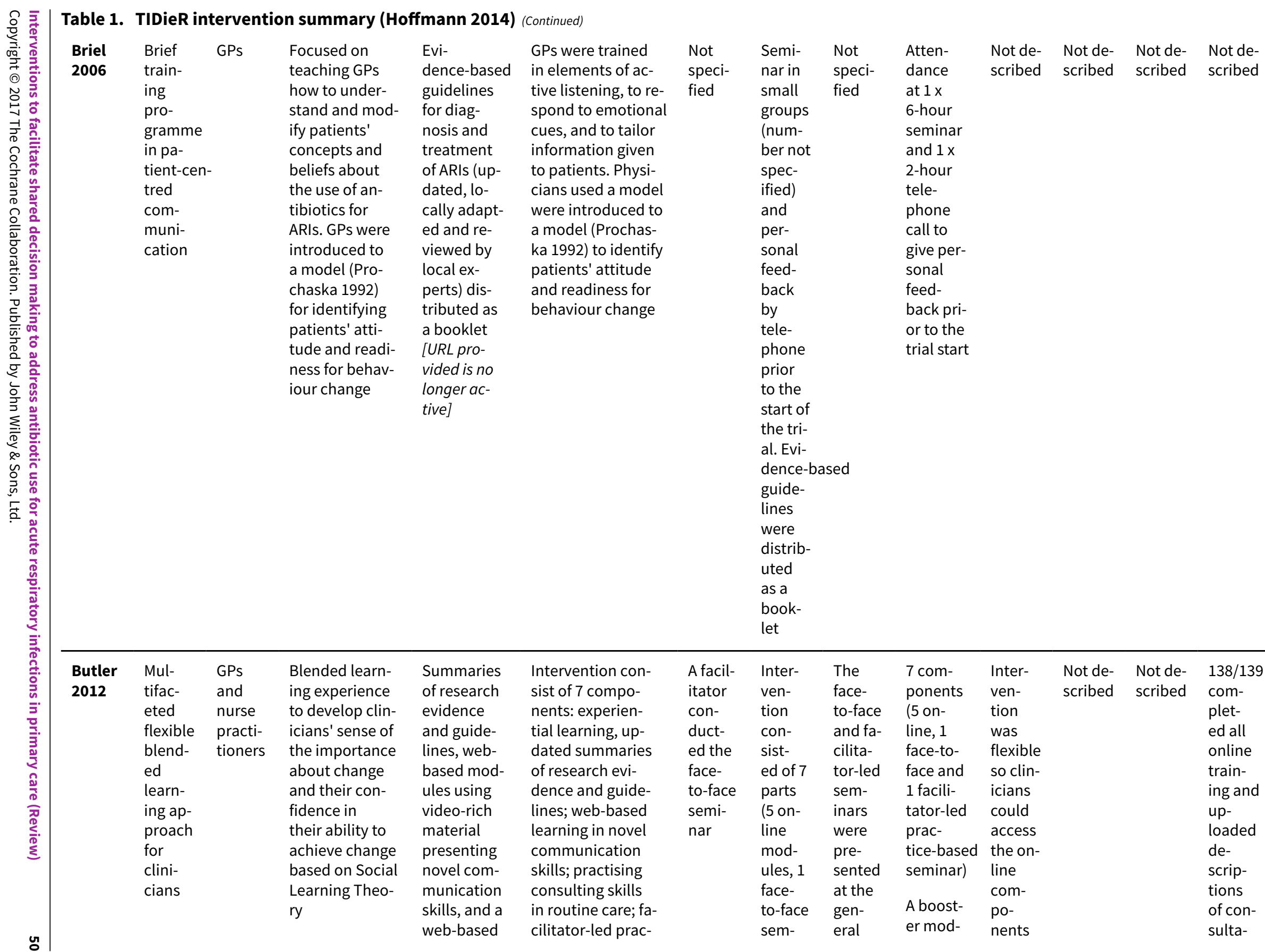




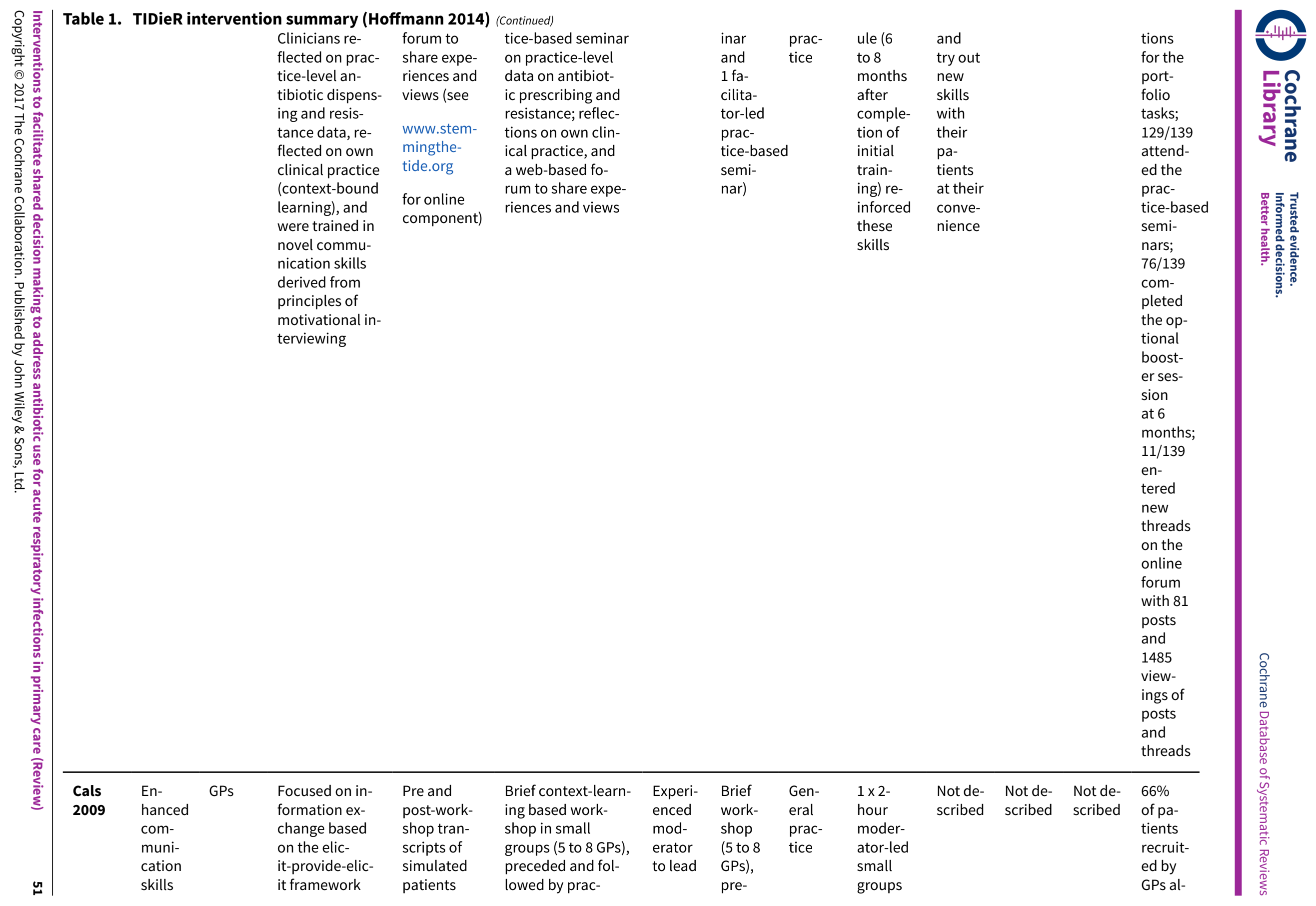




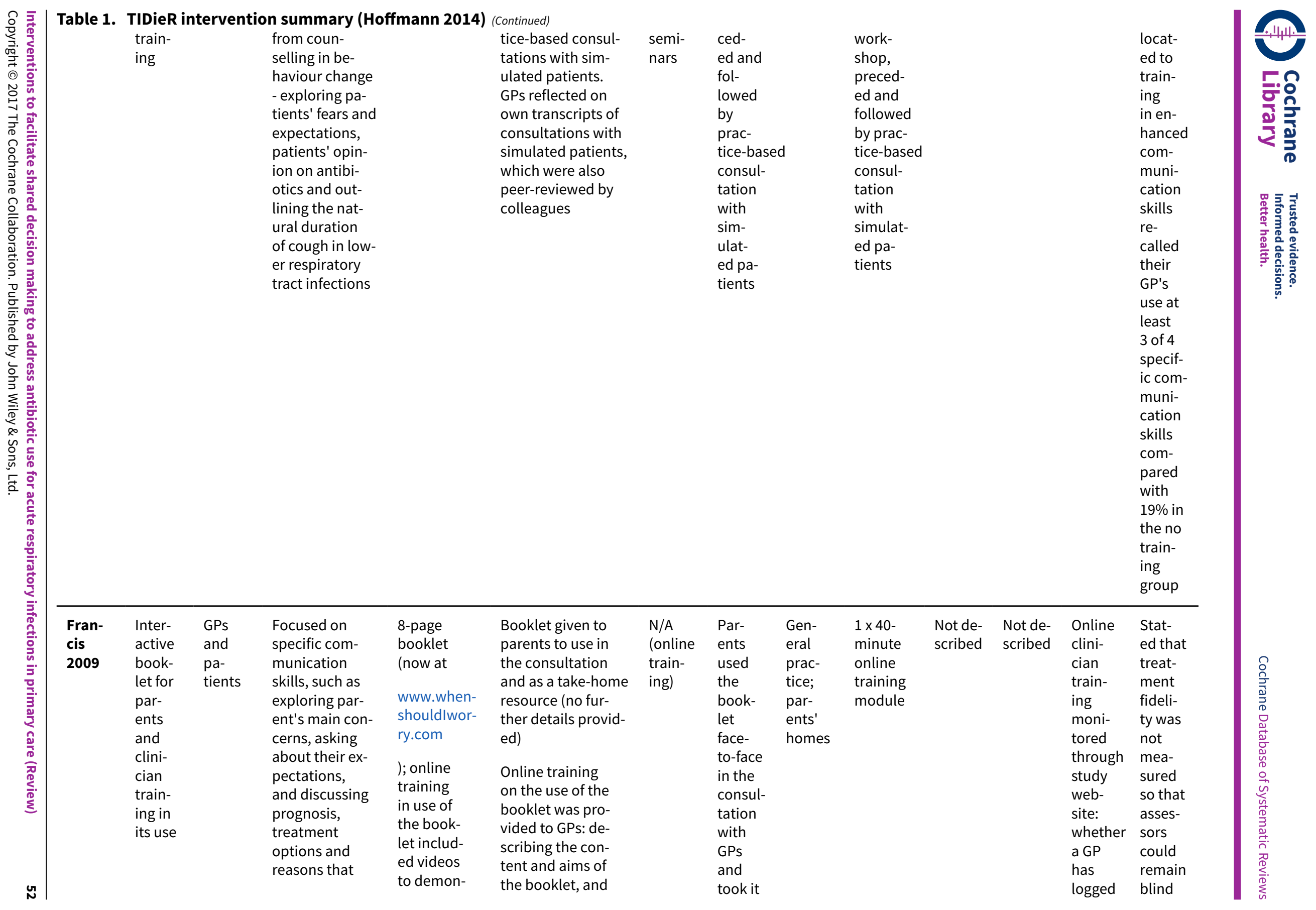




\section{should prompt}

strate use

of the book-

within the use

a consul- use of specific com-

tation, as munication skills

well as au-

dio feeds,

pictures

and links to

study mate-

rials [origi-

nal URL no

longer ac-

tive] home;

GP

train-

ing in

use of

book-

let was

online on to to the

the study

site, group

how

much

time

spent

on it

and

which

pages

were

viewed

\section{Online tu-}

torial and

Online self tutorial comprising 5 mod-

Trained

Online

Fami-

$1 \times 2-$

Not de- Not de- Not de-

Of the cision mak-

workshop

2-hour online

tators

tutori-

ly prac- hour on-

face- teach- rial, fol-

to-face ing lowed

videos, ex- by a facilitator-led

aimed to help

ercises and

on-site interactive

municate to pa- decision

workshops aimed

tients the prob- aids to help to help physicians

ability of a bac-

review and inte-

communi-

grate concepts ac-

work-

units

by $1 \times 2$ -

hour on-

site in-

teractive

work-

shop.

benefits

cate to their

quired during on-

and harms as

patients the line training

Partic-

ipants

had 1

month

terial ARIs

to com-

and bene-

fits/harms

of antibiot-

ic use. De-

cision aids

were avail-

plete

the pro-

physi-

(2hysi-

cians,

com-

pleted

both

the on-

line tu-

tori-

al and

work-

shop;

16

com-

plet-

ed on-

ly the

work-

shop;

15 only

consultation

the tu-

torial;

and 28

com-

family prac-

pleted

ing units 


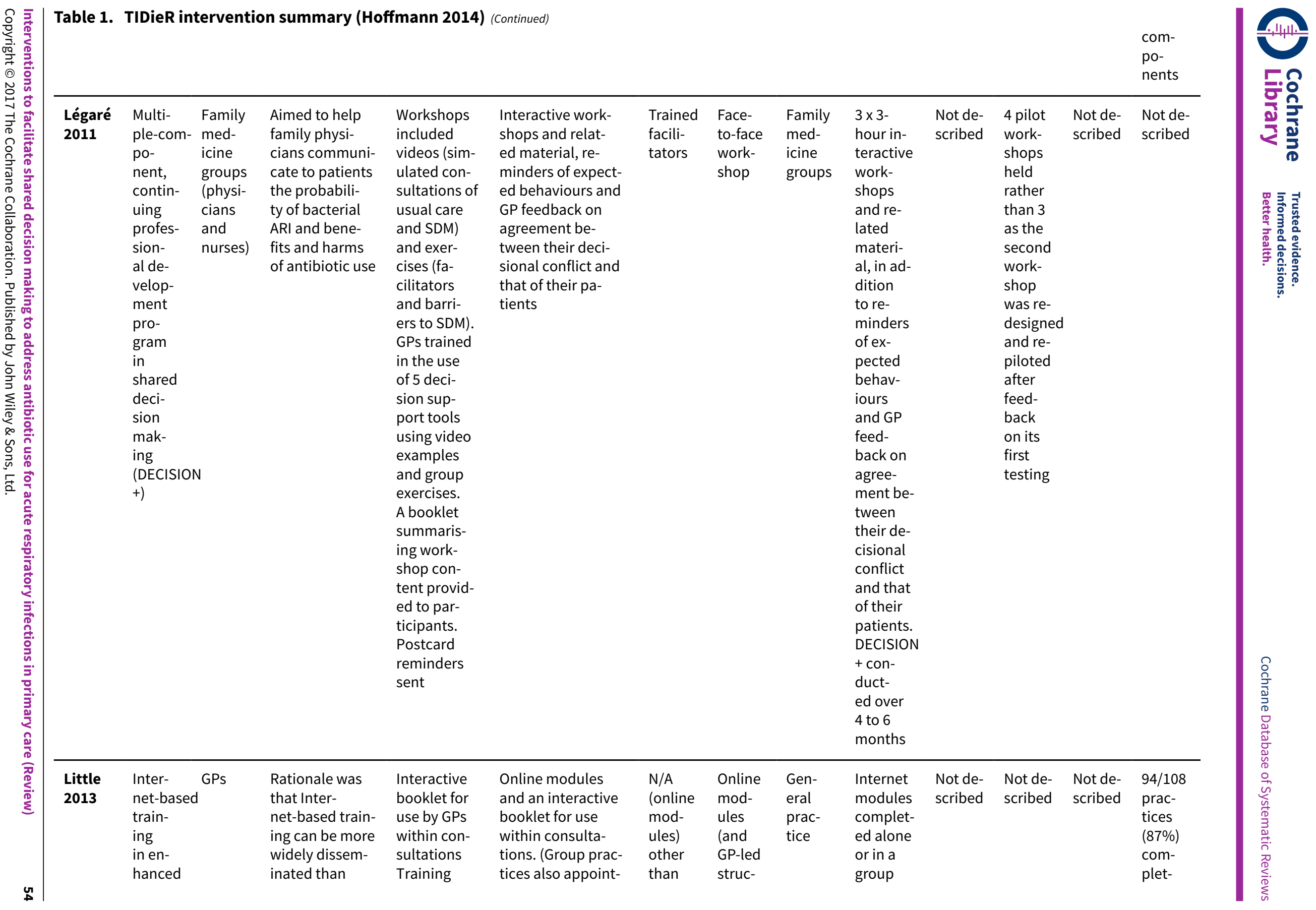




\begin{tabular}{|c|c|c|c|c|c|c|c|c|c|c|c|c|c|c|}
\hline & $\begin{array}{l}\text { com- } \\
\text { muni- } \\
\text { cation } \\
\text { skills }\end{array}$ & & $\begin{array}{l}\text { face-to-face } \\
\text { training. Train- } \\
\text { ing focused on } \\
\text { eliciting pa- } \\
\text { tients' expecta- } \\
\text { tions and con- } \\
\text { cerns, natural } \\
\text { disease course, } \\
\text { treatments, } \\
\text { agreement on } \\
\text { a management } \\
\text { plan, summing } \\
\text { up and guid- } \\
\text { ance on when } \\
\text { to re-consult }\end{array}$ & $\begin{array}{l}\text { support- } \\
\text { ed by video } \\
\text { demonstra- } \\
\text { tions of con- } \\
\text { sultation } \\
\text { techniques }\end{array}$ & $\begin{array}{l}\text { ed a lead GP to or- } \\
\text { ganise a structured } \\
\text { meeting on pre- } \\
\text { scribing issues) }\end{array}$ & $\begin{array}{l}\text { lead } \\
\text { GP at } \\
\text { each } \\
\text { prac- } \\
\text { tice to } \\
\text { organ- } \\
\text { ise a } \\
\text { meet- } \\
\text { ing } \\
\text { (not } \\
\text { spe- } \\
\text { cific } \\
\text { to just } \\
\text { this } \\
\text { arm of } \\
\text { the in- } \\
\text { terven- } \\
\text { tion } \\
\text { though) }\end{array}$ & $\begin{array}{l}\text { tured } \\
\text { prac- } \\
\text { tice-bas } \\
\text { meet- } \\
\text { ing) }\end{array}$ & & & & & & $\begin{array}{l}\text { ed the } \\
\text { com- } \\
\text { muni- } \\
\text { cation } \\
\text { train- } \\
\text { ing. } \\
\text { Mean } \\
\text { (SD) } \\
\text { time } \\
\text { spent } \\
\text { on the } \\
\text { web- } \\
\text { site } \\
\text { was } \\
37 \text { (29) } \\
\text { min- } \\
\text { utes }\end{array}$ & 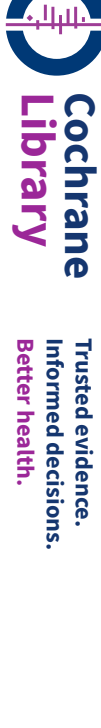 \\
\hline $\begin{array}{l}\text { Welsche } \\
2004\end{array}$ & $\begin{array}{l}\text { Group } \\
\text { edu- } \\
\text { cation } \\
\text { meet- } \\
\text { ing } \\
\text { with } \\
\text { con- } \\
\text { sensus } \\
\text { proce- } \\
\text { dure } \\
\text { and } \\
\text { com- } \\
\text { muni- } \\
\text { cation } \\
\text { skills } \\
\text { train- } \\
\text { ing }\end{array}$ & $\begin{array}{l}\text { GPs/ } \\
\text { phar- } \\
\text { ma- } \\
\text { cists } \\
\text { and } \\
\text { their } \\
\text { assis- } \\
\text { tants, } \\
\text { and } \\
\text { pa- } \\
\text { tients }\end{array}$ & $\begin{array}{l}\text { GPs discussed } \\
\text { evidence for } \\
\text { antibiotic ben- } \\
\text { efit/risk, and } \\
\text { learned com- } \\
\text { munication } \\
\text { techniques to } \\
\text { explore pa- } \\
\text { tients' expecta- } \\
\text { tions and con- } \\
\text { cerns, inform } \\
\text { about natur- } \\
\text { al course of } \\
\text { symptoms, self- } \\
\text { medication and } \\
\text { alarm symp- } \\
\text { toms. Patient } \\
\text { education pro- } \\
\text { vided informa- } \\
\text { tion on the self- } \\
\text { limiting nature } \\
\text { or ARIs, self- } \\
\text { medication and } \\
\text { alarm symp- } \\
\text { toms requiring } \\
\text { re-consultation }\end{array}$ & $\begin{array}{l}\text { Group con- } \\
\text { sensus } \\
\text { guidelines } \\
\text { and pa- } \\
\text { tient waiting } \\
\text { room mate- } \\
\text { rials (poster/ } \\
\text { leaflets) }\end{array}$ & $\begin{array}{l}\text { Group education } \\
\text { meeting with con- } \\
\text { sensus procedure, } \\
\text { with a summa- } \\
\text { ry, and guidelines } \\
\text { mailed } 1 \text { month lat- } \\
\text { er to reinforce con- } \\
\text { sensus reached; } \\
\text { feedback on pre- } \\
\text { scribing behaviour } \\
\text { (post- and pre-in- } \\
\text { tervention insur- } \\
\text { ance claims data) } \\
\text { and practice-lev- } \\
\text { el reporting of ex- } \\
\text { tent prescribing be- } \\
\text { haviours aligned } \\
\text { with consensus } \\
\text { reached; group ed- } \\
\text { ucation session } \\
\text { for GP and phar- } \\
\text { macists assistants } \\
\text { (Dutch guidelines } \\
\text { and skills training } \\
\text { in patient educa- } \\
\text { tion); waiting room }\end{array}$ & $\begin{array}{l}\text { Jointly } \\
\text { led by } \\
\text { GP and } \\
\text { phar- } \\
\text { macist }\end{array}$ & $\begin{array}{l}\text { Group } \\
\text { edu- } \\
\text { cation } \\
\text { meet- } \\
\text { ing for } \\
\text { GPs } \\
\text { with } \\
\text { con- } \\
\text { sensus } \\
\text { proce- } \\
\text { dure } \\
\text { and } \\
\text { com- } \\
\text { muni- } \\
\text { cation } \\
\text { skills } \\
\text { train- } \\
\text { ing, } \\
\text { Group } \\
\text { educa- } \\
\text { tion for } \\
\text { GPs' } \\
\text { and } \\
\text { phar- } \\
\text { ma- }\end{array}$ & $\begin{array}{l}\text { Not de- } \\
\text { scribed }\end{array}$ & $\begin{array}{l}1 \times \text { group } \\
\text { edu- } \\
\text { cation } \\
\text { meet- } \\
\text { ing with } \\
\text { consen- } \\
\text { sus pro- } \\
\text { cedure; } \\
1 \times 2- \\
\text { hour } \\
\text { group } \\
\text { educa- } \\
\text { tion ses- } \\
\text { sion for } \\
\text { GP and } \\
\text { pharma- } \\
\text { cists' as- } \\
\text { sistants; } \\
\text { monitor- } \\
\text { ing and } \\
\text { feed- } \\
\text { back } \\
\text { of pre- } \\
\text { scribing } \\
\text { behav- } \\
\text { iour at } 6\end{array}$ & $\begin{array}{l}\text { Not de- } \\
\text { scribed }\end{array}$ & $\begin{array}{l}\text { Not de- } \\
\text { scribed }\end{array}$ & $\begin{array}{l}\text { Not de- } \\
\text { scribed }\end{array}$ & $\begin{array}{l}\text { Not de- } \\
\text { scribed }\end{array}$ & 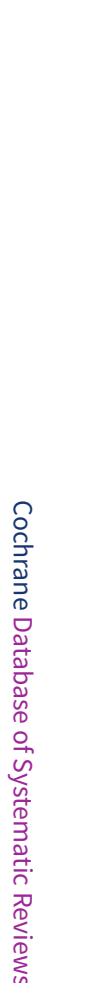 \\
\hline
\end{tabular}




\begin{tabular}{|c|c|c|c|c|c|c|c|}
\hline 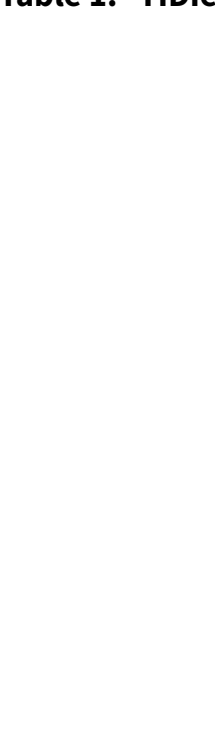 & & $\begin{array}{l}\text { edu } \\
\text { rial }\end{array}$ & $\begin{array}{l}\text { on al mate- } \\
\text { atients }\end{array}$ & $\begin{array}{l}\text { cists' } \\
\text { assis- } \\
\text { tants, } \\
\text { mon- } \\
\text { itor- } \\
\text { ing and } \\
\text { feed- } \\
\text { back } \\
\text { on pre- } \\
\text { scrib- } \\
\text { ing be- } \\
\text { hav- } \\
\text { iour, } \\
\text { and } \\
\text { patient } \\
\text { edu- } \\
\text { cation } \\
\text { materi- } \\
\text { als }\end{array}$ & $\begin{array}{l}\text { months } \\
\text { post-in- } \\
\text { terven- } \\
\text { tion }\end{array}$ & & \\
\hline \multicolumn{8}{|c|}{$\begin{array}{l}\text { ARI: acute respiratory infection } \\
\text { GP: general practitioner } \\
\text { N/A: not applicable } \\
\text { Table 2. Antibiotic prescrip }\end{array}$} \\
\hline \multirow[t]{2}{*}{ Author } & \multirow[t]{2}{*}{ Outcome } & \multirow[t]{2}{*}{$\begin{array}{l}\text { Measure- } \\
\text { ment time } \\
\text { point }\end{array}$} & Intervention (n) & \multirow[t]{2}{*}{ Control } & Effect estimate & $P$ value & Notes \\
\hline & & & & & \multicolumn{2}{|l|}{$\begin{array}{l}\text { Adjusted odds } \\
\text { ratio }(95 \% \mathrm{Cl})\end{array}$} & \\
\hline $\begin{array}{l}\text { Francis } \\
(2009)\end{array}$ & $\begin{array}{l}\text { Antibiotics prescribed at the index } \\
\text { consultation }\end{array}$ & 14 days & $\begin{array}{l}(30 \text { practices }) \mathrm{Pa}- \\
\text { tients }=50 / 256 \\
(19.5 \%)\end{array}$ & $\begin{array}{l}\text { (31 practices) } \\
\text { Patients = 111/272 } \\
(40.8 \%)\end{array}$ & $\begin{array}{l}0.29(0.14 \text { to } \\
0.60)^{a}\end{array}$ & NR & $\mathrm{ICC}=0.24$ \\
\hline \multirow[t]{2}{*}{ Altiner (2007) } & \multirow[t]{2}{*}{$\begin{array}{l}\text { Rate of antibiotic prescriptions (per } \\
\text { acute cough and per GP) }\end{array}$} & 6 weeks & $\begin{array}{l}\text { GPs }=42 \\
\text { Patients }=1021\end{array}$ & $\begin{array}{l}\text { GPs }=44 \\
\text { Patients }=1143\end{array}$ & $\begin{array}{l}0.38(0.26 \text { to } \\
0.56)^{b}\end{array}$ & $<0.001$ & \multirow[t]{2}{*}{$\mathrm{ICC}=0.20$} \\
\hline & & 12 months & $\begin{array}{l}\text { GPs }=28 \\
\text { Patients }=787\end{array}$ & $\begin{array}{l}\mathrm{GPs}=33 \\
\text { Patients }=920\end{array}$ & $\begin{array}{l}0.55(0.38 \text { to } \\
0.80)^{b}\end{array}$ & 0.002 & \\
\hline
\end{tabular}




\begin{tabular}{|c|c|c|c|c|c|c|c|}
\hline Briel (2006) & $\begin{array}{l}\text { Uptake of antibiotic prescriptions as } \\
\text { reported by pharmacists }<2 \text { weeks } \\
\text { after the consultation }\end{array}$ & 14 days & $\begin{array}{l}\text { GPs }=15 \\
\text { Patients }=259\end{array}$ & $\begin{array}{l}\text { GPs }=15 \\
\text { Patients }=293\end{array}$ & $\begin{array}{l}0.86(0.40 \text { to } \\
1.93)^{c}\end{array}$ & NR & $\begin{array}{l}\text { ICC }=0.04 \\
\text { Design effect } \\
=1.6\end{array}$ \\
\hline & & & & & $\begin{array}{l}\text { Adjusted risk } \\
\text { ratio }(95 \% \mathrm{Cl})\end{array}$ & & \\
\hline Little (2013) & Antibiotic prescription & $\begin{array}{l}\text { index consul- } \\
\text { tation }\end{array}$ & $\begin{array}{l}\text { Practices }=61 \\
\text { Patients }=2332\end{array}$ & $\begin{array}{l}\text { Practices }=61 \\
\text { Patients }=1932\end{array}$ & $\begin{array}{l}0.69(0.54 \text { to } \\
0.87)^{\mathrm{d}}\end{array}$ & $<0.0001$ & - \\
\hline Légaré (2012) & $\begin{array}{l}\% \text { patients who decided to use an- } \\
\text { tibiotics immediately after the con- } \\
\text { sultation }\end{array}$ & $\begin{array}{l}\text { Index consul- } \\
\text { tation }\end{array}$ & $\begin{array}{l}\text { Practice units }=6 \\
\text { GPs }=77 \\
\text { Patients }=181\end{array}$ & $\begin{array}{l}\text { Practice units }=6 \\
\text { GPs }=72 \\
\text { Patients }=178\end{array}$ & $\begin{array}{l}0.50(0.30 \text { to } \\
0.70)^{\mathrm{e}}\end{array}$ & - & - \\
\hline & & & & & $\begin{array}{l}\text { Adjusted risk } \\
\text { difference }(95 \% \\
\mathrm{Cl})\end{array}$ & & \\
\hline Légaré (2011) & $\begin{array}{l}\% \text { patients who decided to use an- } \\
\text { tibiotics immediately after the con- } \\
\text { sultation }\end{array}$ & $\begin{array}{l}\text { Index consul- } \\
\text { tation }\end{array}$ & $\begin{array}{l}\text { Medicine groups }= \\
2 \\
\text { GPs }=18 \\
\text { Patients }=81\end{array}$ & $\begin{array}{l}\text { Medicine groups } \\
\text { GPs }=14 \\
\text { Patients }=70\end{array}$ & $-16(-31 \text { to } 1)^{f}$ & 0.08 & - \\
\hline Butler (2012) & $\begin{array}{l}\text { Total no. dispensed oral antibiotic } \\
\text { items per } 1000 \text { registered patients } \\
\text { for the year after the intervention }\end{array}$ & $\begin{array}{l}12 \text {-month pe- } \\
\text { riod }\end{array}$ & $\begin{array}{l}\text { Practices }=34 \mathrm{~Pa}- \\
\text { tients }=7053\end{array}$ & $\begin{array}{l}\text { Practices }=34 \mathrm{~Pa}- \\
\text { tients }=7050\end{array}$ & $-4.2(-0.6$ to -7.7$)$ & 0.02 & - \\
\hline Cals (2009) & $\begin{array}{l}\text { Antibiotic prescribing at the index } \\
\text { consultation }\end{array}$ & $\begin{array}{l}\text { Index consul- } \\
\text { tation }\end{array}$ & $\begin{array}{l}\mathrm{n} / \mathrm{N}=55 / 201 \\
\% \text { crude }(95 \% \mathrm{Cl})^{\mathrm{G}} \\
27.4(25.6 \text { to } 36.6)\end{array}$ & $\begin{array}{l}\mathrm{n} / \mathrm{N}=123 / 230 \\
\% \text { crude }(95 \% \mathrm{Cl}) \mathrm{g} \\
53.5(43.8 \text { to } 63.2)\end{array}$ & -26.1 (\% crude) & $<0.01^{\mathrm{h}}$ & $\mathrm{ICC}=0.12$ \\
\hline Cals (2013) & $\begin{array}{l}\text { Proportion of episodes of respiratory } \\
\text { tract infections during follow-up for } \\
\text { which a GP was seen and that antibi- } \\
\text { otics were prescribed for }\end{array}$ & $\begin{array}{l}\text { Mean } 3.67 \\
\text { years fol- } \\
\text { low-up }\end{array}$ & $\begin{array}{l}n=178 \\
\%(95 \% \mathrm{Cl}) \\
26.3(20.6 \text { to } 32.0)\end{array}$ & $\begin{array}{l}\mathrm{n}=201 \\
\%(95 \% \mathrm{Cl}) \\
39.1(33.1 \text { to } 45.1)\end{array}$ & $-10.4^{i}$ & $0.02^{\mathrm{i}}$ & - \\
\hline $\begin{array}{l}\text { Welschen } \\
(2006)\end{array}$ & $\begin{array}{l}\% \text { practice encounters for acute } \\
\text { symptoms of the respiratory tract for } \\
\text { which antibiotics were prescribed }\end{array}$ & $\begin{array}{l}\text { Index consul- } \\
\text { tation }\end{array}$ & Review groups $=6$ & Review groups $=6$ & $\begin{array}{l}-10.7(-20.3 \text { to }- \\
1.0) j\end{array}$ & - & $\begin{array}{l}\text { Practice }= \\
0.17\end{array}$ \\
\hline
\end{tabular}


${ }^{a}$ Two level (practice and patient) random intercept logistic regression models.

bAfter backward elimination, four explanatory variables remained in the model: patients' disease severity, measured on a four-point scale (odds ratio 4.8 , $95 \% \mathrm{Cl} 3.9$ to 5.9 per step on scale, $\mathrm{P}$ value $<0.001$ ), and average practice severity (severity of the disease rated by the GP) (odds ratio $0.14,95 \% \mathrm{Cl} 0.06$ to 0.33 , $\mathrm{P}$ value $<0.001$ per category step on the scale), patients having fever (odds ratio $1.80,95 \% \mathrm{Cl} 1.35$ to $2.39, \mathrm{P}$ value $<0.001$ compared with no fever) and frequency of fever in practice, as determined by the log odds (odds ratio $1.31,95 \% \mathrm{Cl} 1.08$ to 1.59 , $\mathrm{P}$ value $=0.007$ per category step on the scale).

'Logistic regression with random effects for each cluster and patient covariates (age, sex, education, days with restrictions at baseline).

dThe adjusted model adjusted for baseline prescribing and clustering by physician and practice, and additionally controlled for age, smoking, sex, major cardiovascular or respiratory comorbidity, baseline symptoms, crepitations, wheeze, pulse higher than 100 beats per minute, temperature higher than $37.8^{\circ} \mathrm{C}$, respiratory rate, blood pressure, physician's rating of severity and duration of cough.

eAdjusted for cluster design, baseline values and patient age group (for analyses at teaching unit and physician levels).

fP value adjusted for baseline values and the study's cluster design.

gCalculated and inflated for clustering by using standard deviation inflated by variance inflation factor.

hCalculated from second order penalised quasi-likelihood multilevel logistic regression model adjusted for variance at general practitioner and practice level (random intercept at practice and general practitioner level). Models included both interventions and interaction term of interventions.

iP values from multilevel linear regression model to account and correct for variation at the level of family physician, and to adjust for both interventions, RTI-episodes treated with antibiotics during baseline period, chronic obstructive pulmonary disease comorbidity.

Intervention effect in multi-level analysis

$\mathrm{Cl}$ : confidence interval

GP: general practitioner

NR: not reported

Table 3. Number or rate of re-consultations

\begin{tabular}{|c|c|c|c|c|c|c|c|}
\hline Author & Outcome & $\begin{array}{l}\text { Measure- } \\
\text { ment time } \\
\text { point }\end{array}$ & Intervention & Control & Effect estimate & $P$ value & Notes \\
\hline \multirow[t]{2}{*}{ Briel (2006) } & \multirow[t]{2}{*}{$\begin{array}{l}\text { Re-consulta- } \\
\text { tions }\end{array}$} & \multirow[t]{2}{*}{$\begin{array}{l}\text { Within } 14 \\
\text { days }\end{array}$} & $\mathrm{n} / \mathrm{N}(\%)$ & $\mathrm{n} / \mathrm{N}(\%)$ & Adjusted rate ratio $(95 \% \mathrm{Cl})^{a}$ & \multirow[t]{2}{*}{ NR } & \multirow[t]{2}{*}{-} \\
\hline & & & $113 / 253(44.7)$ & $143 / 290(49.3)$ & $0.97(0.78$ to 1.21$)$ & & \\
\hline \multirow[t]{3}{*}{ Butler (2013) } & \multirow{3}{*}{$\begin{array}{l}\text { Re-consulta- } \\
\text { tions after in- } \\
\text { dex consulta- } \\
\text { tion)b }\end{array}$} & Within 7 days & Median (IQR) & Median (IQR) & Median difference $(95 \% \mathrm{Cl})^{c}$ & \multirow{3}{*}{$\begin{array}{l}P \text { value }= \\
0.446^{d} \\
P \text { value = } \\
0.411^{d}\end{array}$} & \multirow[t]{3}{*}{-} \\
\hline & & days & 5.10 (4.70 to 7.92$)$ & 6.43 (4.04 to 7.84$)$ & $-1.33(-2.12$ to 0.74$)$ & & \\
\hline & & $\begin{array}{l}\text { Within } 31 \\
\text { days }\end{array}$ & 9.06 (7.53 to 12.62$)$ & 11.38 (7.39 to 14.05$)$ & $-2.32(-4.76$ to 1.95$)$ & & \\
\hline
\end{tabular}

Within 31

$-2.32(-4.76$ to 1.95$)$ 


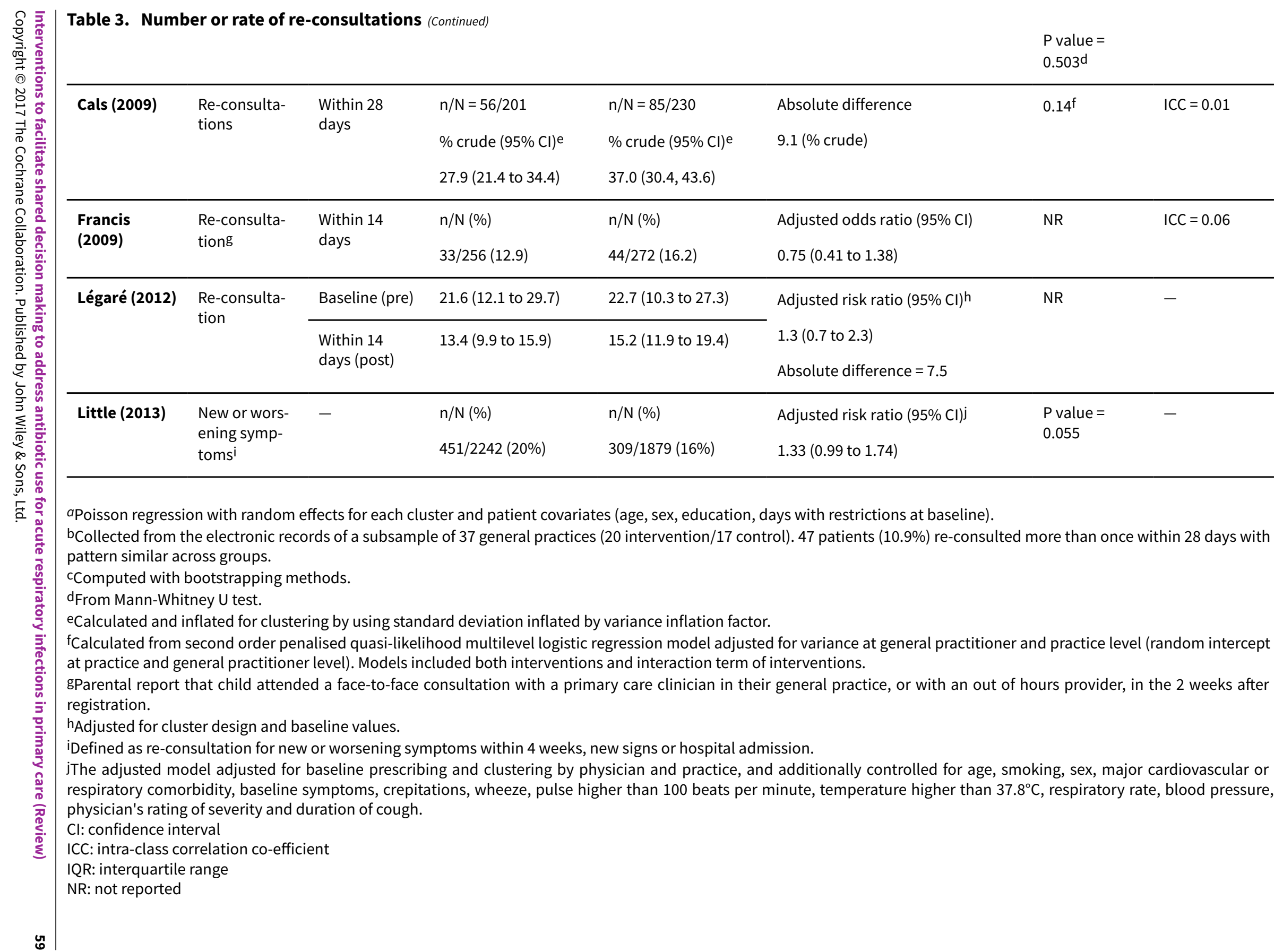




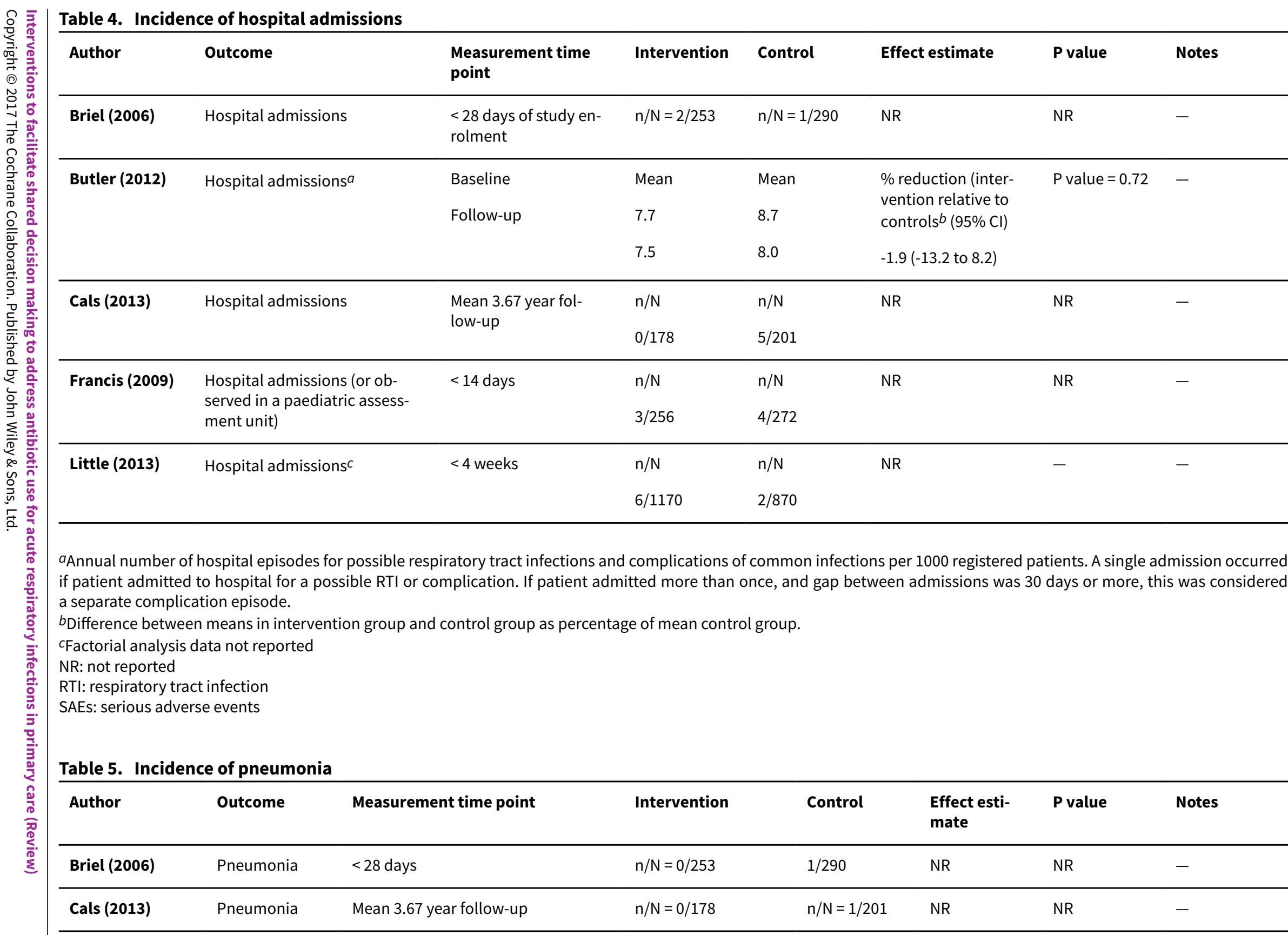


NR: not reported

Table 6. Patient satisfaction

\begin{tabular}{|c|c|c|c|c|c|c|c|}
\hline Author & Outcome & $\begin{array}{l}\text { Measure- } \\
\text { ment time } \\
\text { point }\end{array}$ & Intervention & Control & Effect estimate & $P$ value & Notes \\
\hline Briel (2006) & $\begin{array}{l}\text { Patient satisfaction (Pa- } \\
\text { tient Satisfaction Ques- } \\
\text { tionnaire) }{ }^{a}\end{array}$ & 7 and 14 days & $121 / 253(47.8)$ & $142 / 290(49.0)$ & $\begin{array}{l}\text { Adjusted OR (95\% } \\
\text { Cl)b } \\
1.00 \text { (0.64 to } 1.31)\end{array}$ & NR & - \\
\hline Cals (2009) & $\begin{array}{l}\text { Patient satisfaction (\% } \\
\text { at least 'very satisfied' } \\
\text { on Likert scale)c }\end{array}$ & 28 days & $\begin{array}{l}\mathrm{n} / \mathrm{N}=144 / 201 \\
\%(\text { crude } 95 \% \mathrm{Cl})^{\mathrm{d}} \\
78.7(72.5 \text { to } 84.9)\end{array}$ & 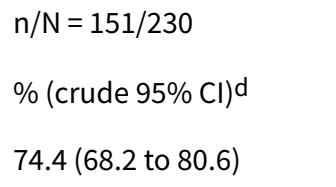 & 4.3 & $\begin{array}{l}\mathrm{P} \text { value }= \\
0.88 \mathrm{e}\end{array}$ & - \\
\hline $\begin{array}{l}\text { Francis } \\
(2009)\end{array}$ & $\begin{array}{l}\text { Parent satisfaction (Lik- } \\
\text { ert scale)f }\end{array}$ & 14 days & $\mathrm{n} / \mathrm{N}(\%)=222 / 246(90.2)$ & $\mathrm{n} / \mathrm{N}(\%)=246 / 263(93.5)$ & $\begin{array}{l}\text { Adjusted OR }(95 \% \\
\text { Cl)g } \\
0.6 \text { (0.3 to } 1.2)\end{array}$ & NR & - \\
\hline $\begin{array}{l}\text { Welschen } \\
\text { (2006) }\end{array}$ & $\begin{array}{l}\text { Patient satisfaction (Lik- } \\
\text { ert scale)h }\end{array}$ & $\begin{array}{l}\text { Index consul- } \\
\text { tation }\end{array}$ & $\begin{array}{l}\text { Patient satisfaction }(\%) \\
\text { Baseline (pre) }=4.3(0.3) \\
\text { Follow-up (post) }=4.3 \\
(0.3) \\
\% \text { change }(\mathrm{SD})=0(0.4)\end{array}$ & $\begin{array}{l}\text { Patient satisfaction (\%) } \\
\text { Baseline (pre) }=4.2(0.4) \\
\text { Follow-up (post) }=4.2 \\
(0.3) \\
\text { \% change (SD): } 0(0.4)\end{array}$ & $\begin{array}{l}\text { Mean difference } \\
\text { of changes }(95 \% \\
\mathrm{Cl}) \\
0(-0.2 \text { to } 0.1) \mathbf{i}\end{array}$ & NR & - \\
\hline
\end{tabular}

a\% patients with a maximum score of 70 reported, as satisfaction scores (scale 14 to 70 ; median 68/70) were highly skewed.

bLogistic regression with random effects for each cluster and patient covariates (age, sex, education, days with restrictions at baseline).

c\% at least 'very satisfied'.

dCalculated and inflated for clustering by using standard deviation inflated by variance inflation factor.

eCalculated from models adjusted for variance at general practitioner and practice level.

fTransformed into binary outcomes: 'very satisfied' and 'satisfied' versus 'neutral', 'dissatisfied' and 'very dissatisfied'.

godds ratio $(95 \% \mathrm{Cl})$ from multilevel modelling.

$\mathrm{h}_{1}=$ very dissatisfied to $5=$ very satisfied.

intervention effect in multilevel analysis.

$\mathrm{Cl}$ : confidence interval

OR: odds ratio

오 SD: standard deviation 
Table 7. Decisional conflict

\begin{tabular}{|c|c|c|c|c|c|c|c|}
\hline Author & Outcome & $\begin{array}{l}\text { Measurement } \\
\text { time point }\end{array}$ & Intervention & Control & Effect estimate & $P$ value & Notes \\
\hline Légaré (2012) & $\begin{array}{l}\text { Decisional conflict } \\
(\mathrm{GPs})^{a}\end{array}$ & $\begin{array}{l}\text { Immediately after } \\
\text { consultation }\end{array}$ & $\begin{array}{l}\text { Baseline: } 4.5 \text { (0 to } 9.0 \text { ) } \\
\text { Follow-up: } 4.6 \text { (0 to } 6.1 \text { ) }\end{array}$ & $\begin{array}{l}\text { Baseline: } 3.0 \text { ( } 0 \text { to } \\
5.9 \text { ) } \\
\text { Follow-up:1.1 (0 to } \\
2.4 \text { ) }\end{array}$ & $\begin{array}{l}\text { Adjusted RR } \\
3.4(0.3 \text { to } 38.0)\end{array}$ & NR & - \\
\hline Légaré (2012) & $\begin{array}{l}\text { Decisional conflict } \\
\text { (patients) }\end{array}$ & $\begin{array}{l}\text { Immediately after } \\
\text { consultation }\end{array}$ & $\begin{array}{l}\text { Baseline: } 5.1 \text { (0 to } 13.5) \\
\text { Follow-up: } 4.6 \text { (2.6 to } 7.4)\end{array}$ & $\begin{array}{l}\text { Baseline: } 4.2 \text { ( } 0 \text { to } \\
8.9 \text { ) } \\
\text { Follow-up: } 6.3 \text { ( } 0 \text { to } \\
12.8 \text { ) }\end{array}$ & $\begin{array}{l}\text { Adjusted RR: } \\
0.8 \text { (0.2 to } 2.4)\end{array}$ & NR & - \\
\hline Légaré (2011) & $\begin{array}{l}\text { Correlation of deci- } \\
\text { sional conflict be- } \\
\text { tween GPs and pa- } \\
\text { tients } a\end{array}$ & $\begin{array}{l}\text { Immediately after } \\
\text { consultation }\end{array}$ & $\begin{array}{l}\text { Baseline: } 0.14 \\
\text { Follow-up: } 0.24\end{array}$ & $\begin{array}{l}\text { Baseline: }-0.05 \\
\text { Follow-up: } 0.02\end{array}$ & $\begin{array}{l}\text { Difference at fol- } \\
\text { low-up }(95 \% \mathrm{Cl}) \\
0.26(-0.06 \text { to } 0.53)\end{array}$ & 0.06 & - \\
\hline
\end{tabular}

aProportion of participants who had a value of 2.5 or more on the Decision Conflict Scale (where $1=$ low decisional conflict and $5=$ very high decisional conflict).

bPresented as correlation of family physicians' and patient's DCS scores (Pearson's r).

$\mathrm{Cl}$ : confidence interval

GP: general practitioner

NR: not reported

RR: risk ratio

\section{Table 8. Decisional regret}

\begin{tabular}{|c|c|c|c|c|c|c|c|}
\hline Author & Outcome & $\begin{array}{l}\text { Measurement } \\
\text { time point }\end{array}$ & Intervention & Control & Effect estimate & P value & Notes \\
\hline Légaré (2012) & $\begin{array}{l}\text { Decisional regret } \\
\text { a }\end{array}$ & $\begin{array}{l}2 \text { weeks after con- } \\
\text { sultation }\end{array}$ & $\begin{array}{l}\text { Baseline: } 10.5 \pm 15.4 \\
\text { Follow-up: } 12.4 \pm \\
19.1\end{array}$ & $\begin{array}{l}\text { Baseline: } 10.8 \pm \\
20.8 \\
\text { Follow-up: } 7.6 \pm \\
13.7\end{array}$ & $\begin{array}{l}\text { Adjusted mean difference } \\
4.8(0.9 \text { to } 8.7)\end{array}$ & - & - \\
\hline Légaré (2011) & $\begin{array}{l}\text { Patients (\%) with } \\
\text { decisional regret }\end{array}$ & $\begin{array}{l}2 \text { weeks after con- } \\
\text { sultation }\end{array}$ & $\begin{array}{l}\text { Baseline: } 1 \\
\text { Follow-up: } 7\end{array}$ & $\begin{array}{l}\text { Baseline: } 1 \\
\text { Follow-up: } 9\end{array}$ & $\begin{array}{l}\text { Difference at follow-up } \\
(95 \% \mathrm{Cl})\end{array}$ & 0.91 & - \\
\hline
\end{tabular}




\begin{tabular}{|c|c|c|c|c|c|c|c|}
\hline \multicolumn{8}{|c|}{$-2(-12$ to 5$)$} \\
\hline \multicolumn{8}{|c|}{$\begin{array}{l}a=\text { Decisional Regret Scale used, where } 0=\text { very low regret and } 100=\text { very high regret } \\
\mathrm{CI} \text { : confidence interval }\end{array}$} \\
\hline \multicolumn{8}{|c|}{ Table 9. Patient enablement } \\
\hline Author & Outcome & $\begin{array}{l}\text { Measure- } \\
\text { ment time } \\
\text { point }\end{array}$ & Intervention & Control & Effect estimate & P value & Notes \\
\hline Briel (2006) & $\begin{array}{l}\text { Patient enablement (Patient En- } \\
\text { ablement Instrument; scale } 0 \text { to } \\
\text { 12) }\end{array}$ & 7 and 14 days & $\begin{array}{l}\text { Mean (SD): } 8.49 \\
(1.98)\end{array}$ & $\begin{array}{l}\text { Mean (SD): } 8.15 \\
(2.03)\end{array}$ & $\begin{array}{l}\text { Adjusted coeffi- } \\
\text { cient }(95 \% \mathrm{Cl})^{a} \\
0.35(-0.05 \text { to } 0.75)\end{array}$ & NR & - \\
\hline Cals (2009) & $\begin{array}{l}\text { Patient enablement (Patient En- } \\
\text { ablement Instrument; max score } \\
\text { is 12) }\end{array}$ & 28 days & $\begin{array}{l}\text { Median (IQR) score: } \\
3(4) \\
\text { Mean (SD) score: } \\
3.29(2.52)\end{array}$ & $\begin{array}{l}\text { Median (IQR) score: } \\
3(4) \text { d } \\
\text { Mean (SD) score: } \\
3.06(2.54)\end{array}$ & - & $\begin{array}{l}\mathrm{NR} \\
0.70^{\mathrm{b}}\end{array}$ & - \\
\hline $\begin{array}{l}\text { Francis } \\
(2009)\end{array}$ & $\begin{array}{l}\text { Parent enablement (Modified Pa- } \\
\text { tient Enablement Instrument, } \\
\text { scale } 1 \text { to } 10)^{c}\end{array}$ & 14 days & $\begin{array}{l}n / N(\%): 99 / 246 \\
(40.2)\end{array}$ & $\begin{array}{l}n / N(\%): 94 / 262 \\
(35.9)\end{array}$ & $\begin{array}{l}\text { Adjusted OR }(95 \% \\
\mathrm{Cl}) \\
1.20(0.84 \text { to } 1.73)\end{array}$ & NR & - \\
\hline \multicolumn{8}{|c|}{$\begin{array}{l}{ }^{a} \text { Linear regression with random effects for each cluster } \\
\text { bCalculated from models adjusted for variance at gener } \\
\text { cPresented results are \% with parent enablement score } \\
\text { dComparator is 'no skills training'. } \\
\text { Cl: confidence interval } \\
\text { IQR: interquartile range } \\
\text { NR: not reported } \\
\text { OR: odds ratio } \\
\text { SD: standard deviation } \\
\text { Table 10. Quality of the decision made (GPs) }\end{array}$} \\
\hline Author & Outcome & $\begin{array}{l}\text { easure- } \\
\text { ent time } \\
\text { oint }\end{array}$ & tervention & ntrol & fect estimate & P value & Notes \\
\hline
\end{tabular}




\begin{tabular}{|c|c|c|c|c|c|c|c|}
\hline Légaré (2012) & $\begin{array}{l}\text { Quality of decision made } \\
\text { (GPs) (0 to } 10 \text { Likert scale) }\end{array}$ & $\begin{array}{l}\text { After consul- } \\
\text { tation }\end{array}$ & $\begin{array}{l}\text { Baseline: } 8.7 \pm 1.5 \\
\text { Follow-up: } 8.5 \pm 1.6\end{array}$ & $\begin{array}{l}\text { Baseline: } 8.7 \pm 1.5 \\
\text { Follow-up: } 8.5 \pm 1.5\end{array}$ & $\begin{array}{l}\text { Adjusted mean differ- } \\
\text { ence } \\
0.0(-0.4 \text { to } 0.4)\end{array}$ & NR & - \\
\hline Légaré (2011) & $\begin{array}{l}\text { Quality of decision made } \\
\text { (GPs) (0 to } 10 \text { Likert scale) }\end{array}$ & $\begin{array}{l}\text { After consul- } \\
\text { tation }\end{array}$ & $\begin{array}{l}\text { Baseline: } 8.8 \pm 1.1 \\
\text { Follow-up: } 8.7 \pm 1.2\end{array}$ & $\begin{array}{l}\text { Baseline: } 8.3 \pm 1.4 \\
\text { Follow-up: } 8.5 \pm 1.3\end{array}$ & $\begin{array}{l}\text { Difference at follow-up } \\
(95 \% \mathrm{Cl}) \\
0.2(-0.34 \text { to } 0.89)\end{array}$ & 0.29 & - \\
\hline $\begin{array}{l}\text { Cl: confidence int } \\
\text { GP: general pract } \\
\text { NR: not reported } \\
\text { Table 11. Qua }\end{array}$ & ity of the decision made (pa & ents) & & & & & \\
\hline Author & Outcome & $\begin{array}{l}\text { Measure- } \\
\text { ment time } \\
\text { point }\end{array}$ & Intervention & Control & Effect estimate & $P$ value & Notes \\
\hline Légaré (2012) & $\begin{array}{l}\text { Quality of decision made (pa- } \\
\text { tients) (0 to } 10 \text { Likert scale) }{ }^{a}\end{array}$ & $\begin{array}{l}\text { After consul- } \\
\text { tation }\end{array}$ & $\begin{array}{l}\text { Baseline: } 8.2 \pm 1.1 \\
\text { Follow-up: } 8.2 \pm 1.3\end{array}$ & $\begin{array}{l}\text { Baseline: } 8.2 \pm 1.4 \\
\text { Follow-up: } 8.4 \pm 1.0\end{array}$ & $\begin{array}{l}\text { Adjusted mean differ- } \\
\text { ence } \\
0.2(-0.6 \text { to } 0.2)\end{array}$ & NR & - \\
\hline Légaré (2011) & $\begin{array}{l}\text { Quality of the decision made } \\
\text { (patients) (0 to } 10 \text { Likert scale) } \\
a\end{array}$ & $\begin{array}{l}\text { After consul- } \\
\text { tation }\end{array}$ & $\begin{array}{l}\text { Baseline: } 8.2 \pm 2.1 \\
\text { Follow-up: } 8.7 \pm 1.9\end{array}$ & $\begin{array}{l}\text { Baseline: } 8.4 \pm 1.9 \\
\text { Follow-up: } 8.6 \pm 1.9\end{array}$ & $\begin{array}{l}\text { Difference at follow-up } \\
(95 \% \mathrm{Cl}) \\
0.1(-0.88 \text { to } 0.94)\end{array}$ & 0.57 & - \\
\hline \multicolumn{8}{|c|}{$\begin{array}{l}a \text { Likert scale where } 0=\text { very low quality and } 10=\text { very high quality. } \\
\text { CI: confidence interval } \\
\text { NR: not reported }\end{array}$} \\
\hline
\end{tabular}




\section{AP PEN DICES}

\section{Appendix 1. MEDLINE (Ovid) search strategy}

1 exp Respiratory Tract Infections/ (297579)

2 (respiratory adj2 (infection* or inflam $\left.\left.{ }^{\star}\right)\right)$.tw. (31350)

3 pharyngitis.tw. (4164)

4 sinusit*.tw. (11403)

5 (acute adj2 rhinit*).tw. (174)

6 (rhinosinusit ${ }^{\star}$ or nasosinusit*).tw. (4197)

7 common cold $^{*}$.tw. (2806)

8 coryza.tw. (379)

9 (throat* adj2 (sore ${ }^{\star}$ or inflam ${ }^{\star}$ or infect $\left.{ }^{\star}\right)$ ).tw. (3897)

10 laryngit*.tw. (1305)

11 tonsillit*.tw. (4080)

12 bronchit $^{\star}$.tw. (18478)

13 bronchiolit*.tw. (8053)

14 pneumon*.tw. (133425)

15 (bronchopneumon* or pleuropneumon*).tw. (5382)

16 Cough/ (12409)

17 cough $^{\star}$.tw. (34227)

18 exp Otitis Media/ (21649)

19 otitis media.tw. (16032)

20 (aom or ome).tw. (6083)

21 Croup/ (970)

22 (croup or pseudocroup or laryngotracheobronchit* or laryngotracheit ${ }^{\star}$ ).tw. (1971)

23 or/1-22 (451019)

24 exp Anti-Bacterial Agents/ (537825)

25 antibiotic ${ }^{\star}$.tw,nm. (242634)

26 or/24-25 (640170)

2723 and 26 (79549)

28 exp Decision Making/ (122846)

29 exp decision support techniques/ (62827)

30 exp Decision Theory/ (9884)

31 (decision $^{\star}$ or decid ${ }^{\star}$ or option ${ }^{\star}$ or choice or choose $^{\star}$ or deliberat ${ }^{\star}$ ).tw. (618268)

32 exp Informed Consent/ (35917)

33 (informed adj3 (consent ${ }^{\star}$ or agree ${ }^{\star}$ or assent $\left.{ }^{\star}\right)$ ).tw. (23002)

34 Health Knowledge, Attitudes, Practice/ (74387)

35 "Attitude of Health Personnel"/ (92103)

36 professional-patient relations/ or physician-patient relations/ (82522)

37 exp Consumer Participation/ (32440)

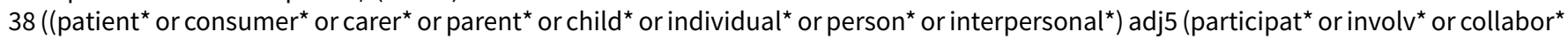
or cooperat ${ }^{\star}$ or co-operat* or engag $^{\star}$ or consult ${ }^{\star}$ or feedback* or interaction*)).tw. (184609)

39 (values ${ }^{\star}$ or prefer $\left.{ }^{\star}\right)$.tw. $(981018)$

40 exp Communication/ (369188)

41 (communicat $^{\star}$ or negotiat ${ }^{\star}$ or facilitat* or discuss $\left.^{\star}\right)$.tw. (1366627)

42 health education/ or exp consumer health information/ or patient education as topic/ (125443)

43 ((patient ${ }^{\star}$ or consumer ${ }^{\star}$ or parent $\left.^{\star}\right)$ adj3 (educat* or informat $\left.\left.^{\star}\right)\right) . t w$. (58615)

44 (shar* adj2 information*).tw. (3292)

45 sdm.tw. (869)

46 ((patient ${ }^{\star}$ or client ${ }^{\star}$ or subject or person or consumer ${ }^{\star}$ or family or families or carer ${ }^{\star}$ or care giver ${ }^{\star}$ ) and (professional ${ }^{\star}$ or physician $^{\star}$ or clinician* or practitioner*)).tw. (327702)

47 Risk Assessment/ (180413)

48 ((check or clarify) adj3 understanding).tw. (222)

49 (patient adj2 (understanding or expect*)).tw. (3479)

50 problem defin*.tw. (230)

51 (ask adj2 question*).tw. (1819)

52 (assess $^{\star}$ adj2 risk ${ }^{\star}$ ).tw. (50234)

53 self-manag*.tw. (8193)

54 equipoise.tw. (596)

55 checklist*.tw. (18085) 
56 (goal adj2 set $\left.{ }^{\star}\right)$. tw. (2180)

57 consensus.tw. (98026)

58 concordance.tw. (26142)

59 agreement*.tw. (155845)

60 (action* adj2 plan*).tw. (5452)

61 or/28-60 (3975067)

6227 and $61(14717)$

\section{Appendix 2. EMBASE (Elsevier) search strategy}

\#53 \#23 AND \#26 AND \#52 28861

\#52 \#27 OR \#28 OR \#29 OR \#30 OR \#31 OR \#32 OR \#33 OR \#34 OR \#35 OR \#36 OR \#37 OR \#38 OR \#39 OR \#40 OR \#41 OR \#42 OR \#43 OR \#44 OR \#45 OR \#46 OR \#47 OR \#48 OR \#49 OR \#50 OR \#51 3678076

\#51 'self-manage':ab,ti OR equipoise:ab,ti OR checklist:ab,ti OR consensus:ab,ti OR concordance:ab,ti OR agreement*ab,ti OR (action* NEAR/2 plan*):ab,ti OR (goal NEAR/2 set*):ab,ti AND [embase]/lim298331

\#50 (assess ${ }^{*}$ NEAR/2 risk $^{*}$ ):ab,ti AND [embase]/lim53641

\#49 (ask NEAR/2 question*):ab,ti AND [embase]/lim1736

\#48 (problem NEAR/1 defin*):ab,ti AND [embase]/lim327

\#47 (patient NEAR/2 (understanding OR expect ${ }^{\star}$ )):ab,ti AND [embase]/lim4348

\#46 ((check OR clarify) NEAR/3 understanding):ab,ti AND [embase]/lim203

\#45 'risk assessment'/de AND [embase]/lim276013

\#44 patient*:ab,ti OR client*:ab,ti OR subject:ab,ti OR person:ab,ti OR consumer*ab,ti OR family:ab,ti OR families:ab,ti OR carer*ab,ti OR 'care giver':ab,ti OR 'care givers':ab,ti AND (professional*:ab,ti OR physician*:ab,ti OR clinician*:ab,ti OR practitioner*:ab,ti) AND [embase]/ $\lim 349162$

\#43 sdm:ab,ti AND [embase]/lim776

\#42 (shar* NEAR/2 information*):ab,ti AND [embase]/lim2631

\#41 ((patient* OR consumer* OR parent*) NEAR/3 (educat* OR informat*)):ab,ti AND [embase]/lim59024

\#40 'patient education'/de OR 'consumer health information'/de AND [embase]/lim41224

\#39 communicat*:ab,ti OR negotiat*:ab,ti OR facilitat*ab,ti OR discuss*:ab,ti AND [embase]/lim1335786

\#38 'interpersonal communication'/de OR 'communication skill'/de OR 'nonverbal communication'/exp OR 'persuasive communication'/ de OR 'verbal communication'/de OR 'conversation'/de AND [embase]/lim117435

\#37 values*:ab,ti OR prefer*:ab,ti AND [embase]/lim995711

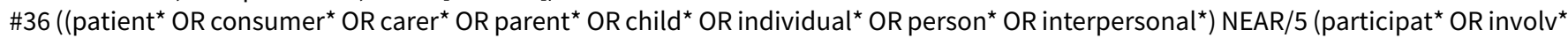
OR deliberat* OR collabor* OR cooperat* OR 'co-operate' OR 'co-operates' OR

'co-operation' OR engag* OR consult* OR feedback* OR interaction*)):ab,ti AND [embase]/lim197067

\#35 'patient participation'/de AND [embase]/lim6904

\#34 'doctor patient relation'/de AND [embase]/lim39102

\#33 'attitude to health'/de AND [embase]/lim7634

\#32 (treatment ${ }^{\star}$ NEAR/2 option*):ab,ti AND [embase]/lim65145

\#31 (informed NEAR/3 (consent* OR agree*)):ab,ti AND [embase]/lim32077

\#30 'informed consent'/de AND [embase]/lim39300

\#29 decision*:ab,ti OR decid*:ab,ti OR option*:ab,ti OR choice*:ab,ti OR choose*:ab,ti OR deliberat*:ab,ti AND [embase]/lim639112

\#28 'decision support system'/de AND [embase]/lim4763

\#27 'decision making'/de OR 'patient decision making'/de OR 'medical decision making'/de OR 'clinical decision making'/de AND [embase]/lim158809

\#26 \#24 OR \#25 892667

\#25 antibiotic ${ }^{\star}:$ ab,ti AND [embase]/lim219681

\#24 'antibiotic agent'/exp AND [embase]/lim842466

\#23 \#1 OR \#2 OR \#3 OR \#4 OR \#5 OR \#6 OR \#7 OR \#8 OR \#9 OR \#10 OR \#11 OR \#12 OR \#13 OR \#14 OR \#15 OR \#16 OR \#17 OR \#18 OR \#19

OR \#20 OR \#21 OR \#22 518323

\#22 croup:ab,ti OR pseudocroup:ab,ti OR laryngotracheobronchit*:ab,ti OR laryngotracheit*:ab,ti AND [embase]/lim1492

\#21 'otitis media':ab,ti OR aom:ab,ti OR ome:ab,ti AND [embase]/lim19731

\#20 'otitis media'/exp AND [embase]/lim21150

\#19 cough*:ab,ti AND [embase]/lim37668

\#18 'coughing'/de AND [embase]/lim52337

\#17 bronchopneumon*:ab,ti OR pleuropneumon*:ab,ti AND [embase]/lim3817

\#16 pneumon*:ab,ti AND [embase]/lim131768

\#15 bronchiolit*:ab,ti AND [embase]/lim8788

\#14 bronchit*:ab,ti AND [embase]/lim15885

\#13 tonsillit*:ab,ti AND [embase]/lim3497

\#12 laryngit*:ab,ti AND [embase]/lim1237

\#11 (throat* NEAR/2 (sore* OR inflam OR infect $\left.{ }^{\star}\right)$ ):ab,ti AND [embase]/lim4582 
\#10 'sore throat'/de AND [embase]/lim8854

\#9 'common cold':ab,ti OR 'common colds':ab,ti OR coryza:ab,ti AND [embase]/lim2828

\#8 'common cold symptom'/de AND [embase]/lim269

\#7 rhinosinusit*:ab,ti OR nasosinusit*:ab,ti AND [embase]/lim4585

\#6 (acute NEAR/2 rhinit*):ab,ti AND [embase]/lim179

\#5 sinusit*:ab,ti AND [embase]/lim11343

\#4 pharyngit*:ab,ti AND [embase]/lim4248

\#3 (respiratory NEAR/2 (infection* OR inflam*)):ab,ti AND [embase]/lim33268

\#2 'respiratory tract inflammation'/exp AND [embase]/lim275986

\#1 'respiratory tract infection'/exp AND [embase]/lim198937

\section{Appendix 3. Web of Science (Thomson Reuters) search strategy}

\begin{tabular}{|c|c|}
\hline \#7 & $\begin{array}{l}\# 6 \text { AND \#5 } \\
\text { DocType = All document types; Language = All languages; }\end{array}$ \\
\hline \#6 & $\begin{array}{l}\text { TOPIC: }\left(\text { random }^{*} \text { or placebo }{ }^{*} \text { or }\left(\left(\text { sing } l^{*} \text { or doubl }{ }^{\star}\right) \text { NEAR } / 1 \text { blind }^{\star}\right) \text { or allocat }{ }^{*} \text { or crossover }{ }^{*} \text { or "cross }\right. \\
\text { over") OR TITLE: (trial) } \\
\text { DocType=All document types; Language=All languages; }\end{array}$ \\
\hline \#5 & $\begin{array}{l}\text { \#4 AND \#3 } \\
\text { DocType=All document types; Language=All languages; }\end{array}$ \\
\hline \#4 & 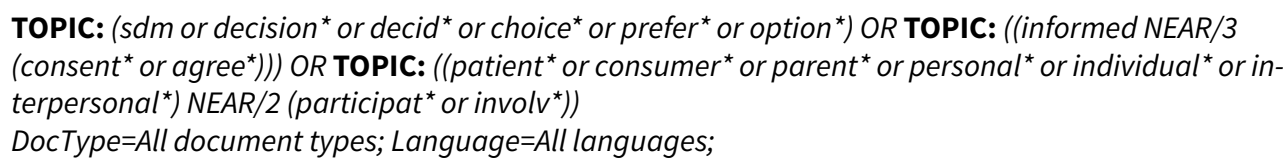 \\
\hline \#3 & $\begin{array}{l}\# 2 \text { AND \#1 } \\
\text { DocType=All document types; Language=All languages; }\end{array}$ \\
\hline \#2 & $\begin{array}{l}\text { TOPIC: (antibiotic }{ }^{*} \text { or antibacterial }{ }^{*} \text { or anti-bacterial }{ }^{*} \text { ) } \\
\text { DocType=All document types; Language=All languages; }\end{array}$ \\
\hline$\# 1$ & 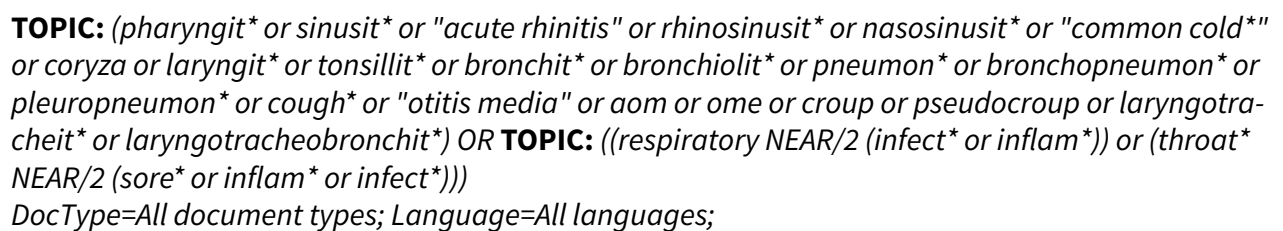 \\
\hline
\end{tabular}

WHAT'S NEW

\begin{tabular}{lll}
\hline Date & Event & Description \\
\hline 8 February 2017 & Amended & $\begin{array}{l}\text { Minor formatting change to Table 1 with rows and columns } \\
\text { swapped, to improve ease of reading. }\end{array}$ \\
\hline
\end{tabular}

\section{CONTRIBUTIONSOF AUTHORS}

Tammy Hoffmann (TH) conceived the original idea for the review.

Peter Coxeter (PC) was responsible for drafting the protocol.

TH and Chris Del Mar (CDM) contributed content and methodological expertise and provided advice and guidance on the development of the draft protocol and final editing.

Interventions to facilitate shared decision making to address antibiotic use for acute respiratory infections in primary care (Review) 
Elaine Beller (EB) provided statistical advice and guidance.

Leanne McGregor conducted independent screening (titles/abstract and full text) and data extraction.

\section{DECLARATIONS OF INTEREST}

Peter Coxeter: none declared

Chris B Del Mar: none declared

Leanne McGregor: none declared

Elaine M Beller: none declared

Tammy Hoffmann: none declared

\section{SOURCES OF SUPPORT}

\section{Internal sources}

- No sources of support supplied

\section{External sources}

- National Health and Medical Research (NHMRC), Australia.

The Centre for Research Excellence in Minimising Antibiotic Resistance from Acute Respiratory Infections (CREMARA; NHMRC grant APP1044904).

\section{INDEX TERMS}

\section{Medical Subject Headings (MeSH)}

${ }^{\star}$ Decision Making; Acute Disease; Anti-Bacterial Agents [ ${ }^{\star}$ therapeutic use]; Patient Participation; Primary Health Care; Randomized Controlled Trials as Topic; Respiratory Tract Infections [ ${ }^{\star}$ drug therapy]

\section{MeSH check words}

Humans 